\title{
Rating Shopping or Catering? An Examination of the Response to Competitive Pressure for CDO Credit Ratings
}

\author{
John M. Griffin* \\ Jordan Nickerson \\ The University of Texas at Austin
}

and

Dragon Yongjun Tang

The University of Hong Kong

(C) All rights reserved. Please do not post, cite, or quote without authors' permission.

April 25, 2013

\footnotetext{
* The authors can be reached at John.Griffin@utexas.edu, Jordan.Nickerson@phd.mccombs.utexas.edu, and yjtang@hku.hk. We thank Alexander Ljungqvist (the editor), an anonymous referee, Dion Bongaerts, Lauren Cohen, Shane Corwin, Jess Cornaggia, Joshua Coval, Tom George, Laurie Goodman, Jay Hartzell, Jian Hu, John Hund, Paul Hsu, Kris Jacobs, Ayla Kayhan, Albert Kyle, Tse-chun Lin, Avri Ravid, Sylvain Raynes, Ann Rutledge, Alessio Saretto, Mark Seasholes, Rik Sen, Chester Spatt, Sheridan Titman, Stuart Turnbull, and seminar participants at Erasmus University Rotterdam, Hong Kong University of Science and Technology, the Chinese University of Hong Kong, the University of Houston, the Securities and Exchange Commission, the University of Hong Kong, the University of Texas at Austin, the 2012 Conference on Current Topics in Financial Regulation, and the 2012 Western Finance Association, for their helpful discussion and Stephen Jaquess, Christopher Miller, and Danny Marts for their excellent research assistance. Part of this research was conducted while Griffin was a visiting scholar at the Harvard Business School. We also thank the McCombs Research Excellence Fund and Hong Kong Research Grants Council GRF \#753010 for their generous support.
} 


\title{
Rating Shopping or Catering? An Examination of the Response to Competitive Pressure for CDO Credit Ratings
}

\begin{abstract}
We examine whether "rating shopping" or "rating catering" is a more accurate characterization of rating agency interactions regarding collateralized debt obligations (CDOs) prior to the credit crisis. Although investors paid a premium for dual-ratings, AAA CDO tranches rated by both Moody's and S\&P defaulted more frequently than tranches rated by only one of them, which is inconsistent with pure rating shopping. Even though AAA-rated tranche sizes were typically identical, there was considerable disagreement between S\&P's and Moody's assumptions on default correlations and even collateral quality. Rating agencies made upward adjustments beyond their model outputs when their competitor had more lenient assumptions. Finally, although S\&P's and Moody's adjustments and disagreements were not reflected in yields at issuance, they were reflected in subsequent rating downgrades, suggesting that rating agencies later reverted towards their initial models.
\end{abstract}


By both facilitating the housing bubble and triggering massive write-downs for banks, structured products and their credit ratings are often perceived to be among the most important drivers of the 2007-2009 credit crisis. ${ }^{1}$ A striking feature of this episode is that major rating agencies unanimously gave AAA ratings to trillions of dollars of collateralized debt obligations (CDOs). Several theories have offered competing models and policy solutions regarding rating agency competition and rating inflation. Most of these models are customized to the universe of complex securities; yet, surprisingly little empirical work has examined the role of rating agency competition within structured finance ratings. In this paper, we use unique data to empirically evaluate "rating shopping" and "rating catering" as explanations for CDO credit rating agency behavior.

The first and often-cited view called "rating shopping" refers to a situation where issuers solicit ratings from multiple agencies and then choose the most favorable ones (as modeled by Skreta and Veldkamp (2009), Faure-Grimaud, Peyrache, and Quesada (2009), and Farhi, Lerner, and Tirole (2011)). In this line of analysis, even though rating agencies adhere to their standards and issue unbiased ratings, rating inflation is a natural consequence of the rating shopping process and not driven by the rating agencies. Hence, if rating solicitation is publicly disclosed (as Dodd-Frank calls for), ${ }^{2}$ then rating shopping will be innocuous as investors can infer the true value of CDOs from the number of ratings initially solicited and finally granted (Sangiorgi and Spatt (2011)).

A second scenario is called "rating catering." Reputational concern, a commonly cited incentive, is not always sufficient for rating agencies to report truthfully even in theory (Mathis, McAndrews, and Rochet (2009)). The first part of rating catering still involves rating shopping by the issuers. However, rating agencies may not strictly adhere to their standards due to a focus on current and future revenues or market share. The incentive to attract business by inflating ratings is

\footnotetext{
${ }^{1}$ For example, Coffee (2009) and Partnoy (2009 and 2010) argue that reliance on credit ratings and trust in credit rating agencies were main causes of the credit crisis beginning with dramatic devaluation of AAA-rated CDOs.

2 http://www.sec.gov/spotlight/dodd-frank/creditratingagencies.shtml.
} 
carefully modeled by Bolton, Freixas, and Shapiro (2012), who show that competition facilitates rating catering. Under pressure from investment banks, the rating agency with the more stringent standard will need to stretch their standards to match their more lenient competitor. Such explicit competition could lead to a "race to the bottom" (as shown more generally by Golan, Parlour, and Rajan (2011)). ${ }^{3}$ In this view, rating agencies fight for market share and cater to issuers' demands.

The empirical literature finds mixed evidence on the consequences of rating agency competition. In the corporate bond domain, Becker and Milbourn (2011) find that competition from Fitch lowers the overall rating quality of Moody's and S\&P through rating inflation and find no support for rating shopping. Kisgen and Strahan (2010) find some evidence consistent with catering in that a new rating agency (DBRS) issues more optimistic ratings prior to official regulatory acceptance. ${ }^{4}$ Cornaggia and Cornaggia (2013) find that issuer-paid ratings are less accurate and timely. In contrast, Bongaerts, Cremers, and Goetzmann (2012) find some evidence of rating agency shopping for corporate bonds near the investment grade boundary. Analyzing asset-backed securities (ABS), Benmelech and Dlugosz (2009b) find some support for rating shopping, as they show that ABS collateral with only one rating was downgraded more often. ${ }^{5}$ The theoretical literature emphasizes that both rating shopping (Skreta and Veldkamp (2009), Sangiorgi and Spatt (2011)) and rating inflation (Opp, Opp, and Harris (2013)) are more likely to occur in the CDO market due to its opacity and complexity. Nevertheless, no prior empirical study examines rating

\footnotetext{
${ }^{3}$ See also Smith (2008). Consistent with this view, Cornaggia, Cornaggia and Hund (2013) find that ratings inflation increases with the income that rating agencies receive across asset classes.

${ }^{4}$ Fulghieri, Strobl, and Xia (2012) find that unsolicited credit ratings can be beneficial and Bruno, Cornaggia, and Cornaggia (2012) find that investor-paid ratings (from Egan-Jones) are superior. Cohen (2011) provides some evidence of rating shopping in the CMBS market. Xia (2012) finds that competition from Egan-Jones improves S\&P corporate bond ratings, especially for opaque firms. Kraft (2011) finds mixed evidence as to whether Moody's caters their bond ratings. John, Ravid, and Reisel (2010) find rating biases from self-serving bond notching practices. Goodman et al. (1997) also argue that the entrance of Fitch may have led to the softening of rating criteria. For corporate bonds, Fong, Hong, Kacperczyk, and Kubik (2011) find that equity analysts and CDS markets can act as substitutes for the role of rating analysts. Ljungqvist, Marston, and Wilhelm (2006) find that equity analyst recommendations do not influence the outcome of underwriter competition.

5 They also caution that "it is not clear that rating shopping led to the rating collapse as the majority of the tranches in our sample are rated by 2 or 3 agencies." Their data ends in January 2008 before many waves of downgrading.
} 
shopping and catering in the CDO domain. Moreover, our primary empirical approach is quite distinct from previous work as our measure of competitive pressure is direct and exogenous (predetermined by rating agencies' methodologies and criteria before coming to specific CDOs).

We start by examining the general CDO universe using comprehensive Bloomberg data, with a focus on the prevalence of multiple ratings. In contrast to the basic shopping premise that only the most desirable ratings will be retained, from 1997 to 2007, 84.7\% of all AAA CDO capital with a rating from either Moody's or S\&P also receives a rating from the other agency. For dualrated tranches that were rated AAA by at least one of these two agencies, $96.3 \%$ of the capital received identical AAA ratings from Moody's and S\&P.

We examine this large universe of $2,790 \mathrm{CDOs}$ to see if the presence of multiple ratings matters. AAA yield spreads for CDOs rated by one rating agency were larger than those deals rated by both agencies, indicating that investors valued dual-ratings. However, in contrast to the rating shopping view, we find that CDOs rated by S\&P or Moody's exclusively actually performed better than deals both agencies rated together. Thus, although investors seemed to have valued dual certification, dual-rated AAA tranches suffered larger losses than solo-rated deals.

To understand how multiple ratings might be harmful, we collect unique data for 716 CDOs with detailed model inputs from both Moody's and S\&P. Surprisingly, there is considerable disagreement between Moody's and S\&P on the key assumptions_-probabilities of default differ on average by $30.3 \%$ on the same deal and default correlations differ by $57.2 \%$. Gauged by a common model, the assumption differences translate into a 10.5\% difference in AAA tranche size. We find some evidence that, because of its slightly tougher modeling, S\&P might have been under more pressure to cater on individual deals as compared to Moody's. Empirical results also suggest that underwriters may have targeted Moody's model more often than S\&P's when structuring CDOs. 
One way to reconcile different model inputs and outputs with the same ratings is to consider adjustments beyond modeling. Each agency has published methodological documents outlining their collateral evaluation process. Issuing adjustments in response to differences in assumptions relative to a competitor contradicts rating agency claims of independence. We find that when Moody's model produces ten percent more AAA than S\&P's, S\&P issues a seven percent adjustment above its model output. Conversely, when the AAA size given S\&P's collateral assumptions is ten percent larger than the AAA size given Moody's assumption, Moody's issues a 3.5 percent positive adjustment. It appears that both rating agencies consider the influence of a competitor's actions, indicating that ratings are not assigned independently. S\&P seems to move toward Moody's evaluation more than Moody's moves relative to S\&P. While the results in this section present evidence for catering, our regression results are only reduced-form approximations of the interaction between rating agencies. We find symmetrical effects for S\&P with the collateral risk results, which is also possible if S\&P systematically adjusts their rating toward their competitor's collateral assessment due to non-modeled data.

To help further separate out these explanations, we examine the relation between adjustments and future performance. If adjustments are made for legitimate reasons, such as incorporating the use of non-modeled data, then adjustments should be positively related to future performance. If adjustments were made to simply match a competitor for business concerns, then these adjustments should be related to poor performance, and rating agencies would eventually undo their actions. We further find that adjustments made by both Moody's and S\&P at issuance predict their future downgrading, indicating that adjustments were not helpful. Moreover, when S\&P assessed a CDO's collateral to be riskier than Moody's, they later downgraded the CDO more than Moody's (and vice versa). Ultimately, it appears that while rating agencies originally agreed about ratings, they disagreed on subsequent ratings in a manner verifying the original disagreements about 
collateral risk. Our findings point to rating agencies catering for business concerns. Nevertheless, it is also important to recognize that rating catering is not entirely distinct from rating shopping. Rating catering occurs when agencies yield to competitive pressures, which exist when issuers can shop among raters. Future research should further evaluate the intersection between rating shopping and catering in other contexts.

The European Commission has published new standards implementing Regulation (EC) No. $1060 / 2009^{6}$ to encourage competition, but our findings suggest that unless safeguards are put in place, increasing competition may actually lower rating quality. The Dodd-Frank Act proposes several areas for the U.S. Securities and Exchange Commission (SEC) to study and to potentially implement reforms. But after the December 2012 SEC report, ${ }^{7}$ it appears to some that little reform may actually take place (Foley (2013)). One basic but tangible implication of our study is that credit rating agencies should clearly report all their key assumptions, underlying data used in their calculations, the full methodology they follow, fees received, and especially any non-modeling or discretionary choices for all ratings so that the determinants of ratings and adjustments can be examined more closely.

Our paper relates to a growing literature improving the understanding of problems in structured finance valuation and ratings. Coval, Jurek, and Stafford (2009a) show that the most senior tranches of CDOs were massively mispriced, and Coval, Jurek, and Stafford (2009b) demonstrate that $\mathrm{CDO}$ valuation models hinged on a high degree of confidence in the parameter inputs. Our paper shows that rating agencies could have known from their competitor's evaluations that there existed substantial parameter uncertainty in key inputs such as collateral default correlations. Ashcraft, Goldsmith-Pinkham, and Vickery (2010) show that RMBS standards deteriorated from 2005 to 2007. He, Qian, and Strahan $(2011,2012)$ find that while larger issuers

${ }^{6} \mathrm{http}: / /$ ec.europa.eu/internal_market/securities/agencies/index_en.htm

7 http://www.sec.gov/news/studies/2012/assigned-credit-ratings-study.pdf 
received more favorable MBS ratings at issuance and experienced subsequent worse performance, deals from larger issuers also sold at higher yields, suggesting that investors were at least partially aware of the additional risk. For CDO ratings, Griffin and Tang (2011) show that the business group within S\&P uses more favorable assumptions than the surveillance group, suggesting that conflicts of interest may play a role in the ratings process. Griffin and Tang (2012) show that upward adjustments beyond S\&P's main model increased from 2004 to $2007 .{ }^{8}$ They are unable to satisfactorily explain adjustments with economic determinants. Our paper extends this literature by relating the adjustments of both major rating agencies to the actions of their competitor, and hence providing a partial explanation for why rating agencies may make adjustments.

The rest of this paper is organized as follows. Section 1 details the differences between Moody's and S\&P's CDO modeling approaches and develops our hypotheses. Section 2 describes the data. Section 3 examines the effects of multiple credit ratings on yields and performance using comprehensive Bloomberg data. Section 4 documents differences in the implied AAA size from Moody's and S\&P and the differences in their modeling approaches. Section 5 relates rating adjustments to disagreement over collateral risk. Section 6 uses adjustments and collateral risk disagreements to predict future rating downgrading. Section 7 concludes.

${ }^{8}$ They find that reasonable factors which might explain adjustments, like manager quality and excess spread, have no ability to explain adjustments. They find larger adjustments when the CRA model yields a low amount of AAA, and that positive adjustments from one CRA are negatively related to future rating performance. Stanton and Wallace (2012) find that CMBS subordination levels decreased through 2007, which they interpret as support for the regulatory-capital arbitrage model of Opp, Opp, and Harris (2013). Begley and Purnanandam (2012) show that equity tranche sizes vary across deals with sensible features such as asymmetric information. Faltin-Traeger and Mayer (2011) show that mortgage-backed securities (MBS) collateral included in CDOs underperformed other MBS. Lax standards (Keys, Mukherjee, Seru, and Vig (2010) and Mian and Sufi (2009)) or misrepresentation (Piskorski, Seru, and Witkin (2013) and Griffin and Maturana (2013)) in the mortgage origination process could have inflated the collateral quality of mortgage related CDOs as analyzed by Barnett-Hart (2009). 


\section{CDO Credit Ratings}

\subsection{CDO Rating Approaches}

$\mathrm{CDO}$ notes are issued by special purpose vehicles (SPVs) with different seniority levels and payoff schedules secured by a collateral asset pool. ${ }^{9}$ The size, rating, and value of each tranche are determined by modeling the hypothetical default probabilities and the default correlation across all collateral assets. Although the concepts are similar, there are some fundamental differences between the binomial expansion technique (BET) method used by Moody's and the Gaussian Copula Monte Carlo Simulation approach of S\&P. ${ }^{10}$

\subsection{The Rating Process}

The underwriter typically proposes a deal structure along with legal documents when soliciting credit ratings for the notes from the major credit rating agencies (CRAs). The CDO structurers from the underwriting investment bank often keep in close communication with the rating analysts. If disagreement arises between a CRA and the underwriter, the underwriter may discuss these disagreements with the rating agency and seek to persuade the analyst that higher ratings are indeed justifiable. Although S\&P would not directly discuss rating assumptions and results with Moody's, the investment banker may selectively discuss the preliminary rating indicators of one rating agency with the other. ${ }^{11}$ If the underwriter was unable to obtain their desired ratings, they could (before Dodd-Frank) pay a small contract-breaking fee to hide this rating information.

\footnotetext{
${ }^{9}$ Lucas, Goodman, and Fabozzi (2006), Rutledge and Raynes (2010), Longstaff and Rajan (2008), Benmelech and Dlugosz (2009a), Sanders (2009), and Coval, Jurek, and Stafford (2009b) detail CDO structure and mechanics.

${ }_{10}$ Our understanding of the rating and modeling process is based on official documents from Moody's and S\&P describing rating methodologies, numerous conversations with current and former employees of both rating agencies, and former investment bank employees who interacted with rating agencies. Griffin and Tang (2011, 2012) describe relevant components of the issuance and rating process. Internet Appendix IA 2.A provides a more detailed modeling description.

${ }^{11}$ Eric Kolchinsky, former team managing director of Moody's, told the Financial Crisis Inquiry Commission (FCIC, 2010) that "It was well understood that if one rating agency said no, then the banker could easily take their business to another. During my tenure at the head of US ABS CDOs, I was able to say no to just one particularly questionable deal... the banker enlisted another rating agency and received the two AAA ratings he was looking for." Gary Witt, another former team managing director of Moody's, told FCIC that "Underwriters... are also more than willing to use the threat of dropping an agency from a transaction to try to obtain leverage on whatever issue is of concern to them."
} 
The underwriter may still potentially use ratings from another rating agency, though CDO prospectuses often specify which rating agencies will issue ratings and their levels. After the deal is rated and the collateral pool is fully purchased, or "ramped," each credit rating agency's surveillance team monitors the performance of the $\mathrm{CDO}$ and updates the credit ratings when necessary. Most of our analysis uses data from the first available surveillance reports issued by both rating agencies, supplemented by pre-sale and new issue reports.

\subsection{Collateral Credit Quality Disagreements}

Besides different modeling approaches, each rating agency has fixed, published criteria used when evaluating a deal's collateral default correlation and credit quality. Moody's and S\&P's evaluation criteria vary, hence these key correlation and asset quality assumptions can differ across rating agencies on the same deal. To meaningfully compare the magnitude of these disagreements, we evaluate a CDO using each set of assumptions, but under the same rating model.

\subsection{Hypotheses}

When issuers shop for ratings from multiple rating agencies and rating agencies maintain their standards, CDOs that receive ratings from two or more rating agencies should be of higher quality and therefore perform better than those receiving ratings from one rating agency. This reasoning has previously been discussed by Benmelech and Dlugosz (2009b) and Bongaerts, Cremers, and Goetzmann (2012).

\section{H1 A: With credit rating agency shopping, securities with two or more ratings should perform better than}

\section{those only able to receive one rating.}

Alternatively, rating agencies may respond to competitive pressure by catering their services in order to maintain or gain market share. In such scenarios, the presence of more than one credit rating should not be an indicator of deal quality. 
H1: With rating catering, dual ratings provide no certification value and should not be positively related

\section{to future performance.}

Beyond model performance, we can examine actual rating practices. Discerning the motivation for an 'adjustment' to a rating is difficult for a single rating agency in isolation, but possible with our rating agency comparison between S\&P and Moody's. Suppose for a hypothetical CDO, Moody's model warranted a higher amount of AAA than S\&P solely because Moody's classified the underlying collateral as being of higher quality and/or having lower default correlations. In this case, S\&P is disadvantaged by their stricter evaluation of collateral quality and correlations. The difference between S\&P's model output under S\&P's assumptions and S\&P's model output under Moody's assumptions is an estimate for how the different collateral evaluations affect the AAA size. We call this difference the collateral risk disagreement $(C R D)$, which we use to gauge the scale of an agencies disadvantage. For example, if the S\&P AAA SDR (or scenario default rate, S\&P's model output) with S\&P's assumptions is 0.30 and the SDR is 0.20 under Moody's assumptions, then the collateral risk disagreement is 0.10 , indicating that S\&P viewed the collateral as riskier. In a similar manner, we can also examine $A A A$ Model Difference between the two rating agencies, which is the model implied AAA size of the rating agency's competitor (i.e. Moody's) minus the model implied AAA size of the agency being examined (i.e. S\&P).

Both rating agencies have formal guidelines as to how they should measure the underlying collateral quality and default correlation among assets. This process is not decided on a deal-by-deal basis. With rating agency catering, when one rating agency makes relatively more optimistic evaluations of the collateral risk, the other rating agency may face a choice of issuing a positive adjustment or losing business. 
H2: With only credit rating agency shopping and no catering, rating agencies' adjustments should be unrelated to AAA Model Difference and Collateral Risk Disagreement (CRD).

H2A: With rating agency catering, S\&P's adjustments should be positively related to its $A A A$ Model Difference and Collateral Risk Disagreement (CRD), and vice versa for Moody's.

Rating agency competition is most relevant for new ratings. This is when the largest fees are paid and when underwriters are trying to place the CDO notes to investors. The ratings may become less inflated during busts when reputational concerns are higher (Bolton, Freixas, and Shapiro (2012)). If the credit crisis triggers a decrease in investor trust, rating agencies may need to be more truthful in their downgrading after the start of the crisis, reverting back to their initial evaluations. This means that if adjustments were made to gain business, we would expect CDOs with larger adjustments to experience greater downgrades. Alternatively, under the rating shopping theory where agencies are truth-telling, any adjustments used to incorporate non-modeling data in order to increase rating accuracy, would not lead to greater downgrades.

H3: With rating shopping, adjustments should not be correlated with future downgrades.

H3A: With rating catering, CDOs with larger positive adjustments will experience more rapid and severe downgrading.

Extending this intuition also leads to implications in terms of relative downgrading. If one rating agency had a much worse initial assessment of the collateral at issuance (positive $C R D$ ), but issued a positive adjustment due to catering, we expect that rating agency to downgrade the CDO more severely than its competitor. In other words, when rating agencies are forced to downgrade CDOs due to poor performance, S\&P downgrades will be more severe relative to Moody's for those CDOs where they initially had a much worse assessment of the CDO's collateral risk. 
H4: With only credit rating agency shopping and no catering, initial Collateral Risk. Disagreement (CRD) should be unrelated to future relative downgrading.

H4A: With rating catering, $C D O$ s with worse initial collateral assessments by $S \& P$ relative to Moody's will have relatively greater subsequent downgrades by S\&P as compared to Moody's.

\section{Data and Descriptive Statistics}

\subsection{The Full Sample}

We first use a large universe of CDOs to examine the prevalence of dual ratings from Moody's and S\&P. We retrieve ratings data for all CDOs listed on Bloomberg, with issuance dates from 1997 to 2007 with data collection details outlined in the Internet Appendix IA 2.B. ${ }^{12}$ AAA tranches are our focus because they account for the majority (75 to 80\%) of capital issued. Table 1 includes 5,525 AAA-rated tranches from 2,790 CDOs with a total value of $\$ 1.80$ trillion. The Securities Industry and Financial Markets Association (SIFMA) has kept track of global CDO issuance since 2000. Over the period of 2000-2007, our sample represents a principal value of $\$ 1,406.9$ billion, which makes up $81.4 \%$ of the $\$ 1,727.5$ billion Global CDO Issuance reported by SIFMA over the same period.

Panel A of Table 1 shows that $60.7 \%$ of those tranches have ratings from both Moody's and S\&P, but not Fitch, and an additional 17.0\% have ratings from Moody's, S\&P, and Fitch. Thus, 77.7\% of the tranches and $84.7 \%$ of the AAA capital have ratings from both Moody's and S\&P. Another $8.2 \%$ of the AAA-rated CDO capital has a single rating from either Moody's or S\&P, and 7.0\% has ratings from either Moody's or S\&P in conjunction with Fitch. Overall, Moody's and S\&P play the dominant role in AAA CDO ratings.

\footnotetext{
12 This Bloomberg sample has many CDOs under duplicate tickers which we identify and remove based on ticker names and tranche sizes/ratings.
} 
Next, we analyze if there is disagreement across ratings. We consider all tranches rated by Moody's and S\&P with at least one AAA rating by either agency. Panel B of Table 1 shows that 96.3\% of the AAA tranche capital has matching AAA ratings. In $0.9 \%$ of the cases, S\&P rates the tranche AAA and Moody's rating is lower, while $2.8 \%$ of the time Moody's gives the AAA rating and S\&P's rating is lower. Therefore, in the vast majority of cases, Moody's and S\&P issue the same AAA ratings.

\subsection{The Smaller Sample with Detailed Data}

We now turn to describing our specific detailed data set that is collected from the first available surveillance reports obtained from both S\&P and Moody's. Only detailed data from S\&P and Moody's are collected because Fitch is a much smaller player in the market and the data is extremely time intensive to collect. Surveillance reports typically (but not always) appear after the collateral assets for the CDOs are fully purchased. We are only able to locate surveillance data on 1,452 CDOs for Moody's and 1,577 CDOs for S\&P. The intersection of our list of reports generates 1,385 CDOs which were rated by both agencies over the life of the CDO. We lose 449 CDOs because of a lack of key data from Moody's reports, ${ }^{13}$ reducing our sample to 936 CDOs. To maintain comparability between credit rating agencies, we compare surveillance data that is within 180 days of the other rating agency. This restriction excludes another 206 CDOs, leaving 730 CDOs with the necessary data for the overlapping sample. For S\&P reports we have the actual credit risk model output (SDR) for 649 reports. We estimate S\&P's SDR for the remaining 81 with missing SDR information. ${ }^{14}$ We also exclude 14 CDOs whose first surveillance reports are observed over 12 months after issuance. For those 14 issuances, we do not observe S\&P's or Moody's original evaluation of each deal's collateral pool, and therefore cannot estimate the initial AAA adjustment.

\footnotetext{
${ }^{13}$ For those 449 CDOs, Moody's does not report the diversity score, but instead discloses an alternate measure of collateral correlation (Moody's Asset Correlation, or MAC) which does not fit within the framework of the BET model.

${ }^{14}$ We use a simple Monte Carlo simulation model and replicate S\&P's SDRs quite closely_obtaining an adjusted $R^{2}$ of 0.954 for the overlapped sample with actual SDRs as shown in the Internet Appendix Table IA.2.
} 
Thus, our final sample consists of 716 CDOs. Because Moody's does not disclose its model output, we do not have a reference point to judge the success of our replication of Moody's model. However, our Moody's modeling replication strictly follows their extensive BET model documentation. $^{15}$

\section{The Perception and Informational Content of Multiple Ratings}

In this section we first examine the market perception of dual versus single ratings through AAA-rated CDO tranche yield spreads at issuance and then deliberate the ultimate value of multiple ratings as captured in future deal performance.

\subsection{Did the Market Price in Credit Rating Shopping or Catering at Issuance?}

Perceived risk at issuance by market participants is inferred from the weighted-average coupon spread of all AAA-rated tranches, or yield spread when available, over a risk-free interest rate such as the three-month Libor rate. If investors perceived rating shopping to be a possibility, then we expect tranches of CDOs with only one AAA rating to be considered as deals that were unsuccessfully shopped for multiple AAA ratings. These tranches would have a higher yield than CDOs with a rating from both Moody's and S\&P. If investors perceived that rating agencies simply catered their ratings to meet their competitor, then one would expect no difference in yield between single versus dual-rated AAA tranches.

We compare the yield at issuance for CDOs rated by both S\&P and Moody's with those rated by only one agency. Each CDO is placed into one of three mutually exclusive groups: One Rater, Two - Disagree, or Two - Agree. The first category contains all CDOs that were rated by either S\&P or Moody's, but not both. Any CDO that is rated by both agencies, but where one agency gives

\footnotetext{
15 All the CDOs in our sample have a diversity score reported, which is used in Moody's BET model. A Moody's service representative confirmed that when diversity scores were reported, the BET model was the model used. If Moody's used an alternative model at issuance, any relation between BET outputs and future rating performance would indicate a reversion back to the BET model.
} 
a AAA rating to more tranches than its competitor is placed into the second category. All remaining CDOs belong to the Two - Agree group, which serves as the base case.

Table 2 presents OLS regression results of CDO AAA spreads on these three categorical variables. Within our sample, Bloomberg had tranche coupon rates for 2,466 CDOs and prices at issuance for 1,085 of those deals. We take two approaches to deal with the missing price data. In the first, we back-out yields over Libor for the CDOs with pricing data, and for the remaining data use the credit spread above Libor (implicitly assuming that the price is at par). ${ }^{16}$ For the second, we only use the smaller sample with pricing data. When all CDOs are considered in the first column, investors demand a credit spread 5.2 basis points higher $(t$-stat=3.42) for CDOs only rated by one agency. ${ }^{17}$ For deals rated by both agencies, but where they disagree on the portion receiving a AAA rating, there is weak statistical evidence that investors demand a larger spread.

In the second specification, we impose the restriction that S\&P rate the deal. The One Rater category now contains those CDOs only rated by S\&P. Investors demand an even higher spread of 8.8 basis points when S\&P rates the deal alone. In the third specification we require that Moody's rate the CDO. The spread demanded by investors for deals rated by both agencies is not statistically different from those rated by Moody's alone. Collateral type and vintage year effects are included in all regressions, in addition to controls for deals rated by Fitch and those with pricing data, when applicable.

In the remaining specifications, we take a more conservative approach and only include CDOs whose pricing data is available, resulting in a smaller sample. The estimated premium decreases slightly to 4.0 basis points $(t$-stat $=2.23)$ for deals rated by only one agency, and 5.6 basis

\footnotetext{
${ }^{16}$ CDOs are sold through private placements and prices are not always explicitly disclosed. The methodology we follow to calculate the yield spread from the credit spread and selling price is presented in Appendix IA 2.E.

${ }_{17}$ This result is consistent with He, Qian, and Strahan (2012)'s findings for MBS. They find that the yields of non-AAArated MBS tranches with one rating (two ratings) are 7-9\% (4-5\%) higher than MBS with three ratings. Also, non-AAArated MBS tranches with rating disagreement have 11\% higher yields than tranches with identical ratings.
} 
points $(t$-stat $=2.14)$ if S\&P rates the deal without Moody's. The effect for CDOs rated by only Moody's continues to be statistically insignificant. This is consistent with at least some investors perceiving rating shopping to be the likely scenario; investors ask for a higher yield for single-rated issues because they perceive that a second rating was requested but not granted. The four basis point increase in credit spread amounts to an approximately $\$ 1,531,600$ higher CDO price which is more than three times the $\$ 500,000$ new-issue rating fee that is apparently typical for this size of a deal. ${ }^{18}$ This also provides a motive as to why issuers pay for what otherwise might seem like a redundant certification, two AAA ratings.

\subsection{Does Rating Performance Indicate Shopping or Catering?}

If the market is correct and shopping is rampant, a deal with dual rating agency certification should perform better than a deal that was only able to obtain a single rating as described in Hypothesis H1A. However, under rating catering, dual rating certification is not informative because rating agencies are pushing to gain business, as outlined in Hypothesis H1. To examine these issues, we look at two intuitive measures of future performance: 1) the number of notches the initially AAA-rated tranches of a CDO are downgraded as of June 30, 2010 and 2) the likelihood that a deal experiences an Event of Default (EOD), as defined in the CDO's prospectus. ${ }^{19}$

Measuring performance with ratings can be advantageous to the extent that credit ratings represent a forward-looking measure of expected performance. However, EODs are issued when a particular deal fails to meet any one of a set of conditions pre-specified in its prospectus, ranging

\footnotetext{
${ }^{18}$ If we take our average AAA tranche size of $\$ 547$ million, for a seven-year duration CDO, the duration approximation gives $7 * .0004 * \$ 547,000,000=\$ 1,531,600$. Rating fees are from “U.S. Structured Ratings Fee Schedule Collateralized Debt Obligations Amended 3/7/2007," prepared by S\&P, S\&P-PSI 0000036-50, for the U.S. Senate. 19 The likelihood that the AAA tranches of a CDO are downgraded to the lowest rating possible is also examined. We generally find similar results that are displayed in Internet Appendix Table IA 3.
} 
from a failed interest coverage ratio test to a failure to fully meet its interest payment obligations. Such events are not up for interpretations. ${ }^{20}$

Before performing a formal analysis, we examine the rating and downgrade performance graphically. Each CDO is placed into one of the three disjoint groups previously described, One Rater, Two - Disagree and Two - Agree. The One Rater and Two - Disagree samples are smaller and may be skewed towards different types of CDOs. For this reason, and as a rough control for type differences, we standardize the collateral type distribution of all three samples to have the same weights as the entire sample before calculating the mean within a group-year.

Panel A of Figure 1 shows the average number of notches (with $90 \%$ confidence intervals) that the lowest AAA tranche of a CDO was downgraded by S\&P by issuance year for the three groups. Because a rating by S\&P is required to be included in the sample, the One Rater group contains only CDOs that were rated by S\&P and not Moody's. For 2005 onwards, those CDOs only rated by S\&P are downgraded by fewer notches than those rated by both S\&P and Moody's, whether they agree on the AAA tranches or not. The reported confidence intervals suggest the difference is significant overall, which we will test more formally using a regression framework shortly.

Panel B shows the analogous graph when focusing on CDOs rated solely by Moody's compared to those that received dual ratings. As opposed to the previous panel, up until 2005, dualrated CDOs in either group experienced fewer downgrades relative to those only rated by Moody's, although the magnitude and statistical confidence of the difference is rather small. Starting in 2006 this pattern dramatically changed, with deals rated by Moody's and not S\&P outperforming their

\footnotetext{
${ }^{20}$ Nevertheless, it is possible that a deal has suffered irrevocable damage and has not yet received an EOD notice. It is also possible that the detailed searching process for the EOD notices, as outlined in Internet Appendix IA 2.B, did not locate such a notice.
} 
counterparts. Furthermore, the magnitude of the differences increased from roughly one notch in previous years to over five notches for 2006 and two notches for 2007.

Panel C of Figure 1 illustrates the differences across all three mutually exclusive groups for a separate measure of CDO performance, the Event of Default notice. Similar to the previous two panels, while the performance of both dual-rated groups for CDOs originating up until 2005 perform in either a similar fashion or slightly better than those with a single rating, this pattern does not hold for the latter part of the sample. For CDOs in 2006-2007 (where the majority of CDO capital is issued), dual-rated deals where ratings agree (Two - Agree group) largely underperform statistically and economically those with one rating.

To control for other determinants of rating performance, Panel A of Table 3 presents ordered or plain logit regression results with the above measures of CDO performance as dependent variables. In the first two columns, we examine all CDOs that were rated by S\&P with S\&P downgrade notches as the dependent variable. The relative likelihood of a CDO being downgraded when rated by S\&P and not Moody's is roughly one-half of that when being rated by both agencies, a result that is highly statistically significant $\left(z^{-s t a t}=-3.26\right)$.

Although all regressions include controls for vintage year and collateral type, it is also possible that there is some form of omitted CDO risk that we cannot capture from the fixed effects. To control for the market's perception of relative risk at issuance, we also include specifications with the weighted-average credit spread on all AAA tranches at issuance. ${ }^{21}$ Nevertheless, the relative likelihood of the One Rater variable (in the second column) is similar. When both agencies rate a $\mathrm{CDO}$ but do not agree on the portion of the $\mathrm{CDO}$ that receives a AAA rating, the likelihood of being downgraded by S\&P in the future is statistically indistinguishable from the case when both agencies agree on the AAA size of the CDO. The third and fourth columns perform similar

\footnotetext{
${ }^{21}$ By requiring coupon spreads, we lose 324 observations, leaving a final sample of 2,466 CDOs.
} 
regressions for those CDOs rated by Moody's with performance measured by the number of notches downgraded. There is no difference in future downgrading by Moody's for CDOs they rate alone, relative to those they also rate with S\&P, after controlling for credit spread.

The fifth column shifts the focus to our second measure, Event of Default notice, as the dependent variable in an ordinary logit regression. Single rated deals, either by S\&P or Moody's, are significantly less likely to experience an EOD (odds ratio of 0.28 ). When credit spreads are included as a control variable in the sixth column, the odds ratio increases to 0.37 , but remains significant. ${ }^{22}$

Our results differ from Benmelech and Dlugosz (2009b), who find that structured finance collateral with dual ratings performed better than those with one rating. However, they examine the performance of underlying collateral that make up a set of 534 ABS CDOs instead of the performance of the actual CDO tranches as we do. ${ }^{23}$ Therefore, we repeat our analysis for only those CDOs whose underlying collateral are comprised of ABS securities. Panel B of Table 3 reports the results of this analysis. Overall, we find the same relationships in this ABS CDO sample.

Since Event of Default notices are a hard measure of CDO performance not determined by rating agencies, Table 4 presents the results of logit and probit regressions where we focus solely on these EOD notices. In addition, for comparisons across rating agencies and for comparability with Benmelech and Dlugosz (2009b), we adopt their framework for Table 4. The first specification finds that, after controlling for initial credit spreads, vintage and collateral type effects, the odds of experiencing an Event of Default when possessing a sole rating is roughly one-eighth of those for deals that have two ratings.

\footnotetext{
22 Similar analysis is performed using OLS and ordered probit regressions to eliminate the possibility of a specific modeling framework driving our results. We find similar results in all specifications performed. These results are reported in the Internet Appendix Table IA.4.

${ }^{23}$ In addition to our differences in methods, their ratings data stops in January 2008 when much severe MBS downgrading had yet to occur. Our ratings data extends to June 30, 2010. Cordell, Huang, and Williams (2011) find that ABS CDOs tranches rated by S\&P underperform (in Table 18) but note that their results may be idiosyncratic since this only consists of 23 bonds. We have 640 AAA CDO tranches rated by S\&P but not Moody's.
} 
Specification 3 looks at all the possible combinations of the three agencies that could issue ratings for a deal. The results indicate that the presence of dual ratings for a CDO by the top two agencies, S\&P and Moody's, is associated with a higher chance of default. Furthermore, those securities only rated by S\&P perform better than the base case of being rated by S\&P and Fitch. Ordered probit results with coefficient estimates in specifications 4-6 are consistent with the ordered logit.

The results in this section indicate that, at CDO issuance, investors perceived dual-rated deals to be safer (Table 2), but the subsequent CDO performance (Tables 3-4) suggests that they were incorrect. Overall, we do not find evidence supporting a dual-certification value as called for by rating shopping (H1A). Two possible and related explanations for these findings are that issuers pushed marginal deals to receive dual-ratings, and/or CDOs with dual-ratings were targeted toward less sophisticated investors. If the rating agencies provide ratings which are independent and have not been inflated, the procurement of multiple AAA ratings should be a signal of an extraordinary security. The fact that dual-rated deals were extremely common, yet underperformed, suggests a rating environment where dual-certification was of less value than single-certification. A caveat of the above findings is that our comparison category for One Rater is only 11.1 percent of the deals (as shown in Panel B of Table 1), which motivates our focus on the dual-rated deals. We now shift our attention to the evaluations performed by both S\&P and Moody's for a subset of CDOs for which we have unique data on rating inputs and outputs.

\section{Rating Assumption Differences}

In this section, we first examine Moody's and S\&P's key model assumptions and the degree to which they differ from deal to deal, and then combine those differences into a single summary measure, "collateral risk disagreement" $(C R D)$. 


\subsection{Collateral Asset Default Correlation and Credit Quality}

We first illustrate how the rating agencies account for the credit risk of the underlying collateral, used as model inputs. CDO collateral pools consist of many assets. The credit quality of the CDO's collateral asset pool is characterized by the average default probability. Those default probabilities are derived from the assets' credit ratings in conjunction with historical default data. All else equal, a lower default probability allows a CDO to have larger AAA-rated tranches.

Panel A of Figure 2 presents a scatter-plot of Moody's (y-axis) and S\&P's (x-axis) probability of default estimates by CDO type. The 45-degree line is where the CDOs would fall if the two CRAs agreed perfectly on collateral credit quality. There are considerable deviations from the 45degree line. S\&P assumed higher default probabilities for CLOs relative to Moody's, whose range of assumed default probabilities was tighter. The average absolute difference in collateral default probabilities is 0.046 , which represents a $30.3 \%$ deviation from the average collateral default probability.

Next, we perform a similar comparison for the estimated default correlations among collateral assets. Moody's and S\&P use different terminologies for default correlations, which makes them difficult to compare directly. ${ }^{24}$ We convert both measures into conventional default correlations bounded by $[-1,1] .^{25}$ Panel B of Figure 2 plots Moody's assumed default correlations against those of S\&P for the overlapping sample of CDOs. Moody's and S\&P's assumed CDO default correlations are positively related but they still have considerable disagreement as shown by the large deviations from the 45-degree line. The average absolute difference divided by the average of the two correlation measures is $57.2 \% .^{26}$

\footnotetext{
${ }^{24}$ Moody's uses Diversity Score (DS) to measure how many independent assets are needed to represent the collateral pool. S\&P reports a correlation measure $(\mathrm{CM})$ which is the ratio of the standard deviation of the portfolio default rate computed with correlation to that computed without correlation.

25 Griffin and Nickerson (2012) discuss the economic interpretation and the appropriate level of default correlations.

${ }^{26}$ A third factor for CDO valuation is maturity. Partly due to S\&P's use of 7-year maturity for MBS and Moody's reporting of the legal maturity which is much longer, Moody's assumed maturity is on average 3.6 years longer than
} 


\subsection{Collateral Risk Disagreement}

The disagreements on credit quality and default correlation may allow for considerable crosssectional variations in AAA sizes as long as the effects are not offsetting. We have two goals: 1) we want to measure the combined effect of assumption differences regarding both default correlations and underlying collateral default probability, and 2) we want to measure these assumption differences in terms of their effect on AAA sizes.

In order to compare Moody's and S\&P's inputs and models in a meaningful way, we need to transform these inputs by the same function. Hence, we plug evaluations from both rating agencies into our version of S\&P's model to obtain the effect on the AAA tranche size. ${ }^{27}$

Figure 3 shows the scatter-plot of these implied AAA size differences under both Moody's and S\&P's assumptions gauged by our highly accurate replication of S\&P's model. Many observations do not fall on the 45 degree line, meaning that the two rating agencies have disagreements regarding the underlying CDO's overall credit risk and hence the underlying AAA tranche size.

It is conceptually possible that Moody's and S\&P's model differences further offset assumption differences such that both Moody's and S\&P's models call for the same AAA sizes. To examine this possibility, in Figure 4 we evaluate the amount of AAA according to our replication of Moody's model with Moody's assumptions and compare it to the amount of AAA according to S\&P's model with S\&P's assumptions. In addition, since S\&P's credit risk model does not consider cash flow modeling, we adjust the model for cash flow considerations using the cash flow consideration of Moody's. Figure 4 shows that there is a large difference between the amount of

S\&P's assumption. Nonetheless, while Moody's reports the legal maturity on these deals, in their modeling process they use a weighted average life that frequently ranges from 6 to 7.5 years and hence is quite similar to S\&P's.

${ }^{27}$ Following Griffin and Tang (2012), we use 1-SDR as the allowable AAA because this is the largest amount strictly feasible from their credit risk model, which is the only one from S\&P publicly available. We will control for the cash flow channel in the regression analysis. 
AAA permissible under Moody's model compared to S\&P's. This raises the question as to how most CDOs received the same ratings.

We define collateral risk disagreement $(C R D)$ as the difference between S\&P's and Moody's assessment of overall collateral risk under the same model (either S\&P's or Moody's model). In Figure 5 we plot the distribution of CRD under S\&P's model. About four-ninths of the CDOs have an implied AAA tranche size more than 5\% different between S\&P and Moody's. The average absolute $C R D$ is $6.0 \%$. To put this in perspective, junior CDO tranches may be $2-5 \%$ of the CDO, so for CDOs "rated at the edge" this difference could be substantial. Relative to a deal's overall collateral risk, the average disagreement as a percentage of SDR for AAA ratings is $10.5 \%$. Additionally, $C R D$ is skewed towards the right side of zero. In $63 \%$ of the sample Moody's has more lenient CDO credit risk assumptions. We explore the cross-sectional implications of the overall model output differences as well as risk disagreements in the next section.

\section{Model Implied AAA, Collateral Risk Disagreement, and AAA Size Adjustments}

The previous section shows that model inputs and model prescribed AAA sizes between Moody's and S\&P are substantially different. Then how can it be that the actual ratings are often identical? To understand this puzzle, we examine the relationship between adjustments beyond rating model outputs and both the difference in model-implied AAA sizes and collateral risk disagreement (Hypotheses $\mathrm{H} 2$ and H2A). For each rating agency, the actual AAA size (for example $80 \%$ ) minus the amount of AAA implied from the rating agency's own model output (say $70 \%$ ) is defined as its AAA adjustment (10\%). We require that both S\&P and Moody's rate a deal for it to be included in our sample, but we do not require that they give identical ratings.

\subsection{Are Adjustments Issued in Response to Differences in Model-Implied AAA Sizes?}

One way to reconcile different model outputs with identical ratings is via adjustments. However, adjustments could be justified with qualitative, non-modeling reasons such as the quality 
of the CDO manager or additional credit support, and not in response to modeling shortcomings relative to a competing agency. AAA adjustments from S\&P and Moody's are reported in Panel A of Internet Appendix Table IA.5. S\&P's average AAA adjustment after being augmented with dealspecific cash flow protection is $1.4 \%$ greater than Moody's ( $p$-value of 0.0006$)$. This is consistent with our findings of S\&P, on average, having less optimistic assessments of collateral risk, and hence, on average, needing to make larger adjustments. ${ }^{28}$

We begin by defining $A A A$ Model Difference for the agency being considered (i.e. S\&P) to be the model implied AAA size of their competitor (i.e. Moody's) minus the model implied AAA size of the agency being examined (i.e. S\&P). We note that the need to issue adjustments for competitive reasons differs across CDOs. This competitive pressure is at its greatest point when the amount of AAA that an agency's model can justify does not meet the AAA size that a competing agency is willing to grant. However, the actual amount of AAA granted by the competitor would also be endogenous in the presence of rating catering. Therefore, we instead use a proxy that is likely correlated with competitive pressure but uses only ex-ante information. This measure is further characterized by two variables: $A A A$ Model Diff. - Positive is set equal to $A A A$ Model Difference when the value is positive, indicating the AAA size implied by the competing agency's (Moody's) model is larger than the model AAA size of the agency being considered (S\&P); AAA Model Diff. - Negative is constructed in a converse fashion, taking on a non-zero value when the model implied AAA size exceeds the model implied AAA of the competing agency. Therefore, when $A A A$ Model DifferencePositive takes on a non-zero value, indicating S\&P's model cannot justify as large of a AAA size as Moody's model, S\&P is more likely to face competitive pressure.

\footnotetext{
${ }^{28}$ It is unclear whether adjustments would be larger for single or dual-rated deals as catering could occur in both cases. In Panel B of Internet Appendix Table IA.5, we contrast the adjustments made by S\&P for deals they rate alone against those they rate together with Moody's. We do not find evidence of adjustments differing between single and dual-rated deals.
} 
Table 5 presents OLS regression results of each agency's adjustments on the differences in model-implied AAA sizes. In the first three specifications, the dependent variable is S\&P's AAA size adjustment while the segmented measure of AAA model difference is the key independent variable. Column 1 does not include any control variables. The coefficient of $1.098(t$-stat $=7.90)$ for $A A A$ Model Diff. - Positive implies that when S\&P's model would give a AAA tranche size $10 \%$ less than Moody's, they give an adjustment beyond their model of $10.98 \%$. The magnitude of this finding decreases slightly to $0.92($-statistic $=5.47)$ after controlling for collateral vintage and CDO type (column 2). If the $A A A$ Model Difference is appropriately split into positive and negative values due to rating pressure, the catering hypothesis calls for the $A A A$ Model Difference - Positive to be related to adjustments. The coefficient for $A A A$ Model Difference - Negative is also statistically significant with a coefficient of $0.342(t$-stat $=4.18)$, yet the null of symmetric coefficients is rejected at conventional levels with a $p$-value of 0.0025 . The relation between adjustments and $A A A$ Model Difference Negative will be discussed in more detail shortly.

Griffin and Tang (2012) found that the most important component in explaining adjustments was that CDOs with a "model-implied small amount of AAA (a high SDR)" received larger adjustments. In column 3, we indeed find a significant relationship between adjustments and SDR. We also add a control for the perceived risk of the deal using the weighted-average credit spread of the AAA tranches. However, the results remain qualitatively similar. The magnitude of the coefficient for $A A A$ Model Diff-Positive does decrease slightly to 0.702 . The $p$-value for the test of equality between $A A A$ Model Diff - Positive and $A A A$ Model Diff - Negative increases to 0.083.

Columns 4 through 6 present analogous results with Moody's adjustment as the dependent variable. The coefficient for the two partitions of $A A A$ Model Difference as well as their difference is smaller relative to the first three columns. After controlling for collateral risk in the final specification, when the amount of AAA justified by Moody's model is 10\% less than S\&P's, they 
issue an adjustment of $3.5 \%$. The positive AAA model difference coefficient is highly significant whereas the negative model difference yields a smaller coefficient of 0.105 and a $t$-statistic of 0.79 . Nevertheless, the $p$-value for the test of equal coefficients is 0.18 , failing to reject the null of equal coefficients.

If rating agencies issue adjustments when there is a competitive pressure to do so, $A A A$ Model Diff - Positive should be related to adjustments. At first glance, it is hard to imagine a reason why a rating agency would issue negative adjustments. However, an underwriter must ultimately structure a CDO's tranche sizes. If their goal is to maximize the portion of the CDO with dual AAA ratings, they may "target" the rating agency which is generally more lenient and set the size of the most senior tranche to the largest possible level while still being rated AAA.

The following example illustrates our point. Suppose that the issuer targets the AAA support level close to Moody's model, perhaps because Moody's is more lenient on average. Yet, there is still considerable variation across deals. If Moody's model yields a AAA size of 79\%, the underwriter sets the size of the most senior tranches so that they make up $80 \%$ of the deal. For this particular deal S\&P's model yields a AAA size of $85 \%$. Therefore, we will observe S\&P issuing a $-5 \%$ adjustment, while $A A A$ Model Diff will be $-6 \%$ from S\&P's viewpoint. In addition, the magnitudes of the negative adjustment and $A A A$ Model Diff - Negative will be positively related. Therefore, if underwriters are more likely to target tranche sizes closer to one rating agency (Moody's), we would expect that the competing agency's (S\&P's) adjustments would be positively related to $A A A$ Model Diff-Negative and for that rating agency's (Moody's) adjustments to be unrelated to $A A A$ Model Diff - Negative.

If underwriters do consistently target a particular rating agency's model, actual AAA sizes should fall closer to the AAA size implied by that agency's model than to their competitor's model. After using our adjustment for cash-flow considerations to S\&P's model, we formally test for this in 
Internet Appendix Table IA.7. We find that in the overall sample, the average distance between Moody's model and realized AAA sizes is $6.53 \%$ while the average distance to S\&P's model (with the Moody's cash flow adjustment) is $8.42 \%$, with their difference having a $p$-value $<0.0001$, indicating that final AAA tranche sizes are closer to Moody's model. In addition, when the final AAA size falls in-between the sizes dictated by the two models, the realized amount is closer to Moody's by 3.02\% ( $\not$-value $=0.0006)$ when Moody's model gives less AAA, and is also closer to Moody's by $1.67 \%(p$-value $=0.086)$ when Moody's model gives more AAA. Thus, underwriters appear to be targeting Moody's model more often, providing a possible reason why S\&P's adjustments (as compared to Moody's) should be more correlated with $A A A$ Model Diff - Negative. Additionally, the coefficients are larger on $A A A$ Model Diff-Positive in the S\&P regressions than in the Moody's regressions (Table 5), which suggest S\&P's adjustment moves more in response to Moody's model than Moody's adjusts relative to S\&P's model - consistent with the targeting explanation.

While the relation between model differences and adjustments is consistent with the catering theory, a potential alternative explanation for the relationship between adjustments and $A A A$ Model Difference is non-modeled considerations by one agency being related to the degree to which their model or collateral evaluation disagrees with those of a competitor. If so, the credit ratings they assign should not be interpreted as an independent assessment of a CDO's risk.

\subsection{Are Different Assessments of Collateral Risk Related to Adjustments?}

As an alternative to using disagreement in model-implied AAA from CRA models, we can focus on the part caused solely by collateral risk disagreement. An advantage of this approach is that our explanatory variable of interest may be subject less to estimation error. ${ }^{29}$ We graphically present

\footnotetext{
${ }^{29}$ Note that we verify that our replication of S\&P's collateral risk model is quite accurate, which is used to construct our measure of collateral risk disagreement. While we follow all available documentation for the cash flow modeling built
} 
the relation between $C R D$ and AAA size adjustment in Figure 6. Panel A shows a positive association between S\&P's AAA adjustment and the collateral risk disagreement between S\&P and Moody's. Panel B displays the analogous relationship between Moody's out-of-model AAA adjustment and disagreement in collateral riskiness. Here $C R D$ is the difference between the AAA allowable under Moody's model when using Moody's assumptions and when using S\&P's assumptions. There does not appear to be a discernible univariate relationship between $C R D$ and Moody's adjustments. Next, we run multivariate regressions to separate the effect of collateral risk disagreement from other factors potentially affecting adjustments.

In a similar fashion to the analysis in the previous section, we split our measure of collateral risk disagreement into two different independent variables, conditioning on the sign of $C R D$, under the assumption that the rating agency is more likely to be under competitive pressure when it has a tougher assessment of collateral risk (CRD - Positive). A possible disadvantage of using $C R D$ is that adjustments are made based on the total output of credit ratings models and not just the collateral risk component. Conditioning on the sign of $C R D$ may be a less accurate way to classify if rating agencies should be under pressure to issue an adjustment, and could lead to less asymmetry between positive and negative CRD.

Panel A of Table 6 presents regression results using S\&P's AAA size adjustment as the dependent variable and the segmented measure of collateral risk disagreement between S\&P's assumptions and Moody's assumptions as the key independent variables. In the first column, when all controls are omitted, the coefficient of 0.967 for $C R D$ - Positive $(t$-stat $=12.11)$ indicates that when S\&P's collateral evaluation leads to a AAA size 10\% less than Moody's evaluation, they issue an adjustment of $9.7 \%$. The coefficient for $C R D-$ Negative is similar, with a $p$-value of 0.726 for the test of their difference. These results remain unchanged when controlling for CDO characteristics

into Moody's model, we cannot assess its accuracy in the same manner. This is because Moody's is careful not to disclose its model output (as one of the coauthors was told by a higher-level Moody's employee). 
(column 2). Moody's and S\&P's models may also differ in the way they model the collateral risk of a particular deal. In column 3 we include Collateral Modeling Difference, the difference between Moody's and S\&P with respect to a deal's collateral default distribution, holding collateral risk assumptions constant. This specification indicates that S\&P's adjustments bear some relation to differences in the agencies' collateral modeling approaches.

We control for model implied collateral risk and perceived CDO risk in column 4. S\&P's collateral risk measure, SDR, is again a strong predictor of S\&P's AAA adjustments. In addition, its inclusion lowers the coefficient estimate of $C R D$ - Positive. The final specification of Panel A of Table 6 includes collateral risk, modeling differences, credit risk, and CDO characteristics and shows that both segments of $C R D$ remain positive and significant. A $t$-test cannot reject the null of equality between the positive and negative $C R D$ variables.

Panel B of Table 6 uses Moody's estimated adjustment as the dependent variable. Here $C R D$ is defined as AAA size with Moody's assumptions minus AAA size with S\&P's assumptions, both under our version of Moody's model. The coefficient of $C R D$ - Positive is positive and strongly statistically significant in all specifications considered, while $C R D-N$ egative is slightly negative and insignificant in all specifications. Moody's issues a positive adjustment when the amount of AAA implied by its model is less than the final amount of AAA that S\&P issues. For a $10 \%$ difference in AAA size under the rating agencies' respective assumptions, the adjustment by Moody's ranges from $2.7 \%$ when no controls are included up to $5.8 \%$ when controlling for modeling differences, collateral risk, and CDO characteristics in the final specification.

Overall, Table 6 shows that there is a positive relationship between collateral risk disagreement and AAA adjustment for both agencies when CRD is positive, but only Moody's adjustments in Panel B exhibit an asymmetrical relationship. CRD's effect is symmetrical for S\&P's adjustments. If rating agencies do factor in non-modeled data in their decisions, which we cannot 
observe, the symmetric results for S\&P's adjustments would imply that S\&P's non-modeled data acts to bring their ratings towards the framework Moody's uses to evaluate risk in the underlying collateral pool. If neither agency's model is more frequently targeted, the catering hypothesis predicts an asymmetric relation between cases where competitive pressure exists and does not exist. However, the evidence of ratings being closer to Moody's model indicates that Moody's may be targeted more often. Thus, the significant coefficient on CRD - Negative for S\&P (but not Moody's) could be because S\&P considers non-modeled data related to Moody's model in their rating decisions, ${ }^{30}$ or because Moody's model is targeted more frequently.

One way to further disentangle these explanations is related to future performance. If rating agencies make adjustments based on non-modeled data for useful reasons, then adjustments may be related to better future rating performance. However, if adjustments are made to simply match a competitor, then they may be related to poor future rating performance as called for by Hypothesis H3A. We will test these predictions in Section 6.2.

\section{Is Collateral Risk Disagreement Recognized by Investors or Borne Out in Future Ratings?}

In this section we ask and answer two remaining questions: 1) Did CDO yield spreads at issuance indicate investor awareness of CRA adjustments? 2) How is subsequent rating performance related to the efficacy of adjustments and collateral risk disagreement?

\subsection{Did Investors Recognize the Presence of Adjustments and Collateral Risk Disagreement at Issuance?}

If investors can detect adjustments, they should demand higher yield spreads for CDOs with larger inflationary adjustments. In practice, it is possibly too difficult for most investors to detect the adjustments made by rating agencies, but they may be able to recognize disagreements between

\footnotetext{
30 A non-modeled adjustment might justifiably be made for qualitative reasons that are difficult to incorporate into modeling. Yet, here the adjustment is correlated with the competitor's collateral assessment, which is something that the rating agency could incorporate quantitatively. It is not clear why a rating agency would adjust ratings with non-modeled data related to their competitor's collateral assessment without making systematic adjustments to their own model or rating methodology if they believed their model was incomplete.
} 
rating agency assessments of underlying collateral risk. Using detailed data from our smaller sample, we examine if investors take adjustments and collateral risk disagreement into consideration by revisiting the credit spreads they demand at issuance.

Table 7 presents the results when the weighted-average AAA credit spreads are regressed on various factors possibly taken into consideration by investors. Both agencies' AAA adjustments are considered in the first specification. Neither S\&P's nor Moody's adjustments have a statistically significant relationship with our proxy of CDO risk. Furthermore, the test of joint significance cannot reject the null with a $\mathrm{p}$-value of 0.61 . In the next specification we shift to metrics that are more accessible to investors, SDR and collateral risk disagreement based on S\&P's model. Both the absolute value of our collateral risk disagreement variable and the square of the variable reflect how much the two agencies disagree in their assessment of collateral risk, possibly related to deal complexity. Neither variation of $C R D$ has an effect on yields. Additionally, after controlling for other deal characteristics including proxies of manager and underwriter experience (columns 4 and 5), SDR becomes statistically insignificant as well. Overall, Table 7 shows that rating agency adjustments and collateral risk disagreement are not factored into CDO yields. Investors seemed unaware of adjustments made by rating agencies and were not compensated for inflationary ratings.

\subsection{Did Adjustments and Collateral Risk Disagreements Predict Future Rating Performance?}

It is important to note that while there is considerable business pressure on rating agencies at issuance, this outside influence attenuates once the notes have been sold. Rating agencies were likely highly concerned about the general perception of structured finance ratings and did not want to downgrade ratings too quickly without legitimate reasons. However, once rating agencies were eventually forced to downgrade, there should be considerably less pressure to match a competitor's ratings in subsequent surveillance analysis. 
If adjustments are explained by some kind of omitted rating variable, one would expect the rating agency to continue to place weight on this rating variable in subsequent rating revisions. In such a case, if AAA adjustments were merely correlated with this omitted variable, future rating changes of the CDO should be unrelated to adjustments (Hypothesis H3). On the other hand, if an agency administered higher ratings than their model initially prescribed for no systematic reason but rather to match a competitor's rating, then whenever the structured finance products began to falter, the agency would revert back to their original beliefs about the riskiness of the deal (Hypothesis $\mathrm{H} 3 \mathrm{~A}$ ) and deals with adjustments would experience faster downgrading.

We begin by employing ordered logit regressions to first test whether there is a relationship between future downgrades and adjustments. Panel A of Table 8 presents odds ratios of regressions where the dependent variable is the number of notches S\&P downgrades the lowest seniority tranche initially receiving a AAA rating as of June 30, 2010. In the first specification our explanatory variable of interest is a standardized version of S\&P's AAA adjustment. Because ABS CDOs were subject to vintage effects in later years that caused the underlying collateral to be of particularly low quality, we include controls for ABS CDOs issued from 2004 to 2007 in addition to standard vintage year effects. A one standard deviation change in S\&P's adjustment increases the odds of experiencing a downgrade by $93 \%$, which is significant at the $1 \%$ level $\left(z^{-s t a t}=3.88\right)$. In the second specification we use an identical set of explanatory variables, but include a standardized version of our CRD measure. When controlling for S\&P's overall adjustment, the amount of disagreement regarding collateral risk relative to Moody's has no explanatory power in explaining future downgrades.

When the overall riskiness of the collateral is controlled for with SDR (column 3) along with credit spreads at issuance, the odds-ratio on S\&P's adjustment both increases to 2.28 and becomes more statistically significant (z-stat=4.31). Following Griffin and Tang (2012), in the first four 
specifications we include dummy variables to control for effects of five downgrading shocks, potentially related to unobserved collateral type, that S\&P issued over the period from 2007 to 2009 related to the composition of the underlying collateral pool. In the fifth specification we exclude those shocks. In all specifications, the odds ratios on S\&P's adjustments are significantly above one.

Panel B of Table 8 presents analogous results relating Moody's future downgrades to standardized versions of their adjustments and CRD. The coefficient on Moody's adjustment remains significant and stable across all specifications, with odds ratios ranging from 1.32 to 1.42 throughout. Furthermore, $C R D$ does not exhibit any ability in explaining Moody's future downgrades. Similar to the one rating agency results in Griffin and Tang (2012), our findings from both Moody's and S\&P, and with a multitude of controls, indicate that positive adjustments from rating agencies are bad for future rating performance. Each rating agency is more likely to downgrade the CDO when they initially issued an upward adjustment, consistent with Hypothesis H3A.

We now turn our attention to the degree to which the two agencies differ in their future evaluations of a deal's riskiness. If S\&P initially issued ratings above what their original assessment of collateral risk dictated, and not from any omitted deal quality variable, then they would issue larger downgrades relative to Moody's on deals where they had much worse initial perceptions of collateral risk (high $C R D$ ) as described in Hypothesis H4A. For each CDO we compute the number of notches that S\&P downgrades the lowest seniority tranche receiving a AAA rating and subtract off the number of notches that Moody's downgraded the same tranche as of June 30, 2010.

Panel C of Table 8 reports the ordered logit regression results of downgrading disagreement on collateral risk disagreement along with other control variables. With control variables for collateral type along with $C R D$ in the first specification, we find that $C R D$ is positive and significant $\left(z_{\text {-stat}}=2.01\right)$. When we control for each agency's adjustment in the second specification, we find 
that the magnitude of $C R D$ 's coefficient increases to an odds ratio of 1.76 ( $z$-stat $=3.51$ ), indicating that a one standard deviation increase in $C R D$ increases the odds of a future downgrade by 76 percent. Through the crisis, divergence in credit ratings reflected the initial disagreement in collateral risk.

One possible explanation for these findings is that S\&P is simply more sensitive to its original assessment of collateral risk. If so, they would tend to downgrade CDOs more severely in the future whose underlying collateral was originally riskier. For this reason we include SDR, which reflects the collateral's riskiness, as well as credit spread at issuance as another proxy for collateral risk. The fourth specification also includes controls for the presence of a Fitch rating, tranche insurance, and proxies for the experience of the underwriter and collateral manager. In the final specification we remove the controls for downgrading shocks. Throughout all specifications, $C R D$ is positive and, with the exception of the final specification when downgrading shocks are not controlled for, is statistically significant in explaining relative downgrading.

On CDOs where S\&P initially thought the collateral to be more risky than Moody's, they subsequently downgraded the CDO more severely than Moody's during the crisis. Since future relative ratings move in the same direction as the initial disagreement in collateral risk, these findings validate the collateral risk disagreement as a measure of disagreement between rating agencies. Agencies reverted back to their original risk disagreements in subsequent ratings, consistent with Hypothesis H4A. More practically, this finding provides additional justification for the recently adopted SEC Rule 17g-7 as part of the implementation of Dodd-Frank Act Section 932 requiring the performance analysis of subsequent rating changes in comparison to initial ratings.

\section{Summary and Concluding Remarks}

We analyze whether "rating shopping" or "rating catering" is the better explanation for CDO ratings before the credit crisis. For the overall CDO universe issued over 1997-2007, we 
examine the popular shopping view that deals with multiple ratings are of better quality than those with only one rating. Contrary to the intuition that rating shopping alone leads to rating inflation, CDOs rated by both Moody's and S\&P default more than those with ratings from either Moody's or S\&P alone. Additionally, when one rating agency issues a AAA rating, in only $3.7 \%$ of cases does the other rating agency issue a non-AAA rating.

For a smaller sample of 716 CDOs rated by Moody's and S\&P with unique rating input and output data, we find large differences in key modeling assumptions. These differences are not offsetting and lead to model-implied AAA support levels that are on average $10.5 \%$ different. We examine how these differences can be consistent with identical AAA ratings. We find that S\&P issues more positive AAA size adjustments when they encounter competitive pressure from Moody's. Similarly, Moody's is more likely to issue a positive adjustment when S\&P uses more favorable assumptions. S\&P's and Moody's adjustments and disagreements were not reflected in yields at issuance. Although the agencies disagreed on underlying assumptions and agreed on ratings at issuance, they later revert back to their initial underlying credit risk assessment. Although we cannot entirely rule out other possible interpretations, the results are generally consistent with rating agencies going beyond their models due to competitive pressure.

Our findings have important implications for regulatory reform. We believe that the DoddFrank Act proposes strides in the right direction in terms of making regulation less reliant on ratings, calling for more transparency, and subjecting rating agencies to expert liability. ${ }^{31}$ However, the implementation of Dodd-Frank by the SEC faces practical challenges, as evidenced by the July 22, 2010 SEC ruling which indefinitely delayed rating agency expert liability. Our findings indicate that

\footnotetext{
${ }^{31}$ Darbellay and Partnoy (2012) carefully survey Dodd-Frank implementation and describe detailed suggestions for further reform. Transparency is shown optimal in theory by Pagano and Volpin (2010). A common objection to transparency is that releasing CRA data and modeling would release rating agency proprietary knowledge and destroy incentives to create better procedures. For CDOs the modeling process used by the rating agencies is already publicly described and the underlying data they use is predominately from trustees.
} 
encouraging more competition among rating agencies within the "issuer pay" model may exacerbate the current problems without further reforms. Full transparency, while not a panacea, can partially offset the conflicts of interest inherent in the issuer-pay model by making it easier to pinpoint rating inflation. Full transparency would enable investors, new rating agencies, academics, and third-party experts to more easily scrutinize ratings. 


\section{References}

Ashcraft, A., P. Goldsmith-Pinkham, and J. Vickery. 2010. MBS Ratings and the Mortgage Credit Boom. Working Paper 449, Federal Reserve Bank of New York Staff Reports.

Barnett-Hart, A. K. 2009. The Story of the CDO Market Meltdown: An Empirical Analysis. Harvard College: BA Dissertation.

Becker, B., and T. Milbourn. 2011. How Did Increased Competition Affect Credit Ratings? Journal of Financial Economics 101:493-514.

Begley, T., and A. Purnanandam. 2012. Design of Financial Securities: Empirical Evidence from Private-label RMBS Deals. Working Paper, University of Michigan at Ann Arbor.

Benmelech, E., and J. Dlugosz. 2009a. The Alchemy of CDO Credit Ratings. Journal of Monetary Economics 56:617-34.

Benmelech, E., and J. Dlugosz. 2009b. The Credit Rating Crisis. NBER Macroeconomics Annual 24:161-208.

Bolton, P., X. Freixas, and J. D. Shapiro. 2012. The Credit Ratings Game. Journal of Finance 67:85112.

Bongaerts, D., M. Cremers, and W. N. Goetzmann. 2012. Tiebreaker: Certification and Multiple Ratings. Journal of Finance 67:113-52.

Bruno, V., J. Cornaggia, and K. R. Cornaggia. 2012. Does Certification Affect the Information Content of Credit Ratings? Working Paper, Indiana University.

Coffee, J. C., 2009, What Went Wrong? An Initial Inquiry into the Causes of the 2008 Financial Crisis, Journal of Corporate Law Studies 9:1-22.

Cohen, A., 2011, Rating shopping in the CMBS market, Working paper, The Board of Governors of the Federal Reserve.

Cordell, L., Y. Huang, and M. Williams. 2011. Collateral Damage: Sizing and Assessing the Subprime CDO Crisis. Working Paper 11-30, Federal Reserve Bank of Philadelphia.

Cornaggia, J., and K. R. Cornaggia, 2013. Estimating the Costs of Issuer-Paid Credit Ratings, Working Paper, Indiana University.

Cornaggia, J., K. R. Cornaggia, and J. Hund. 2013. Credit Ratings Across Asset Classes: A $\equiv$ A? Working Paper, Indiana University.

Coval, J. D., J. W. Jurek, and E. Stafford. 2009a. Economic Catastrophe Bonds. American Economic Review 99:628-66. 
Coval, J. D., J. W. Jurek, and E. Stafford. 2009b. The Economics of Structured Finance. Journal Of Economic Perspectives 23:3-25.

Darbellay, A. and F. Partnoy, 2012, Credit Rating Agencies and Regulatory Reform, Working Paper, University of San Diego School of Law.

Faltin-Traeger, O., and C. J. Mayer. 2011. Lemons and CDOs. Working Paper, Columbia University.

Farhi, E., J. Lerner, and J. Tirole. 2011. Fear of Rejection? Tiered Certification and Transparency. Working Paper 534, IDEI.

Faure-Grimaud, A., E. Peyrache, and L. Quesada. 2009. The Ownership of Ratings. The RAND Journal of Economics 40:234-57.

Financial Crisis Inquiry Commission (FCIC), 2010, The Financial Crisis Inquiry Report: Final Report of the National Commission on the Causes of the Financial and Economic Crisis in the United States, http:/ / fcic.law.stanford.edu/report.

Foley, S., 2013, Rating Agencies: Outlook Unchanged,” Financial Times, January 14, 2013.

Fong, K., H. Hong, M. Kacperczyk, and J. D. Kubik. 2011. Do Security Analysts Discipline Credit Rating Agencies? Working Paper, NYU.

Fulghieri, P., G. Strobl, and H. Xia. 2012. The Economics of Solicited and Unsolicited Ratings. Working Paper, University of North Carolina.

Golan, L., C. Parlour, and U. Rajan, 2011, Competition, Quality, and Managerial Slack, Working Paper, University of Michigan.

Goodman, L., P. Rubinstein, J. Ho, J. Raiff, and Wilfred Wong, 1997, PainWebber Mortgage Strategist, June 3.

Griffin, J. M., and J. Nickerson, 2012, Were CDO Correlation Risk Assumptions Reasonable Ex Ante?, Working Paper, University of Texas.

Griffin, J. M., and D. Y. Tang. 2011. Did Credit Rating Agencies Make Unbiased Assumptions on CDOs? American Economic Review: Papers \& Proceedings 101:125-30.

Griffin, J. M., and D. Y. Tang. 2012. Did Subjectivity Play a Role in CDO Credit Ratings? Journal of Finance 67, 1293-1328.

Griffin, J.M., and G. Maturana. 2013.Who Facilitated Misreporting in Securitized Loans? Working Paper, University of Texas at Austin.

He, J., J. Qian, and P. E. Strahan, 2011, Credit Ratings and the Evolution of the Mortgage-Backed Securities Market. American Economic Review: Papers \& Proceedings 101, 131-135. 
He, J., J. Qian, and P. E. Strahan, 2012, Are All Ratings Created Equal? The Impact of Issuer Size on the Pricing of Mortgage-Backed Securities. Journal of Finance 67, 2097-2137.

Hong, H., and M. Kacperczyk, 2010. Competition and Bias. Quarterly Journal of Economics 125:162782.

John, K., S. A. Ravid, and N. Reisel, 2010, The Notching Rule for Subordinated Debt and the Information Content of Debt Rating, Financial Management 39:489-513.

Keys, B. J., T. Mukherjee, A. Seru, and V. Vig. 2010. Did Securitization Lead to Lax Screening? Evidence from Subprime Loans 2001-2006. Quarterly Journal Of Economics 125:307-62.

Kisgen, D. J., and P. E. Strahan, 2010, Do Regulations Based on Credit Ratings Affect Firm Cost of Capital?, Review of Financial Studies 23:4324-47.

Kraft, P. 2011. Do Rating Agencies Cater? Evidence from Rating-Based Contracts. Working Paper, New York University.

Ljungqvist, A., F. Marston, and W. Wilhelm. 2006. Competing for Securities Underwriting Mandates: Banking Relationships and Analyst Recommendations. Journal of Finance 61:301-40.

Longstaff, F. A., and A. Rajan. 2008. An Empirical Analysis of the Pricing of Collateralized Debt Obligations. Journal of Finance 63:529-63.

Lucas, D., L. S. Goodman, and F. Fabozzi, 2006, Collateralized Debt Obligations: Structures and Analysis, 2nd Edition, Wiley, New York.

Mathis, J., J. McAndrews, and J. Rochet. 2009. Rating the Raters: Are Reputation Concerns Powerful Enough to Discipline Rating Agencies? Journal of Monetary Economics 56:657-74.

Mian, A., and A. Sufi. 2009. The Consequences of Mortgage Credit Expansion: Evidence from the 2007 Mortgage Default Crisis. Quarterly Journal of Economics 124:1449-96.

Opp, C. C., M. M. Opp, and M. Harris. 2013. Rating Agencies in The Face of Regulation. Journal of Financial Economics 108, 46-61.

Pagano, M., and P. Volpin. 2010. Credit Ratings Failures and Policy Options. Economic Policy 25:40131.

Partnoy, F. 2009. Overdependence on Credit Ratings Was a Primary Cause of The Crisis, in D. D. Evanoff, P. Hartmann, and G. G. Kaufman. Ed.: The First Credit Market Turmoil Of The 21st Century: Implications for Public Policy. World Scientific. Singapore.

Partnoy, F. 2010. Historical Perspectives on the Financial Crisis: Ivar Kreuger, the Credit-Rating Agencies, and Two Theories about the Function, and Dysfunction, of Markets. Yale Journal on Regulation 26:431-43. 
Piskorski, T., A. Seru, and J. Witkin. 2013. Asset Quality Misrepresentation by Financial Intermediaries: Evidence from RMBS Market. Working Paper, Columbia University.

Rutledge, A., and S. Raynes. 2010. Elements of Structured Finance. Oxford University Press.

Sanders, A. 2009. A Primer of CDO Valuation. Working Paper, George Mason University.

Sangiorgi, F., and C. Spatt. 2011. Opacity, Credit Rating Shopping, and Bias. Working Paper, Carnegie Mellon University.

SEC, 2008, Summary report of issues identified in the commission staff's examinations of select credit rating agencies, Mimeo, U.S Security and Exchange Commission.

Skreta, V., and L. Veldkamp. 2009. Rating Shopping and Asset Complexity: A Theory of Rating Inflation. Journal of Monetary Economics 56:678-95.

Smith, E. 2008. 'Race to Bottom' at Moody's, S\&P Secured Subprime's Boom, Bust. Bloomberg. http://www.bloomberg.com/apps/news?pid=newsarchive\&sid=ax3vfya_Vtdo

Stanton, R., and N. Wallace. 2012. CMBS Subordination, Ratings Inflation, and the Crisis of 20072009. Working Paper 16206, NBER.

Xia, H., 2012, Can Competition Improve the Information Quality of Credit Ratings?, Working Paper, University of Texas at Dallas. 


\section{Panel A}

\section{S\&P Downgrades}

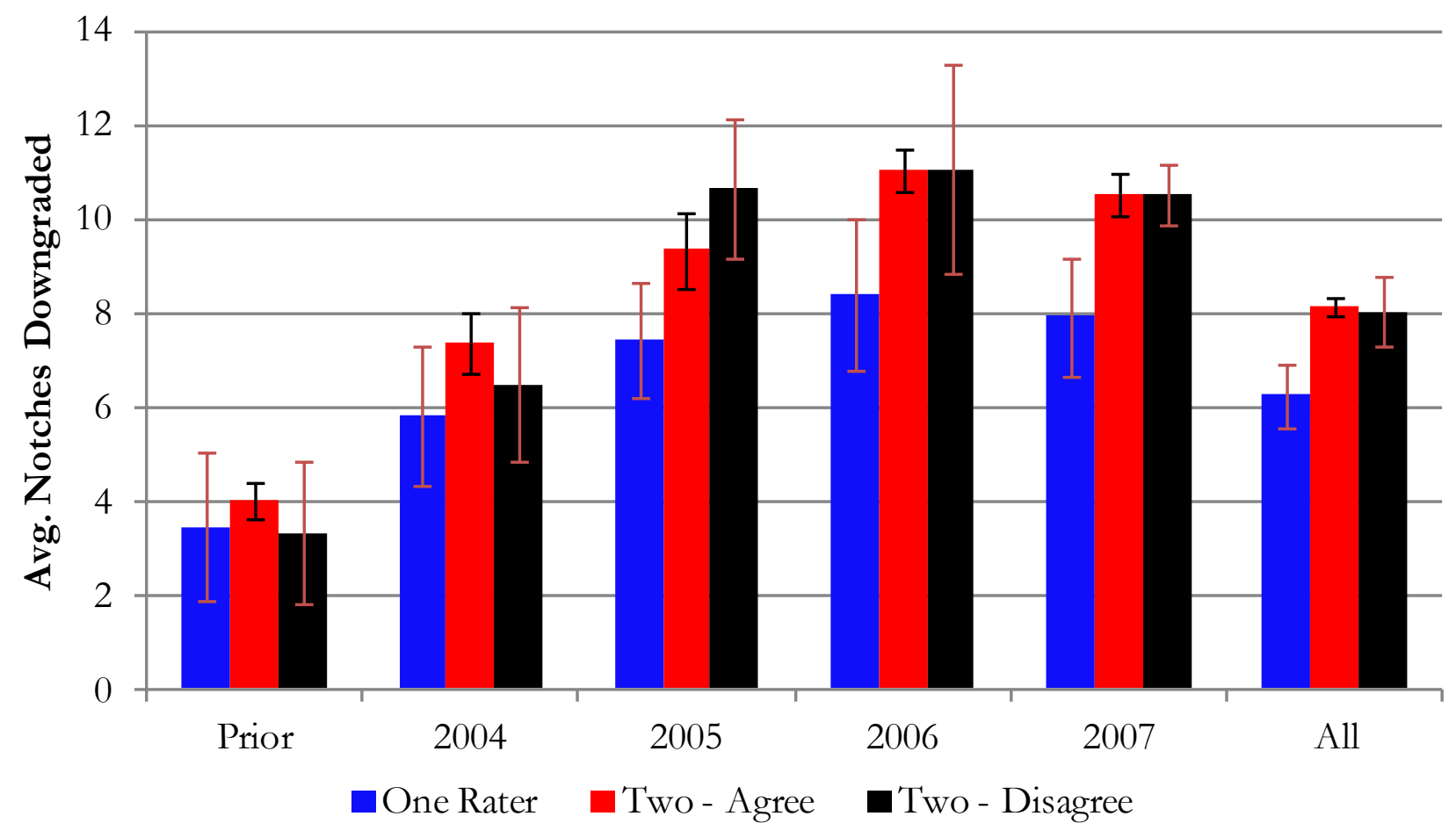

Figure 1

\section{CDO Performance and Agency Participation and Agreement}

This figure illustrates the average number of notches tranches originally rated AAA are downgraded by S\&P (Panel A) and Moody's (Panel B) and percentage of CDOs experiencing an event of default notice (Panel C) by year of issuance. The number of notches downgraded is computed as of June 30, 2010. Two - Agree refers to CDOs who receive a rating by both Moody's and S\&P, and they agree about ratings for all originally AAA tranches. Two - Disagree refers to CDOs who are rated by both S\&P and Moody's and they disagree about ratings on some AAA tranches. The collateral-type distribution for each column is standardized using weights from the overall sample before calculating the mean. Reported for each column is its $90 \%$ confidence interval. 


\section{Panel B}

Moody's Downgrades

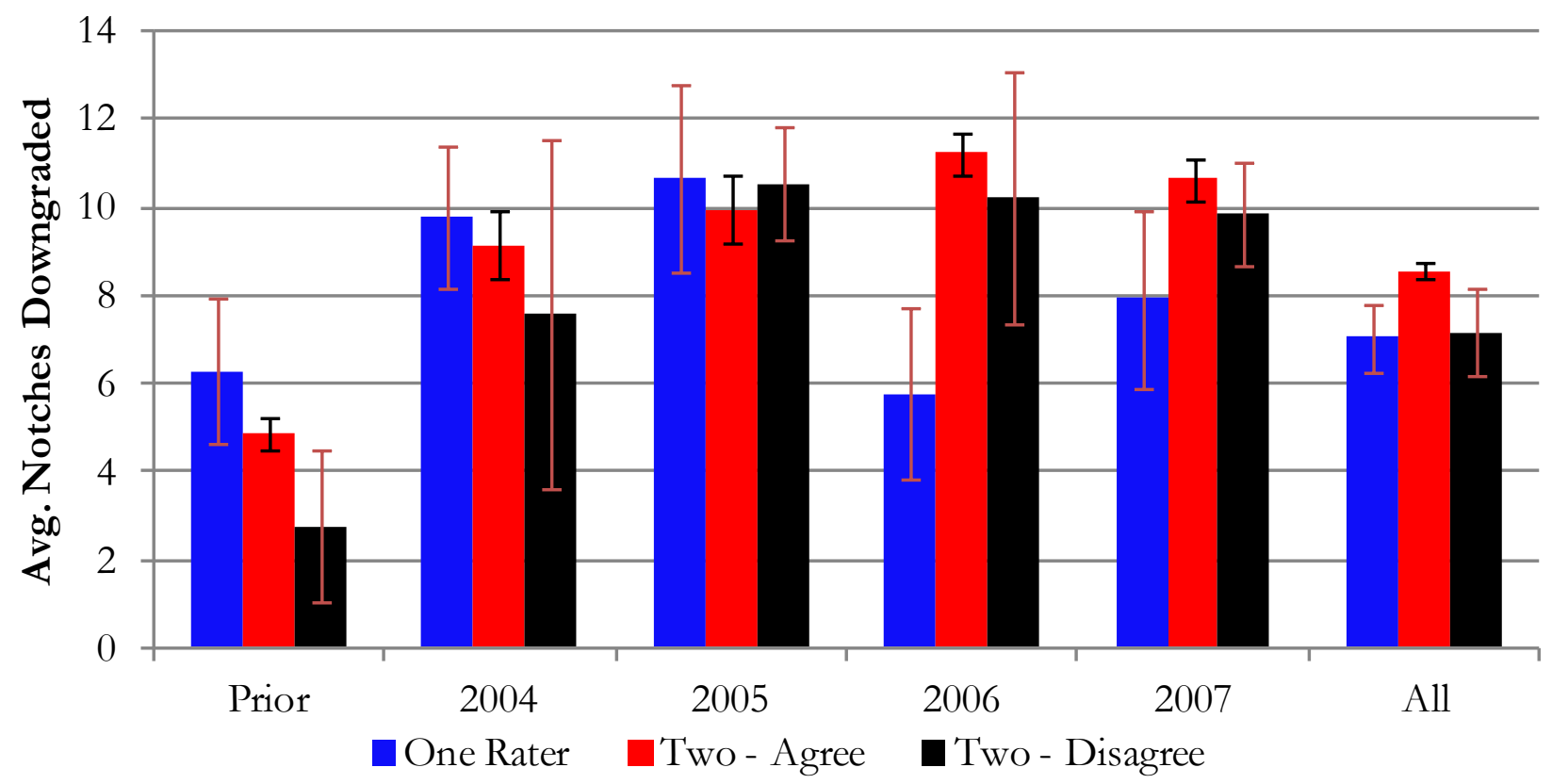

Panel C

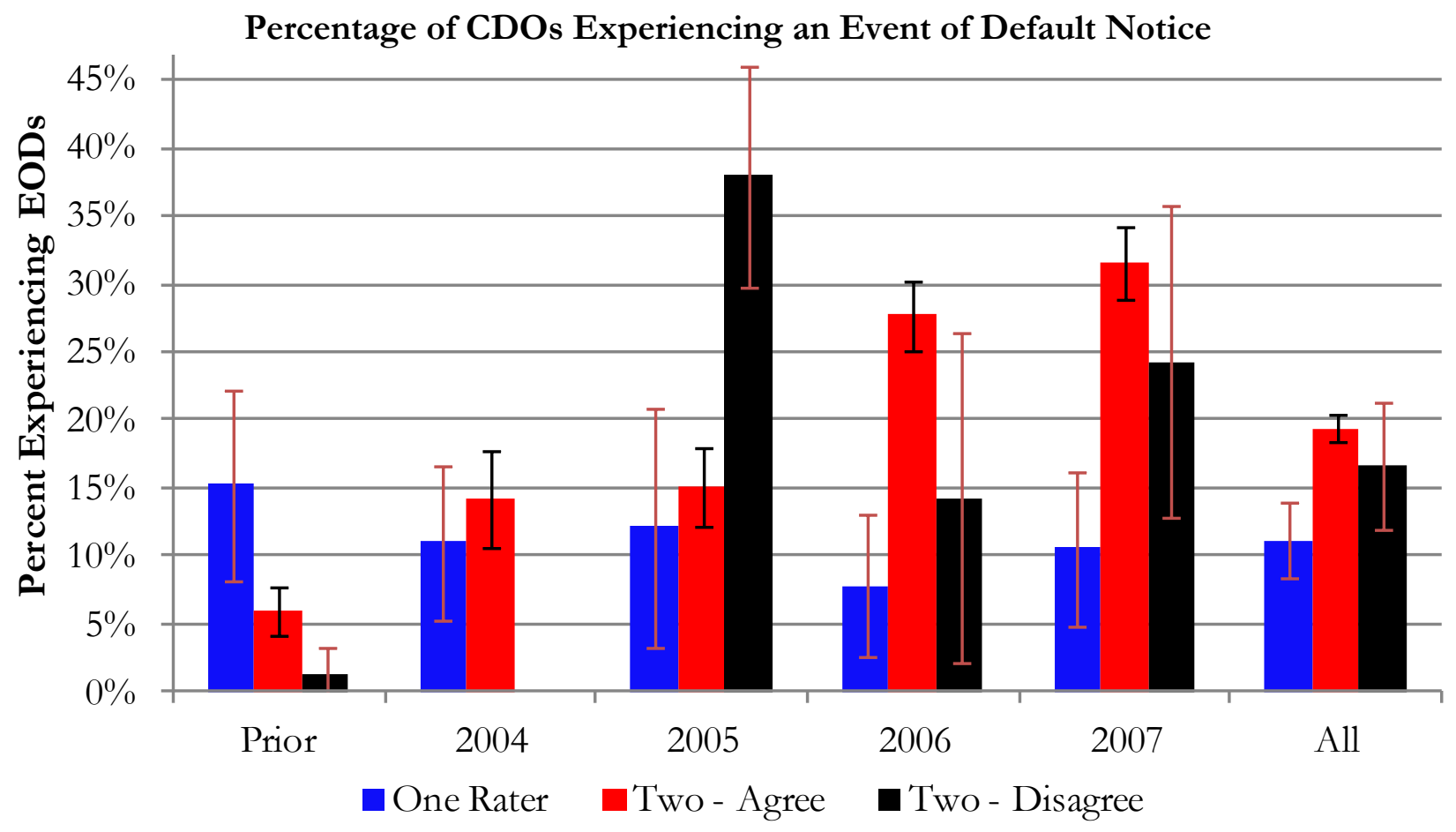




\section{Panel A}

\section{Underlying Asset Default Measure}

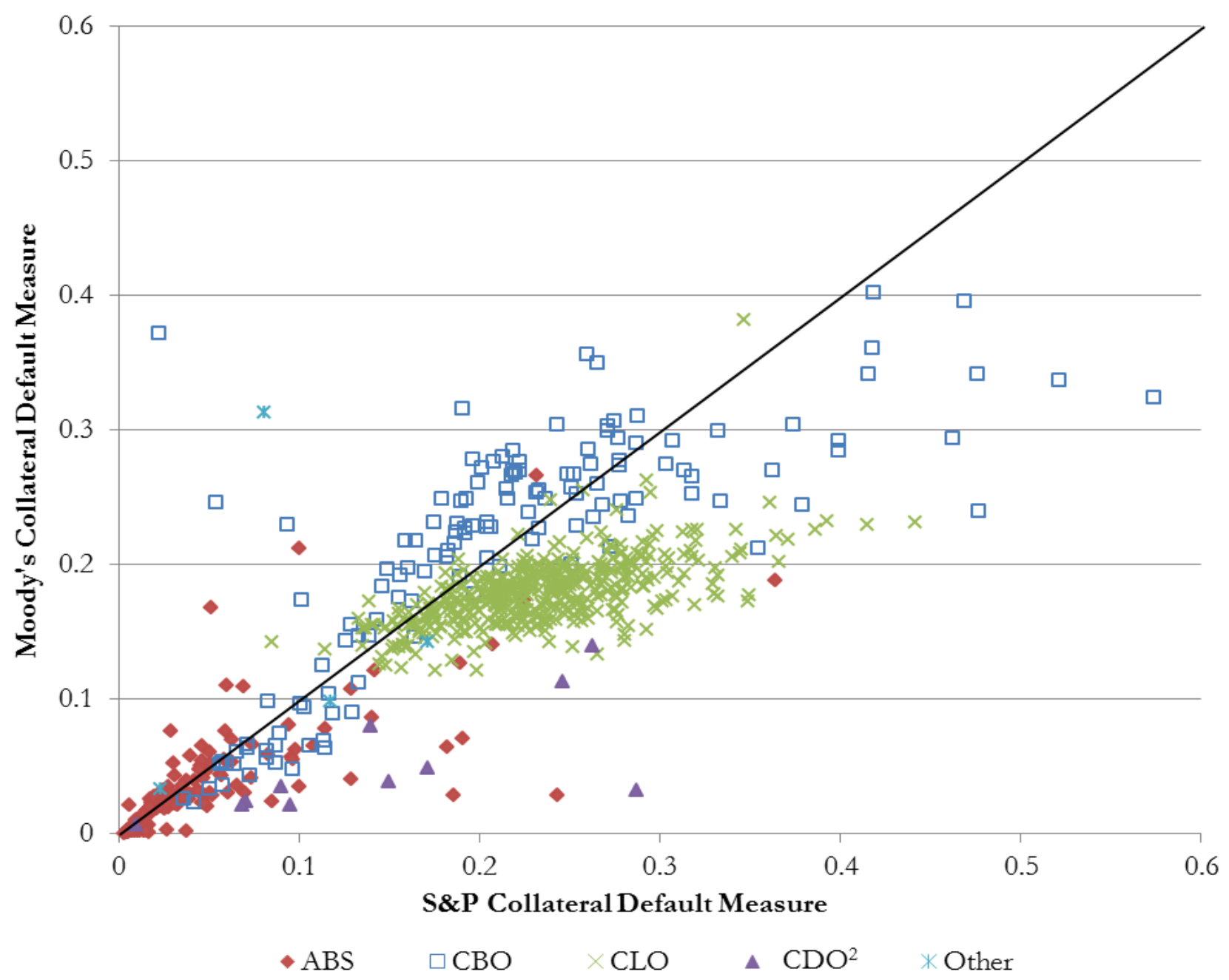

Figure 2

\section{Collateral Probability of Default}

This figure reports the scatter-plot of average probability of default (Panel A) and average pair-wise correlation (Panel B) for the underlying asset pool over the life of the security assumed by S\&P and Moody's. The probability of default, denoted as 'Default Measure,' for S\&P is calculated by multiplying the annualized average probability of default by the weighted average maturity (WAM) of the CDO. The probability of default for Moody's is based on a table of discrete values, acquired from Moody's, that maps weightedaverage rating factor (WARF) and WAM to a probability of default. For CDOs that do not lie on one of these discrete values, it is estimated with a two-way interpolation between the nearest WAMs and WARFs. The WAM reported by S\&P is used for both calculations. This figure reports the histogram (Panel A) and scatter-plot by type of collateral (Panel B) of the average pair-wise correlation between underlying assets' defaults assumed by S\&P and Moody's. The correlations assumed by S\&P and Moody's are estimated from surveillance reports issued by their respective rating agencies using the formulas in Internet Appendix IA 2. 


\section{Panel B}

Underlying Asset Correlations

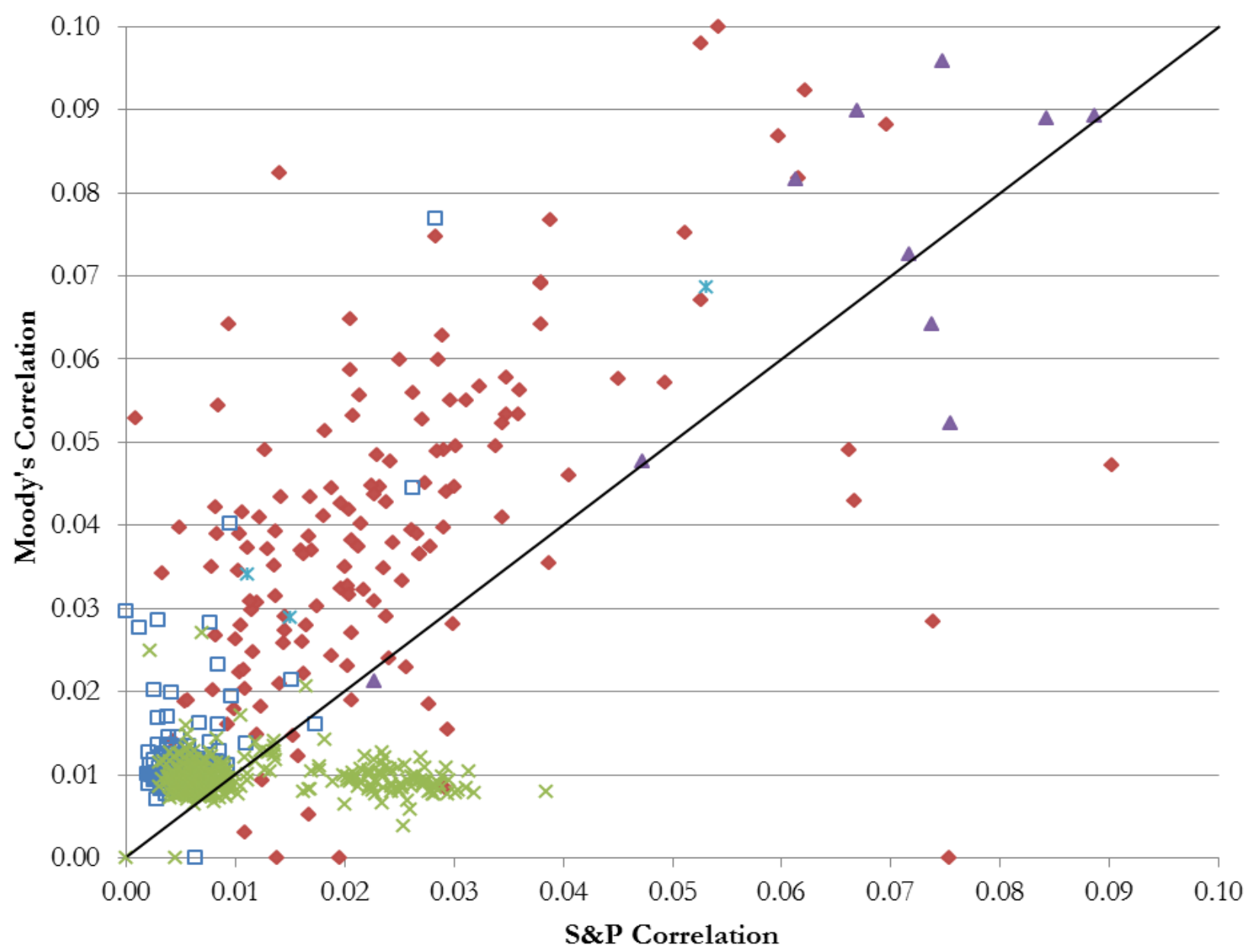

- ABS $\square \mathrm{CBO} \times \mathrm{CLO} \wedge \mathrm{CDO}^{2} *$ Other 


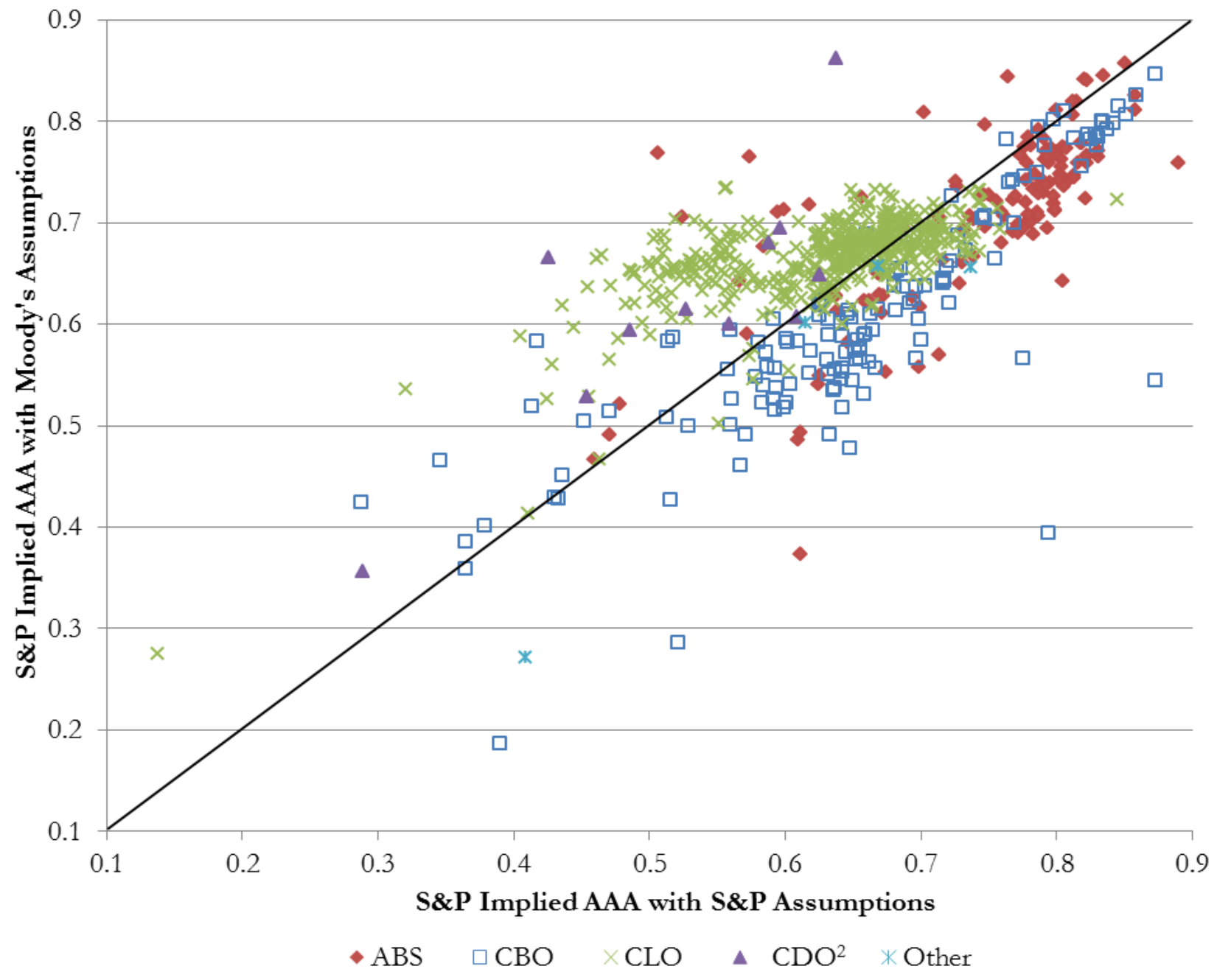

Figure 3

Implied AAA under S\&P's assumptions (x-axis) and Implied AAA under Moody's assumptions (y-axis) both under S\&P's Model

This figure graphs the size of the AAA tranche implied from the S\&P model under the set of S\&P assumptions and the size of the AAA tranche implied from the S\&P model under the set of Moody's assumptions. The WAM reported by S\&P is used for both calculations. 


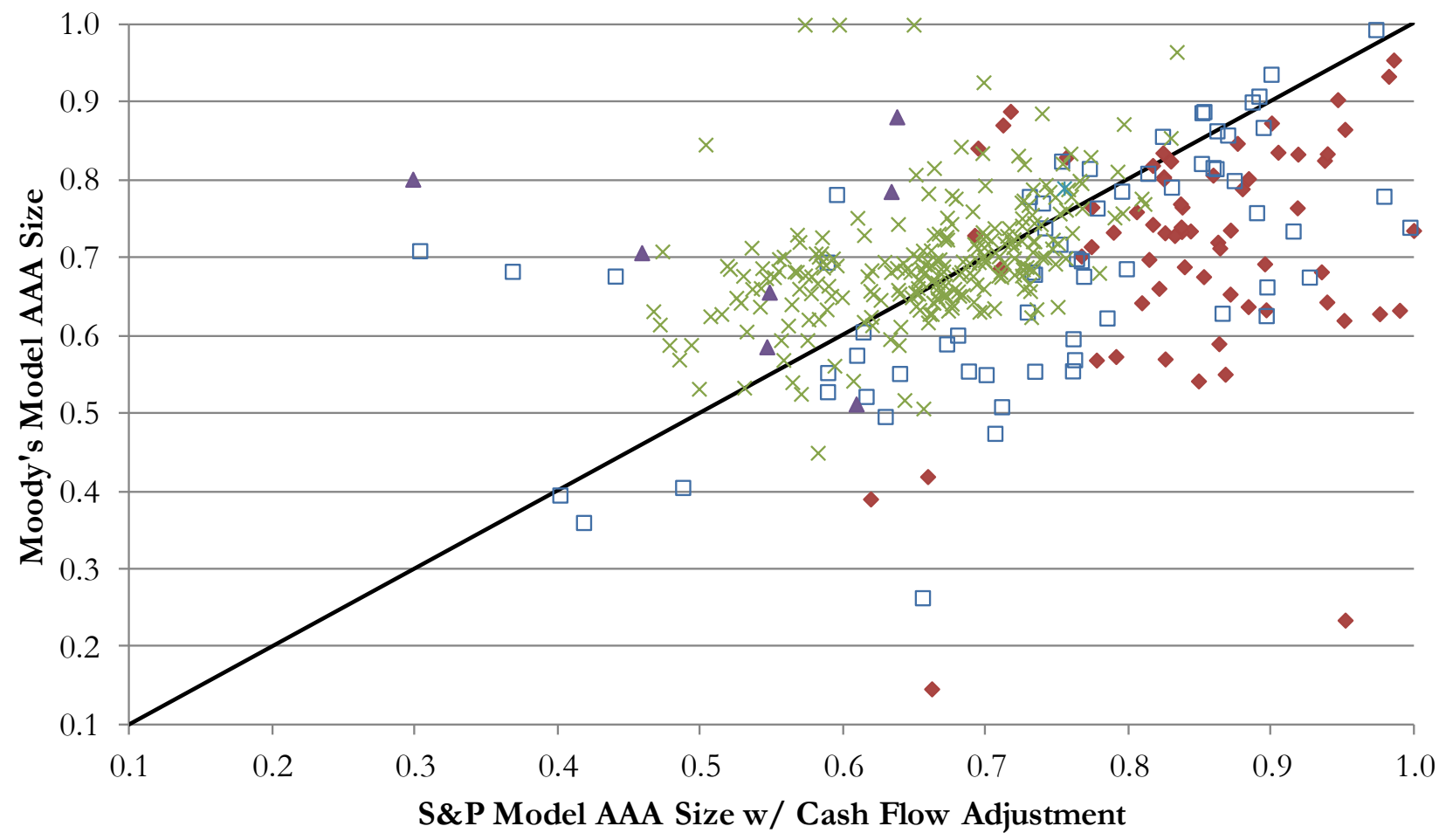

- ABS $\square \mathrm{CBO} \times \mathrm{CLO} \triangle \mathrm{CDO}^{2} *$ Other

\section{Figure 4}

S\&P Model AAA with S\&P's Assumptions (x-axis) and Moody's Model AAA with Moody's Assumptions (y-axis)

This figure graphs the size of the AAA tranche implied from S\&P's model and collateral assumptions and the size of the AAA tranche implied from Moody's model and collateral assumptions. S\&P's model has been augmented with an estimate of deal-specific cash flow protection. To construct this cash flow component, each deal was evaluated under Moody's model. The deal was then re-rated under Moody's model after replacing all cash flow features with the lowest levels observed among any CDO in the dataset. We use the difference between these two AAA amounts as a proxy for the cash flow protection of a CDO, which we add to the amount of AAA under S\&P's model. 


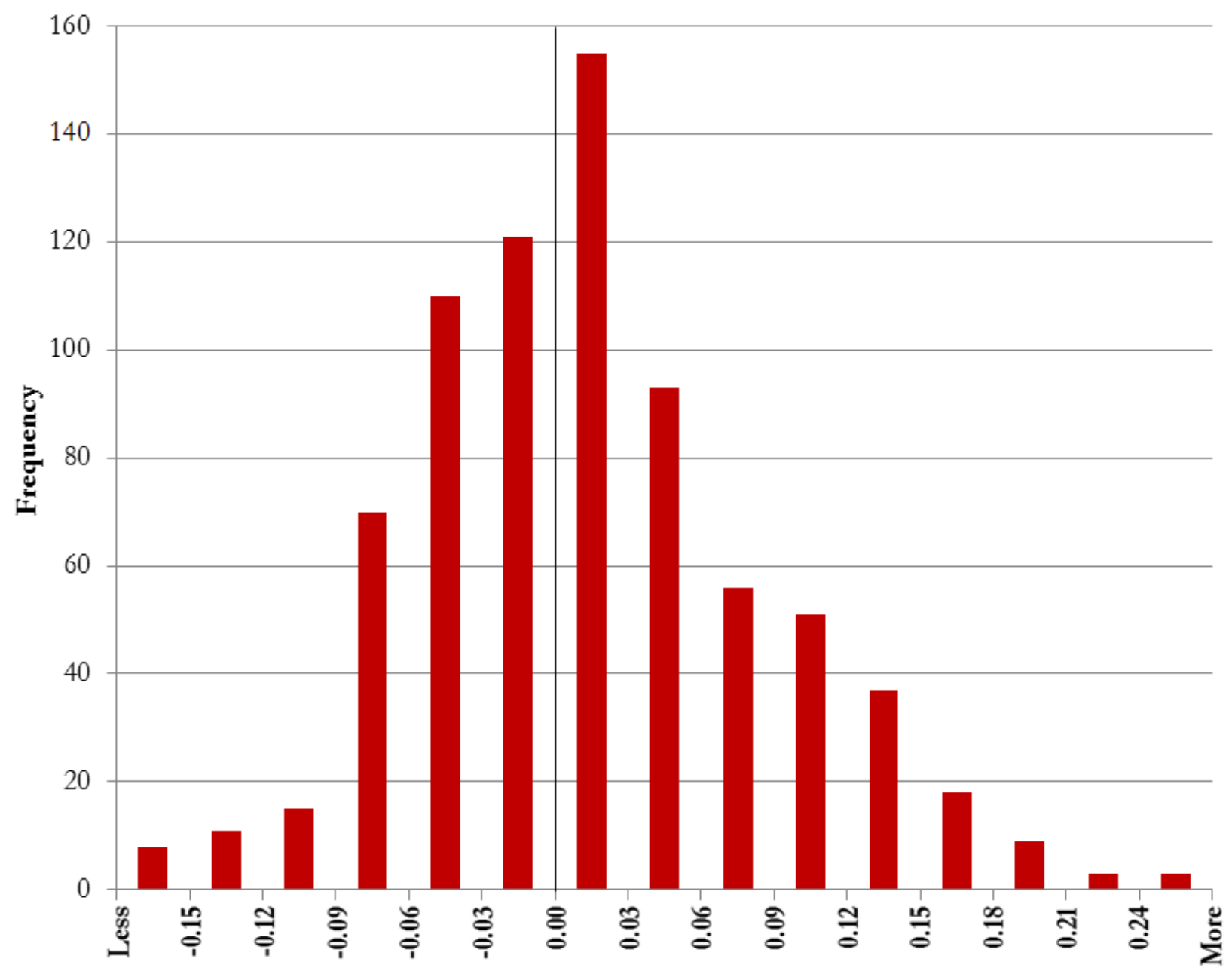

Collateral Risk Disagreement

Figure 5

Collateral Risk Disagreement

This figure reports the histogram of the overall difference in underlying assumptions about collateral quality and correlation as represented by the SDR from the S\&P model under S\&P's assumptions minus the SDR from the S\&P model under Moody's assumptions (Collateral Risk Disagreement). The WAM reported by $\mathrm{S} \& \mathrm{P}$ is used for both calculations. 


\section{Panel A}

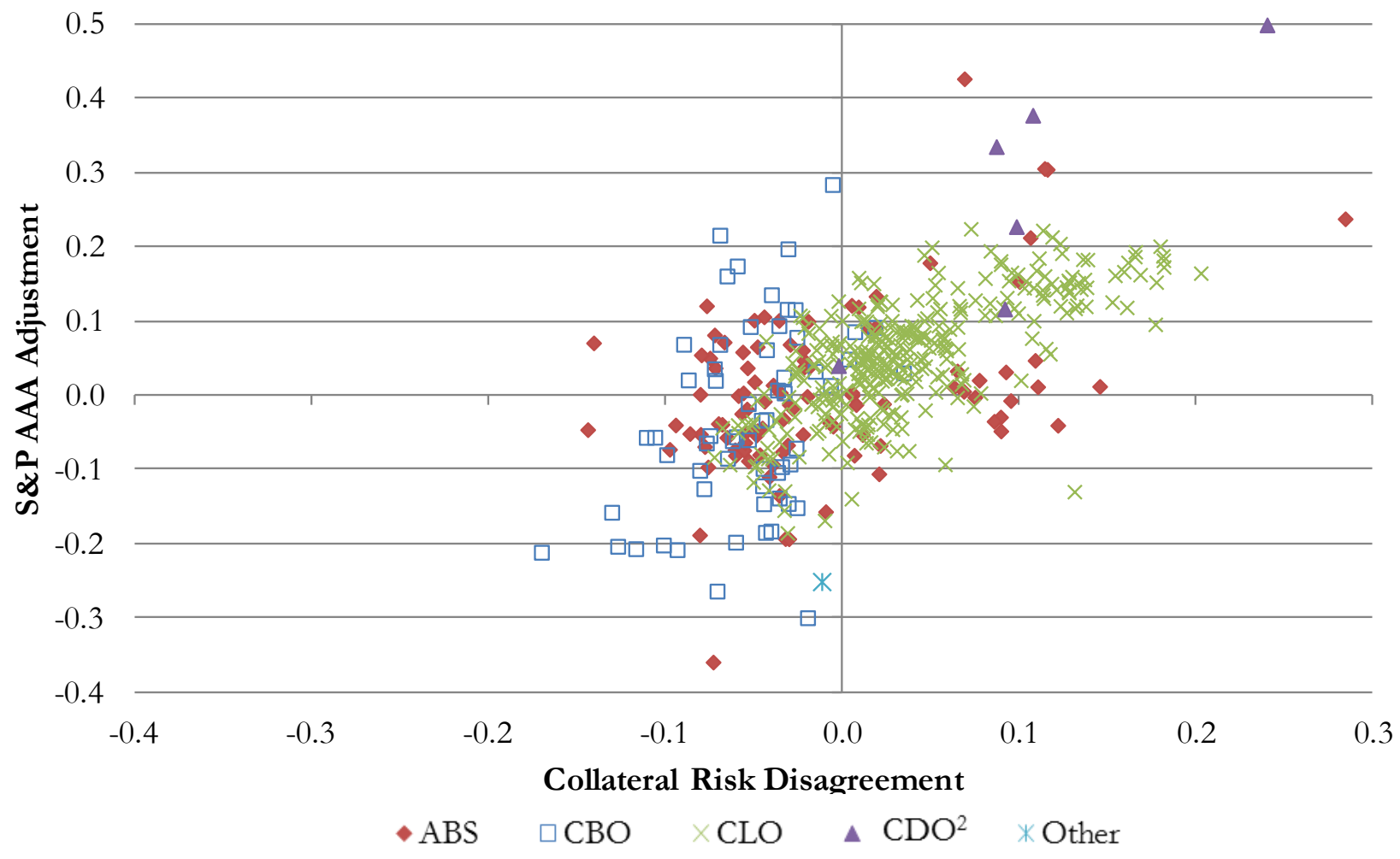

\section{Figure 6}

\section{Collateral Risk Disagreement (x-axis) and S\&P AAA Adjustment (y-axis)}

Panel A graphs the difference in SDRs from the S\&P model under the different rating agency assumptions (Collateral Risk Disagreement) and the adjustment to the AAA size dictated by S\&P reported SDR AAA. The WAM reported by S\&P is used to calculate the difference in SDRs. SDR AAA is the SDR for the AAA scenario obtained directly from S\&P's first surveillance report. Panel B graphs the difference in Moody's model implied AAA under Moody's assumptions and S\&P's assumptions and Moody's adjustment to the AAA tranche size. 


\section{Panel B}

Collateral Risk Disagreement (x-axis) and Moody's AAA Adjustment (y-axis).

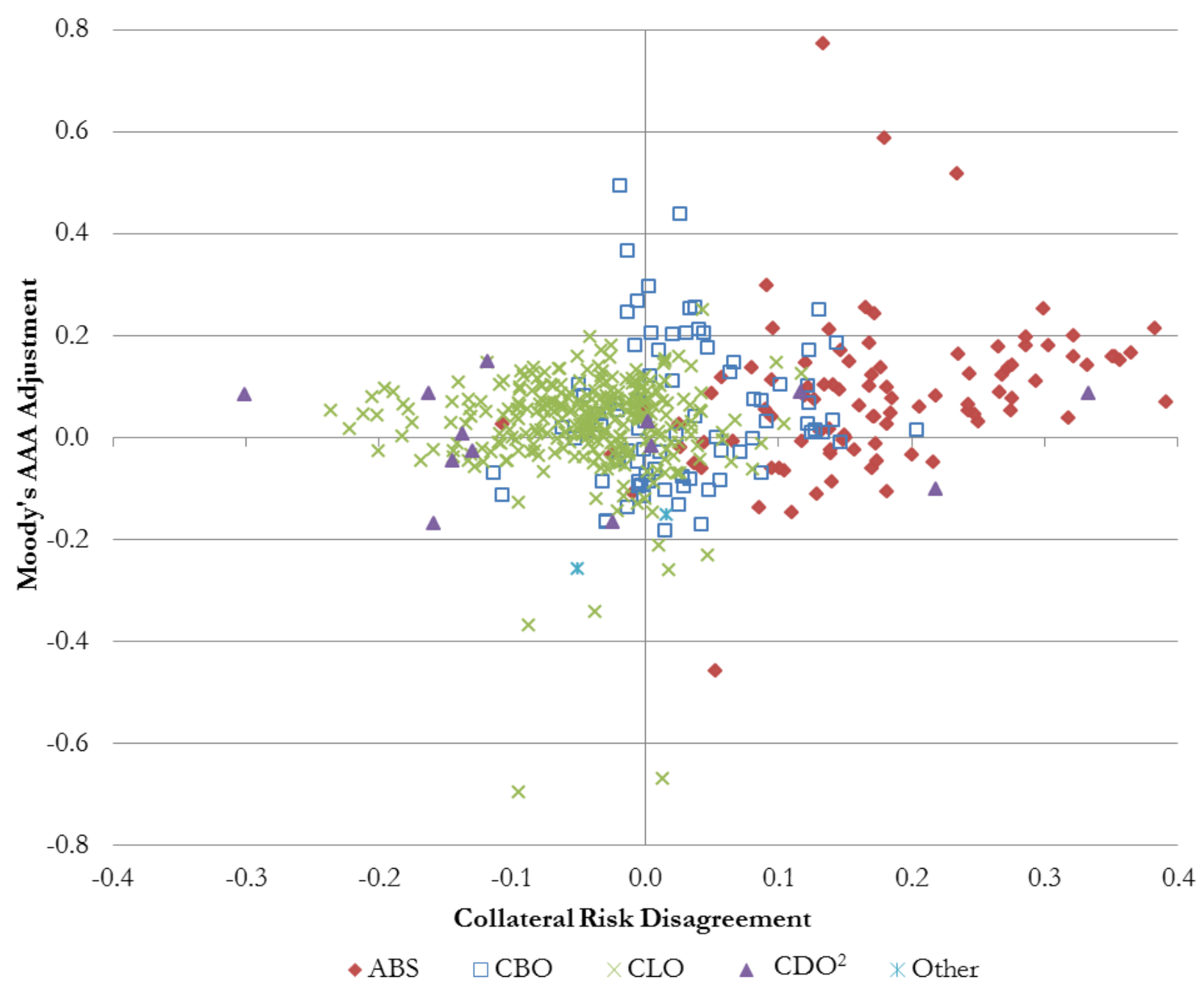




\section{Table 1}

\section{Amount of Bloomberg CDO Universe Rated by the Rating Agencies}

This table reports the ratings coverage of S\&P, Moody's, and Fitch for all CDOs from January 1997 to December 2007 listed in the Bloomberg Database. Panel A reports the coverage by the three rating agencies on all AAA tranches. Only tranches that received a AAA rating by at least one rating agency are included in the sample. The first two rows are mutually exclusive groups; in addition, all remaining rows are mutually exclusive groups. Panel B reports the percentage of AAA tranches that received the same rating by both S\&P and Moody's. All tranches that received a AAA rating by at least one of these rating agencies were included in the analysis.

\begin{tabular}{|c|c|c|c|c|}
\hline \multicolumn{5}{|c|}{ Panel A: AAA Tranche Level Rating Coverage } \\
\hline & Number & $\%$ Total & Capital (\$B) & $\%$ Capital \\
\hline Solo Rating & 611 & 11.1 & 150.4 & 8.3 \\
\hline $\mathrm{S} \& \mathrm{P}$ & 285 & 5.2 & 41.2 & 2.3 \\
\hline Moody's & 300 & 5.4 & 106.8 & 5.9 \\
\hline Fitch & 26 & 0.5 & 2.4 & 0.1 \\
\hline Multiple Ratings & 4914 & 88.9 & 1654.5 & 91.7 \\
\hline SP \& Moody's & 3352 & 60.7 & 857.3 & 47.5 \\
\hline SP \& Fitch & 355 & 6.4 & 66.7 & 3.7 \\
\hline Moody's \& Fitch & 265 & 4.8 & 59.6 & 3.3 \\
\hline S\&P, Moody's \& Fitch & 942 & 17.0 & 670.8 & 37.2 \\
\hline Total & 5525 & - & 1804.8 & - \\
\hline \multicolumn{5}{|c|}{ Panel B: Degree of AAA Tranche Ratings Agreement } \\
\hline & Number & $\%$ & Capital (\$B) & $\%$ Capital \\
\hline Same Rating & 4037 & 94.7 & 1462.2 & 96.3 \\
\hline S\&P AAA only & 192 & 4.5 & 13.2 & 0.9 \\
\hline Moody's AAA only & 34 & 0.8 & 42.9 & 2.8 \\
\hline
\end{tabular}


Table 2

\section{Multiple Credit Ratings and Credit Spreads}

This table reports the results of OLS regressions. The dependent variable is the weighted-average AAA credit spread (yield spread when available). Column headers indicate if the sample consists of CDOs rated by either S\&P or Moody's (Either), S\&P (S\&P), or Moody's (Moody's). One Rater is a dummy variable that takes on a value of one when the deal is rated by either S\&P or Moody's, but not both agencies, and zero otherwise. Two - Disagree is a dummy variable that takes on a value of one when the CDO is rated by both S\&P and Moody's and they disagree about ratings on some AAA tranches, and zero otherwise. Have Pricing Data is a dummy variable that takes on a value of one if tranche issue prices exist, and zero otherwise. Fitch Rated is a dummy variable that is set to one when Fitch rates at least one tranche in the CDO, and zero otherwise. $C D O^{2}$ is a dummy variable that takes on a value of one when the security is a $\mathrm{CDO}$ of $\mathrm{CDO}$ and zero otherwise. $C B O$ is a dummy variable that takes on a value of one when the security is a collateralized bond obligation and zero otherwise. CLO is a dummy variable that takes on a value of one when the security is a collateralized loan obligation and zero otherwise. (ABS) Year Controls indicates specifications when year fixed effects (interacted with an ABS collateral dummy) were used for years 2003-2007. Reported are odds ratios with White (1980) heteroskedasticity-adjusted t-statistics in parentheses.

\begin{tabular}{|c|c|c|c|c|c|c|}
\hline & \multicolumn{3}{|c|}{ All CDOs } & \multicolumn{3}{|c|}{ Require Pricing Data } \\
\hline & Either & $\mathrm{S} \& \mathrm{P}$ & Moody's & Either & S\&P & Moody's \\
\hline One Rater & $\begin{array}{l}0.052 \\
(3.42)\end{array}$ & $\begin{array}{l}0.088 \\
(3.04)\end{array}$ & $\begin{array}{l}0.029 \\
(1.14)\end{array}$ & $\begin{array}{l}0.040 \\
(2.23)\end{array}$ & $\begin{array}{l}0.056 \\
(2.14)\end{array}$ & $\begin{array}{l}0.042 \\
(1.33)\end{array}$ \\
\hline Two - Disagree & $\begin{array}{l}0.048 \\
(1.65)\end{array}$ & $\begin{array}{l}0.171 \\
(2.07)\end{array}$ & $\begin{array}{l}0.017 \\
(0.53)\end{array}$ & $\begin{array}{l}0.078 \\
(1.38)\end{array}$ & $\begin{array}{l}0.146 \\
(1.61)\end{array}$ & $\begin{array}{l}0.114 \\
(1.77)\end{array}$ \\
\hline Have Pricing Data & $\begin{array}{l}-0.030 \\
(-3.66)\end{array}$ & $\begin{array}{l}-0.046 \\
(-4.31)\end{array}$ & $\begin{array}{l}-0.030 \\
(-2.74)\end{array}$ & & & \\
\hline Fitch Rated & $\begin{array}{l}-0.030 \\
(-3.12)\end{array}$ & $\begin{array}{l}-0.015 \\
(-1.07)\end{array}$ & $\begin{array}{l}0.002 \\
(0.15)\end{array}$ & $\begin{array}{l}-0.047 \\
(-3.29)\end{array}$ & $\begin{array}{l}-0.032 \\
(-2.05)\end{array}$ & $\begin{array}{l}-0.033 \\
(-1.98)\end{array}$ \\
\hline $\mathrm{CDO}^{2}$ & $\begin{array}{l}0.134 \\
(5.46)\end{array}$ & $\begin{array}{l}0.133 \\
(3.02)\end{array}$ & $\begin{array}{l}0.096 \\
(3.43)\end{array}$ & $\begin{array}{l}0.136 \\
(3.39)\end{array}$ & $\begin{array}{l}0.141 \\
(3.34)\end{array}$ & $\begin{array}{l}0.108 \\
(2.41)\end{array}$ \\
\hline $\mathrm{CBO}$ & $\begin{array}{l}-0.015 \\
(-0.88)\end{array}$ & $\begin{array}{c}-0.0004 \\
(-0.02)\end{array}$ & $\begin{array}{l}-0.041 \\
(-2.54)\end{array}$ & $\begin{array}{l}-0.020 \\
(-0.98)\end{array}$ & $\begin{array}{l}0.001 \\
(0.05)\end{array}$ & $\begin{array}{l}-0.055 \\
(-2.91)\end{array}$ \\
\hline CLO & $\begin{array}{c}-0.117 \\
(-10.54)\end{array}$ & $\begin{array}{l}-0.091 \\
(-7.38)\end{array}$ & $\begin{array}{l}-0.107 \\
(-8.32)\end{array}$ & $\begin{array}{l}-0.123 \\
(-8.67)\end{array}$ & $\begin{array}{l}-0.074 \\
(-5.29)\end{array}$ & $\begin{array}{l}-0.120 \\
(-6.61)\end{array}$ \\
\hline Intercept & $\begin{array}{c}0.543 \\
(43.03)\end{array}$ & $\begin{array}{c}0.542 \\
(36.95)\end{array}$ & $\begin{array}{c}0.543 \\
(40.51)\end{array}$ & $\begin{array}{c}0.529 \\
(41.68)\end{array}$ & $\begin{array}{c}0.511 \\
(37.30)\end{array}$ & $\begin{array}{c}0.531 \\
(39.49)\end{array}$ \\
\hline ABS Year Controls & $\mathrm{Y}$ & $\mathrm{Y}$ & $\mathrm{Y}$ & $\mathrm{Y}$ & $\mathrm{Y}$ & $\mathrm{Y}$ \\
\hline Year Controls & $\mathrm{Y}$ & $\mathrm{Y}$ & $\mathrm{Y}$ & $\mathrm{Y}$ & $\mathrm{Y}$ & $\mathrm{Y}$ \\
\hline No. Obs. & 2466 & 2232 & 2177 & 1085 & 925 & 937 \\
\hline R-Squared & 0.224 & 0.168 & 0.148 & 0.256 & 0.262 & 0.230 \\
\hline
\end{tabular}




\section{Table 3}

\section{Multiple Credit Ratings and Downgrades}

This table reports the results of plain and ordered logit regressions. The dependent variables are listed in the column headers. ' $S \& P$ Downgrades' is the number of notches that the lowest tranche originally rated AAA was downgraded by S\&P as of June 30, 2010. 'Moody's Downgrades' is the number of notches that the lowest tranche originally rated AAA was downgraded by Moody's as of June 30, 2010. 'E.O.D.' is a binary variable that takes on a value of one if the deal has issued an event of default notice, and zero otherwise. One Rater is a dummy variable that takes on a value of one when the deal is rated by either S\&P or Moody's, but not both agencies, and zero otherwise. Similarly, Two - Disagree is a dummy variable that takes on a value of one when the CDO is rated by both S\&P and Moody's and they disagree about ratings on some AAA tranches, and zero otherwise. Credit Spread (Spread w/ Price) is the weighted-average AAA credit (yield) spread scaled by 10 basis points. Fitch Rated is a dummy variable that is set to one when Fitch rates at least one tranche in the $\mathrm{CDO}$, and zero otherwise. $C D O^{2}$ is a dummy variable that takes on a value of one when the security is a $\mathrm{CDO}$ of $\mathrm{CDOs}$ and zero otherwise. $\mathrm{CBO}$ is a dummy variable that takes on a value of one when the security is a collateralized bond obligation and zero otherwise. CLO is a dummy variable that takes on a value of one when the security is a collateralized loan obligation and zero otherwise. (ABS) Year Controls indicates specifications when year fixed effects (interacted with an ABS collateral dummy) were used for years 20032007. Reported are odds ratios with White (1980) heteroskedasticity-adjusted t-statistics in parentheses.

Panel A: All CDOs

\begin{tabular}{lcccccc}
\hline & \multicolumn{2}{c}{ S\&P Downgrades } & \multicolumn{2}{c}{ Moody's Downgrades } & \multicolumn{2}{c}{ E.O.D. } \\
\hline One Rater & 0.523 & 0.498 & 0.688 & 0.860 & 0.282 & 0.366 \\
& $(-3.26)$ & $(-3.17)$ & $(-1.90)$ & $(-0.69)$ & $(-5.30)$ & $(-3.63)$ \\
Two - Disagree & 1.316 & 0.859 & 0.725 & 0.653 & 0.690 & 0.681 \\
& $(1.38)$ & $(-0.67)$ & $(-1.39)$ & $(-1.74)$ & $(-1.03)$ & $(-1.00)$ \\
Credit Spread & & 1.234 & & 1.254 & & 1.084 \\
& & $(3.14)$ & & $(3.86)$ & & $(2.52)$ \\
Spread w/ Price & & 1.142 & & 1.170 & & 0.911 \\
& & $(2.38)$ & & $(3.57)$ & & $(-1.93)$ \\
Fitch Rated & 0.937 & 0.944 & 0.776 & 0.773 & 0.788 & 0.733 \\
& $(-0.57)$ & $(-0.47)$ & $(-2.37)$ & $(-2.20)$ & $(-1.56)$ & $(-1.85)$ \\
CDO ${ }^{2}$ & 0.738 & 0.478 & 0.970 & 0.723 & 0.663 & 0.572 \\
CBO & $(-1.24)$ & $(-2.46)$ & $(-0.14)$ & $(-1.25)$ & $(-1.75)$ & $(-2.16)$ \\
& 0.750 & 0.944 & 0.888 & 1.042 & 0.229 & 0.287 \\
CLO & $(-1.07)$ & $(-0.21)$ & $(-0.58)$ & $(0.18)$ & $(-2.03)$ & $(-1.67)$ \\
& 0.376 & 0.428 & 0.266 & 0.311 & 0.066 & 0.054 \\
\hline ABS Year Controls & $(-6.94)$ & $(-5.31)$ & $(-9.48)$ & $(-7.88)$ & $(-8.11)$ & $(-7.62)$ \\
Year Controls & $\mathrm{Y}$ & $\mathrm{Y}$ & $\mathrm{Y}$ & $\mathrm{Y}$ & $\mathrm{Y}$ & $\mathrm{Y}$ \\
No. Obs. & $\mathrm{Y}$ & $\mathrm{Y}$ & $\mathrm{Y}$ & $\mathrm{Y}$ & $\mathrm{Y}$ & $\mathrm{Y}$ \\
R-Squared & 2536 & 2231 & 2492 & 2175 & 2790 & 2466 \\
\hline
\end{tabular}


Table 3

Continued

Panel B: ABS CDOs

\begin{tabular}{lcccccc}
\hline & \multicolumn{2}{c}{ S\&P Downgrades } & \multicolumn{2}{c}{ Moody's Downgrades } & \multicolumn{2}{c}{ E.O.D. } \\
\hline One Rater & 0.273 & 0.324 & 0.374 & 0.709 & 0.360 & 0.512 \\
& $(-4.31)$ & $(-3.34)$ & $(-1.80)$ & $(-0.50)$ & $(-3.27)$ & $(-1.93)$ \\
Two - Disagree & 0.811 & 0.897 & 0.571 & 0.656 & 0.704 & 0.737 \\
& $(-0.55)$ & $(-0.26)$ & $(-0.94)$ & $(-0.72)$ & $(-0.77)$ & $(-0.63)$ \\
Credit Spread & & 0.977 & & 0.993 & & 1.093 \\
& & $(-0.83)$ & & $(-0.20)$ & & $(1.85)$ \\
Spread w/ Price & & 0.821 & & 0.908 & & 0.892 \\
& & $(-3.58)$ & & $(-1.63)$ & & $(-1.42)$ \\
Fitch Rated & 0.512 & 0.464 & 0.368 & 0.325 & 0.579 & 0.527 \\
& $(-3.81)$ & $(-3.96)$ & $(-6.01)$ & $(-6.10)$ & $(-3.12)$ & $(-3.31)$ \\
\hline Year Controls & $\mathrm{Y}$ & $\mathrm{Y}$ & $\mathrm{Y}$ & $\mathrm{Y}$ & $\mathrm{Y}$ & $\mathrm{Y}$ \\
No. Obs. & 737 & 657 & 688 & 603 & 766 & 686 \\
R-Squared & 0.096 & 0.104 & 0.089 & 0.091 & 0.141 & 0.151 \\
\hline
\end{tabular}




\section{Table 4}

\section{Multiple Credit Ratings and Event of Default Notices}

This table shows logit and probit regression results. The dependent variable is a binary variable that takes on a value of one if the deal has issued an event of default notice, and zero otherwise. One Rater is a dummy variable that takes on a value of one when the deal is rated by one agency, and zero otherwise. Three Raters is a dummy variable that takes on a value of one when the CDO is rated by 3 agencies, and zero otherwise. Credit Spread (Spread $w /$ Price) is the weighted-average AAA credit (yield) spread scaled by 10 basis points. CBO, CLO, and $C^{2} O^{2}$ are dummy variables denoting the underlying collateral type of the CDO. (ABS) Year Controls indicates specifications when year fixed effects (interacted with an ABS collateral dummy) were used for years 2003-2007. Reported are odds ratios for specifications (1)-(3) and regression coefficients for specifications (4)-(6) with White (1980) heteroskedasticity-adjusted t-statistics in parentheses.

\begin{tabular}{|c|c|c|c|c|c|c|}
\hline & \multicolumn{3}{|c|}{ Logit } & \multicolumn{3}{|c|}{ Probit } \\
\hline & $(1)$ & $(2)$ & (3) & $(4)$ & $(5)$ & (6) \\
\hline One Rater & $\begin{array}{c}0.127 \\
(-3.16)\end{array}$ & & & $\begin{array}{l}-1.008 \\
(-3.13)\end{array}$ & & \\
\hline Three Raters & $\begin{array}{c}0.716 \\
(-1.89)\end{array}$ & & & $\begin{array}{l}-0.186 \\
(-1.87)\end{array}$ & & \\
\hline Only S\&P & & $\begin{array}{c}0.032 \\
(-3.68)\end{array}$ & $\begin{array}{c}0.083 \\
(-2.58)\end{array}$ & & $\begin{array}{l}-2.018 \\
(-4.06)\end{array}$ & $\begin{array}{l}-1.478 \\
(-2.88)\end{array}$ \\
\hline Only Moody's & & $\begin{array}{c}0.457 \\
(-1.02)\end{array}$ & $\begin{array}{l}1.114 \\
(0.13)\end{array}$ & & $\begin{array}{l}-0.376 \\
(-1.08)\end{array}$ & $\begin{array}{l}0.114 \\
(0.29)\end{array}$ \\
\hline S\&P \& Moody's & & & $\begin{array}{l}3.024 \\
(3.52)\end{array}$ & & & $\begin{array}{l}0.615 \\
(3.37)\end{array}$ \\
\hline Moody's \& Fitch & & & $\begin{array}{l}1.502 \\
(0.65)\end{array}$ & & & $\begin{array}{l}0.254 \\
(0.77)\end{array}$ \\
\hline S\&P, Moody's and Fitch & & & $\begin{array}{l}1.900 \\
(1.85)\end{array}$ & & & $\begin{array}{l}0.354 \\
(1.78)\end{array}$ \\
\hline Credit Spread & $\begin{array}{l}1.106 \\
(2.99)\end{array}$ & $\begin{array}{l}1.119 \\
(3.33)\end{array}$ & $\begin{array}{l}1.115 \\
(3.21)\end{array}$ & $\begin{array}{l}0.058 \\
(3.00)\end{array}$ & $\begin{array}{l}0.068 \\
(3.51)\end{array}$ & $\begin{array}{l}0.065 \\
(3.38)\end{array}$ \\
\hline Spread w/ Price & $\begin{array}{c}0.917 \\
(-1.68)\end{array}$ & $\begin{array}{c}0.927 \\
(-1.54)\end{array}$ & $\begin{array}{c}0.936 \\
(-1.35)\end{array}$ & $\begin{array}{l}-0.043 \\
(-1.56)\end{array}$ & $\begin{array}{l}-0.034 \\
(-1.32)\end{array}$ & $\begin{array}{r}-0.030 \\
(-1.15)\end{array}$ \\
\hline $\mathrm{CBO}$ & $\begin{array}{c}0.306 \\
(-1.56)\end{array}$ & $\begin{array}{c}0.335 \\
(-1.43)\end{array}$ & $\begin{array}{c}0.293 \\
(-1.60)\end{array}$ & $\begin{array}{l}-0.377 \\
(-1.12)\end{array}$ & $\begin{array}{l}-0.318 \\
(-0.92)\end{array}$ & $\begin{array}{l}-0.415 \\
(-1.20)\end{array}$ \\
\hline CLO & $\begin{array}{c}0.059 \\
(-7.38)\end{array}$ & $\begin{array}{c}0.063 \\
(-7.19)\end{array}$ & $\begin{array}{c}0.055 \\
(-7.59)\end{array}$ & $\begin{array}{l}-1.300 \\
(-8.24)\end{array}$ & $\begin{array}{l}-1.253 \\
(-7.93)\end{array}$ & $\begin{array}{l}-1.342 \\
(-8.52)\end{array}$ \\
\hline $\mathrm{CDO}^{2}$ & $\begin{array}{c}0.626 \\
(-1.81)\end{array}$ & $\begin{array}{c}0.683 \\
(-1.45)\end{array}$ & $\begin{array}{c}0.602 \\
(-1.91)\end{array}$ & $\begin{array}{l}-0.261 \\
(-1.65)\end{array}$ & $\begin{array}{l}-0.212 \\
(-1.33)\end{array}$ & $\begin{array}{l}-0.287 \\
(-1.79)\end{array}$ \\
\hline ABS Year Controls & $\mathrm{Y}$ & $\mathrm{Y}$ & Y & $\mathrm{Y}$ & Y & $\mathrm{Y}$ \\
\hline Year Controls & $\mathrm{Y}$ & $\mathrm{Y}$ & Y & Y & Y & $\mathrm{Y}$ \\
\hline No. Obs. & 2466 & 2466 & 2466 & 2466 & 2466 & 2466 \\
\hline R-Squared & 0.426 & 0.426 & 0.435 & 0.424 & 0.426 & 0.434 \\
\hline
\end{tabular}




\section{Table 5}

\section{Regressing AAA Adjustment on Differences in Model AAA Sizes and Deal Characteristics}

This table reports the results of OLS regressions. The dependent variable is the S\&P AAA Adjustment (Specifications 1-3) and Moody's AAA Adjustment (Specifications 4-6). AAA Model Diff-Positive (Negative) is set equal to the difference in model-implied AAA sizes when the difference is greater than (less than) zero, and zero otherwise. Additional rows following pairs of explanatory variables with an italicized value report the p-value from a t-test of coefficient equivalence. SDR is the AAA SDR reported in S\&P's surveillance report. Credit Spread is the weighted-average AAA credit spread (yield spread when available) scaled by 10 basis points. $C B O$ is a dummy variable that takes on a value of one when the security is a collateralized bond obligation and zero otherwise. 'CLO' is a dummy variable that takes on a value of one when the security is a collateralized loan obligation and zero otherwise. $C D O^{2}$ is a dummy variable that takes on a value of one when the security is a CDO of CDOs and zero otherwise. Other is a dummy variable that takes on a value of one when the security is not any of the preceding types, or a ABS CDO, and zero otherwise. Fitch Rated is a dummy variable that takes on a value of one when Fitch also rated the AAA tranches and zero otherwise. Insured is a dummy variable that takes on a value of one when at least one of the AAA tranches was wrapped and zero otherwise. $\log ($ Manager $)$ is the $\log$ of the number of previous deals the collateral manager has been involved with. $\log$ (Underwriter) is the log of the number of previous deals the lead underwriter has previously underwritten. Year Controls indicates specifications when year fixed effects were used for years 2003-2007. White (1980) heteroskedasticity-adjusted t-statistics are in the parentheses. 
Table 5

Continued

\begin{tabular}{|c|c|c|c|c|c|c|}
\hline & \multicolumn{3}{|c|}{ S\&P AAA Adjustment } & \multicolumn{3}{|c|}{ Moody's AAA Adjustment } \\
\hline & (1) & (2) & (3) & (4) & (5) & (6) \\
\hline AAA Model Diff - Positive & $\begin{array}{l}1.098 \\
(7.90)\end{array}$ & $\begin{array}{l}0.920 \\
(6.37)\end{array}$ & $\begin{array}{l}0.702 \\
(5.47)\end{array}$ & $\begin{array}{l}0.261 \\
(3.45)\end{array}$ & $\begin{array}{l}0.393 \\
(4.89)\end{array}$ & $\begin{array}{l}0.347 \\
(4.14)\end{array}$ \\
\hline AAA Model Diff - Negative & $\begin{array}{l}0.407 \\
(4.19)\end{array}$ & $\begin{array}{l}0.342 \\
(4.18)\end{array}$ & $\begin{array}{l}0.396 \\
(4.81)\end{array}$ & $\begin{array}{l}0.077 \\
(0.68)\end{array}$ & $\begin{array}{l}0.114 \\
(0.89)\end{array}$ & $\begin{array}{l}0.105 \\
(0.79)\end{array}$ \\
\hline & 0.0007 & 0.0025 & 0.0832 & 0.2546 & 0.1036 & 0.1802 \\
\hline SDR & & & $\begin{array}{l}0.312 \\
(5.12)\end{array}$ & & & $\begin{array}{l}0.096 \\
(1.34)\end{array}$ \\
\hline Credit Spread & & & $\begin{array}{l}-0.001 \\
(-0.36)\end{array}$ & & & $\begin{array}{l}-0.001 \\
(-0.34)\end{array}$ \\
\hline $\mathrm{CBO}$ & & $\begin{array}{l}-0.007 \\
(-0.37)\end{array}$ & $\begin{array}{l}-0.051 \\
(-2.46)\end{array}$ & & $\begin{array}{l}0.030 \\
(1.70)\end{array}$ & $\begin{array}{l}0.012 \\
(0.55)\end{array}$ \\
\hline CLO & & $\begin{array}{l}0.023 \\
(2.11)\end{array}$ & $\begin{array}{l}-0.035 \\
(-1.94)\end{array}$ & & $\begin{array}{l}0.044 \\
(4.57)\end{array}$ & $\begin{array}{l}0.030 \\
(1.81)\end{array}$ \\
\hline $\mathrm{CDO}^{2}$ & & $\begin{array}{l}0.073 \\
(1.97)\end{array}$ & $\begin{array}{l}0.008 \\
(0.25)\end{array}$ & & $\begin{array}{l}0.006 \\
(0.16)\end{array}$ & $\begin{array}{l}0.002 \\
(0.06)\end{array}$ \\
\hline Synthetic & & $\begin{array}{l}0.395 \\
(7.63)\end{array}$ & $\begin{array}{l}0.344 \\
(5.72)\end{array}$ & & $\begin{array}{l}0.020 \\
(0.40)\end{array}$ & $\begin{array}{l}0.036 \\
(0.63)\end{array}$ \\
\hline Fitch Rated & & & $\begin{array}{l}-0.020 \\
(-1.42)\end{array}$ & & & $\begin{array}{l}-0.012 \\
(-0.91)\end{array}$ \\
\hline Insured & & & $\begin{array}{l}0.069 \\
(2.26)\end{array}$ & & & $\begin{array}{l}0.068 \\
(2.60)\end{array}$ \\
\hline Log(Manager) & & & $\begin{array}{l}-0.005 \\
(-1.39)\end{array}$ & & & $\begin{array}{l}-0.005 \\
(-1.44)\end{array}$ \\
\hline Log(Underwriter) & & & $\begin{array}{l}0.002 \\
(0.61)\end{array}$ & & & $\begin{array}{l}-0.003 \\
(-0.90)\end{array}$ \\
\hline Intercept & $\begin{array}{l}0.046 \\
(6.38) \\
\end{array}$ & $\begin{array}{l}0.006 \\
(0.43) \\
\end{array}$ & $\begin{array}{l}-0.042 \\
(-1.37) \\
\end{array}$ & $\begin{array}{l}0.005 \\
(0.77) \\
\end{array}$ & $\begin{array}{l}-0.044 \\
(-3.35) \\
\end{array}$ & $\begin{array}{l}-0.040 \\
(-1.61) \\
\end{array}$ \\
\hline Year Controls & $\mathrm{N}$ & $\mathrm{Y}$ & $\mathrm{Y}$ & $\mathrm{N}$ & $\mathrm{Y}$ & $\mathrm{Y}$ \\
\hline No. Obs. & 486 & 486 & 485 & 486 & 486 & 481 \\
\hline R-Squared & 0.286 & 0.446 & 0.500 & 0.046 & 0.158 & 0.183 \\
\hline
\end{tabular}




\section{Table 6}

\section{Regressing AAA Adjustment on Differences in Assumptions and Deal Characteristics}

This table reports the results of OLS regressions. The dependent variable is the S\&P AAA Adjustment (Panel A) and Moody's AAA Adjustment (Panel B). CRD - Positive (Negative) is set equal to CRD when the value is greater than (less than) zero, and zero otherwise. CRD, or Collateral Risk Disagreement, is the SDR using S\&P's assumptions minus the SDR using Moody's assumptions, under our version of S\&P's model. Additional rows following pairs of explanatory variables with an italicized value report the p-value from a ttest of coefficient equivalence. SDR is the AAA SDR reported in S\&P's surveillance report. Credit Spread is the weighted-average AAA credit spread (yield spread when available) scaled by 10 basis points. Collateral Modeling Difference is the collateral risk using Moody's assumptions under the Moody's model minus the collateral risk under the S\&P model. Collateral Modeling Difference is the AAA size allowable using a deal's cash flow structuring under the Moody's model minus the AAA size allowable using a generic cash flow structure

under the Moody's model. All other independent variables are defined in Table 5. White (1980) heteroskedasticity-adjusted t-statistics are in the parentheses. 


\section{Table 6}

\section{Continued}

Panel A: S\&P AAA Adjustment

\begin{tabular}{|c|c|c|c|c|c|}
\hline & (1) & (2) & (3) & (4) & (5) \\
\hline CRD - Positive & $\begin{array}{c}0.967 \\
(12.11)\end{array}$ & $\begin{array}{l}0.888 \\
(8.14)\end{array}$ & $\begin{array}{c}1.029 \\
(12.70)\end{array}$ & $\begin{array}{l}0.699 \\
(6.07)\end{array}$ & $\begin{array}{l}0.788 \\
(6.48)\end{array}$ \\
\hline \multirow[t]{2}{*}{ CRD - Negative } & $\begin{array}{l}0.887 \\
(4.83)\end{array}$ & $\begin{array}{l}0.783 \\
(3.22)\end{array}$ & $\begin{array}{l}1.002 \\
(5.58)\end{array}$ & $\begin{array}{l}0.942 \\
(3.77)\end{array}$ & $\begin{array}{l}1.007 \\
(4.14)\end{array}$ \\
\hline & 0.7260 & 0.7192 & 0.9029 & 0.4381 & 0.4777 \\
\hline SDR & & & & $\begin{array}{l}0.308 \\
(4.75)\end{array}$ & $\begin{array}{l}0.288 \\
(4.36)\end{array}$ \\
\hline Credit Spread & & & & $\begin{array}{l}0.000 \\
(0.00)\end{array}$ & $\begin{array}{l}0.001 \\
(0.17)\end{array}$ \\
\hline Collateral Modeling Difference & & & $\begin{array}{l}-0.435 \\
(-2.89)\end{array}$ & & $\begin{array}{l}-0.365 \\
(-3.23)\end{array}$ \\
\hline $\mathrm{CBO}$ & & $\begin{array}{l}0.004 \\
(0.18)\end{array}$ & & $\begin{array}{l}-0.029 \\
(-1.37)\end{array}$ & $\begin{array}{l}-0.012 \\
(-0.57)\end{array}$ \\
\hline CLO & & $\begin{array}{l}0.017 \\
(1.45)\end{array}$ & & $\begin{array}{l}-0.036 \\
(-1.96)\end{array}$ & $\begin{array}{l}-0.020 \\
(-1.04)\end{array}$ \\
\hline $\mathrm{CDO}^{2}$ & & $\begin{array}{l}0.093 \\
(2.57)\end{array}$ & & $\begin{array}{l}0.022 \\
(0.63)\end{array}$ & $\begin{array}{l}0.011 \\
(0.32)\end{array}$ \\
\hline Synthetic & & $\begin{array}{l}0.270 \\
(5.06)\end{array}$ & & $\begin{array}{l}0.226 \\
(3.35)\end{array}$ & $\begin{array}{l}0.208 \\
(3.25)\end{array}$ \\
\hline Fitch Rated & & $\begin{array}{l}-0.004 \\
(-0.31)\end{array}$ & & $\begin{array}{l}-0.007 \\
(-0.52)\end{array}$ & $\begin{array}{l}-0.008 \\
(-0.63)\end{array}$ \\
\hline Insured & & $\begin{array}{l}0.060 \\
(1.96)\end{array}$ & & $\begin{array}{l}0.059 \\
(1.97)\end{array}$ & $\begin{array}{l}0.058 \\
(1.91)\end{array}$ \\
\hline Log(Manager) & & $\begin{array}{l}-0.008 \\
(-2.05)\end{array}$ & & $\begin{array}{l}-0.004 \\
(-1.09)\end{array}$ & $\begin{array}{l}-0.004 \\
(-1.10)\end{array}$ \\
\hline Log(Underwriter) & & $\begin{array}{l}0.002 \\
(0.50)\end{array}$ & & $\begin{array}{l}0.002 \\
(0.71)\end{array}$ & $\begin{array}{l}0.002 \\
(0.59)\end{array}$ \\
\hline Intercept & $\begin{array}{l}0.004 \\
(0.75)\end{array}$ & $\begin{array}{l}-0.003 \\
(-0.15)\end{array}$ & $\begin{array}{l}-0.006 \\
(-0.85)\end{array}$ & $\begin{array}{l}-0.068 \\
(-2.06)\end{array}$ & $\begin{array}{l}-0.085 \\
(-2.54)\end{array}$ \\
\hline Year Controls & $\mathrm{N}$ & $\mathrm{Y}$ & $\mathrm{N}$ & $\mathrm{Y}$ & $\mathrm{Y}$ \\
\hline No. Obs. & 492 & 492 & 492 & 490 & 490 \\
\hline R-Squared & 0.399 & 0.456 & 0.417 & 0.491 & 0.498 \\
\hline
\end{tabular}


Table 6

Continued

Panel B: Moody's AAA Adjustment

\begin{tabular}{|c|c|c|c|c|c|}
\hline & $(1)$ & (2) & (3) & (4) & (5) \\
\hline CRD - Positive & $\begin{array}{l}0.267 \\
(2.25)\end{array}$ & $\begin{array}{l}0.533 \\
(3.96)\end{array}$ & $\begin{array}{l}0.386 \\
(3.29)\end{array}$ & $\begin{array}{l}0.543 \\
(3.30)\end{array}$ & $\begin{array}{l}0.580 \\
(3.58)\end{array}$ \\
\hline CRD - Negative & $\begin{array}{l}-0.090 \\
(-1.51)\end{array}$ & $\begin{array}{l}0.018 \\
(0.26)\end{array}$ & $\begin{array}{l}-0.097 \\
(-1.61)\end{array}$ & $\begin{array}{l}0.007 \\
(0.10)\end{array}$ & $\begin{array}{l}-0.008 \\
(-0.11)\end{array}$ \\
\hline SDR & 0.0193 & 0.0022 & 0.0014 & $\begin{array}{c}0.0096 \\
0.091 \\
(1.04)\end{array}$ & $\begin{array}{c}0.0040 \\
0.071 \\
(0.85)\end{array}$ \\
\hline Credit Spread & & & & $\begin{array}{l}0.000 \\
(0.13)\end{array}$ & $\begin{array}{l}0.001 \\
(0.19)\end{array}$ \\
\hline Collateral Modeling Difference & & & $\begin{array}{l}0.554 \\
(4.70)\end{array}$ & & $\begin{array}{l}0.324 \\
(3.46)\end{array}$ \\
\hline $\mathrm{CBO}$ & & $\begin{array}{l}0.020 \\
(1.08)\end{array}$ & & $\begin{array}{l}0.003 \\
(0.16)\end{array}$ & $\begin{array}{l}-0.004 \\
(-0.18)\end{array}$ \\
\hline CLO & & $\begin{array}{l}0.045 \\
(3.90)\end{array}$ & & $\begin{array}{l}0.034 \\
(1.67)\end{array}$ & $\begin{array}{l}0.027 \\
(1.37)\end{array}$ \\
\hline $\mathrm{CDO}^{2}$ & & $\begin{array}{l}0.002 \\
(0.07)\end{array}$ & & $\begin{array}{l}-0.006 \\
(-0.19)\end{array}$ & $\begin{array}{l}0.005 \\
(0.16)\end{array}$ \\
\hline Synthetic & & $\begin{array}{l}0.083 \\
(1.68)\end{array}$ & & $\begin{array}{l}0.076 \\
(1.14)\end{array}$ & $\begin{array}{l}0.089 \\
(1.36)\end{array}$ \\
\hline Fitch Rated & & $\begin{array}{l}-0.009 \\
(-0.68)\end{array}$ & & $\begin{array}{l}-0.008 \\
(-0.60)\end{array}$ & $\begin{array}{l}-0.004 \\
(-0.25)\end{array}$ \\
\hline Insured & & $\begin{array}{l}0.075 \\
(2.44)\end{array}$ & & $\begin{array}{l}0.078 \\
(2.63)\end{array}$ & $\begin{array}{l}0.078 \\
(2.69)\end{array}$ \\
\hline Log(Manager) & & $\begin{array}{l}-0.007 \\
(-1.82)\end{array}$ & & $\begin{array}{l}-0.005 \\
(-1.44)\end{array}$ & $\begin{array}{r}-0.006 \\
(-1.67)\end{array}$ \\
\hline Log(Underwriter) & & $\begin{array}{l}-0.005 \\
(-1.59)\end{array}$ & & $\begin{array}{l}-0.005 \\
(-1.44)\end{array}$ & $\begin{array}{l}-0.004 \\
(-1.39)\end{array}$ \\
\hline Intercept & $\begin{array}{l}0.014 \\
(2.58)\end{array}$ & $\begin{array}{l}-0.003 \\
(-0.19)\end{array}$ & $\begin{array}{l}0.022 \\
(3.77)\end{array}$ & $\begin{array}{l}-0.029 \\
(-1.16)\end{array}$ & $\begin{array}{l}-0.013 \\
(-0.57)\end{array}$ \\
\hline Year Controls & $\mathrm{N}$ & $\mathrm{Y}$ & $\mathrm{N}$ & $\mathrm{Y}$ & $\mathrm{Y}$ \\
\hline No. Obs. & 552 & 552 & 552 & 540 & 540 \\
\hline R-Squared & 0.017 & 0.119 & 0.060 & 0.139 & 0.149 \\
\hline
\end{tabular}


Table 7

\section{Regressing Credit Spread on Differences in Assumptions and Deal Characteristics}

This table reports the results of OLS regressions. The dependent variable is the weighted-average AAA credit spread (yield spread when available) scaled by 10 basis points. S\&P (Moody's) Adjustment is the estimated adjustment S\&P (Moody's) gave to the CDO. SDR is the AAA SDR reported in S\&P's surveillance report. $|C R D|$ is the absolute value of CRD. CRD, or Collateral Risk Disagreement, is the SDR using S\&P's assumptions minus the SDR using Moody's assumptions, under our version of S\&P's model. Fitch Rated is a dummy variable that takes on a value of one when Fitch also rated the AAA tranches and zero otherwise. Insured is a dummy variable that takes on a value of one when at least one of the AAA tranches was wrapped and zero otherwise. All other independent variables are defined in Table 5. Italic values denote p-values from an F-test of joint significance between S\&P's Adjustment and Moody's Adjustment. White (1980) heteroskedasticity-adjusted t-statistics are in the parentheses.

\begin{tabular}{|c|c|c|c|c|c|}
\hline & $(1)$ & (2) & (3) & $(4)$ & $(5)$ \\
\hline S\&P's Adjustment & $\begin{array}{l}-0.119 \\
(-0.15)\end{array}$ & & & $\begin{array}{l}-0.247 \\
(-0.29)\end{array}$ & $\begin{array}{l}-0.127 \\
(-0.15)\end{array}$ \\
\hline Moody's Adjustment & $\begin{array}{l}0.661 \\
(0.76)\end{array}$ & & & $\begin{array}{l}0.518 \\
(0.62)\end{array}$ & $\begin{array}{l}0.418 \\
(0.52)\end{array}$ \\
\hline F-test & 0.6106 & & & 0.7850 & 0.8132 \\
\hline SDR & & $\begin{array}{l}0.941 \\
(1.70)\end{array}$ & $\begin{array}{l}0.977 \\
(1.83)\end{array}$ & $\begin{array}{l}1.084 \\
(1.37)\end{array}$ & $\begin{array}{l}1.194 \\
(1.50)\end{array}$ \\
\hline$|\mathrm{CRD}|$ & & $\begin{array}{l}0.755 \\
(0.88)\end{array}$ & & $\begin{array}{l}-0.771 \\
(-0.53)\end{array}$ & \\
\hline $\mathrm{CRD}^{2}$ & & & $\begin{array}{l}2.789 \\
(0.89)\end{array}$ & & $\begin{array}{l}-8.426 \\
(-1.05)\end{array}$ \\
\hline $\mathrm{CBO}$ & $\begin{array}{l}-0.530 \\
(-3.18)\end{array}$ & $\begin{array}{l}-0.430 \\
(-3.10)\end{array}$ & $\begin{array}{l}-0.434 \\
(-3.16)\end{array}$ & $\begin{array}{l}-0.657 \\
(-3.06)\end{array}$ & $\begin{array}{l}-0.664 \\
(-3.09)\end{array}$ \\
\hline CLO & $\begin{array}{l}-0.637 \\
(-5.29)\end{array}$ & $\begin{array}{l}-0.773 \\
(-5.11)\end{array}$ & $\begin{array}{l}-0.785 \\
(-5.47)\end{array}$ & $\begin{array}{l}-0.837 \\
(-3.91)\end{array}$ & $\begin{array}{l}-0.858 \\
(-4.12)\end{array}$ \\
\hline $\mathrm{CDO}^{2}$ & $\begin{array}{l}0.698 \\
(1.95)\end{array}$ & $\begin{array}{l}0.267 \\
(0.95)\end{array}$ & $\begin{array}{l}0.265 \\
(0.95)\end{array}$ & $\begin{array}{l}0.487 \\
(1.18)\end{array}$ & $\begin{array}{l}0.476 \\
(1.16)\end{array}$ \\
\hline Synthetic & $\begin{array}{l}0.306 \\
(1.17)\end{array}$ & $\begin{array}{l}1.380 \\
(0.96)\end{array}$ & $\begin{array}{l}1.378 \\
(0.97)\end{array}$ & $\begin{array}{l}0.131 \\
(0.41)\end{array}$ & $\begin{array}{l}0.118 \\
(0.39)\end{array}$ \\
\hline Fitch Rated & & & & $\begin{array}{l}-0.076 \\
(-0.56)\end{array}$ & $\begin{array}{l}-0.075 \\
(-0.56)\end{array}$ \\
\hline Insured & & & & $\begin{array}{l}-0.054 \\
(-0.24)\end{array}$ & $\begin{array}{l}-0.065 \\
(-0.29)\end{array}$ \\
\hline Log(Manager) & & & & $\begin{array}{l}0.012 \\
(0.30)\end{array}$ & $\begin{array}{l}0.014 \\
(0.33)\end{array}$ \\
\hline Log(Underwriter) & & & & $\begin{array}{l}-0.083 \\
(-2.68)\end{array}$ & $\begin{array}{l}-0.082 \\
(-2.64)\end{array}$ \\
\hline Intercept & $\begin{array}{c}5.227 \\
(41.87)\end{array}$ & $\begin{array}{c}4.936 \\
(33.79) \\
\end{array}$ & $\begin{array}{c}4.951 \\
(33.45) \\
\end{array}$ & $\begin{array}{c}5.276 \\
(24.07) \\
\end{array}$ & $\begin{array}{c}5.241 \\
(23.66)\end{array}$ \\
\hline Year Controls & $\mathrm{Y}$ & $\mathrm{Y}$ & $\mathrm{Y}$ & $\mathrm{Y}$ & $\mathrm{Y}$ \\
\hline No. Obs. & 490 & 692 & 692 & 490 & 490 \\
\hline R-Squared & 0.626 & 0.594 & 0.594 & 0.633 & 0.634 \\
\hline
\end{tabular}




\section{Table 8}

\section{Collateral Risk Disagreement and Subsequent Credit Ratings}

This table shows ordered logit. The dependent variable is the number of notches an initially AAA tranche is downgraded by S\&P (Panel A), the number of notches downgraded by Moody's (Panel B), and the number of notched downgraded by S\&P minus the number of notches downgraded by Moody's (Panel C). S\&P (Moody's) Adjustment is the estimated adjustment S\&P (Moody's) gave to the CDO. CRD is the SDR using S\&P's assumptions minus the SDR using Moody's assumptions, under our version of S\&P's model. S\&P Adjustment, Moody's Adjustment and CRD are all divided by their standard deviations. Credit Spread is the weighted-average AAA credit spread (yield spread when available) scaled by 10 basis points. Shocks represents the five dates where the most CDOs are downgraded and represents. For example, the first three occur when CDOs backed by various types of RMBS collateral are placed on credit watch or downgraded. (ABS) Year Controls indicates specifications when year fixed effects (interacted with an ABS collateral dummy) were used for years 2003-2007. All other variables are described in Table 5. Reported are odds ratios with White (1980) heteroskedasticity-adjusted t-statistics in parentheses.

Panel A: S\&P Downgrades

\begin{tabular}{|c|c|c|c|c|c|}
\hline & $(1)$ & $(2)$ & $(3)$ & $(4)$ & $(5)$ \\
\hline S\&P's Adjustments & $\begin{array}{l}1.933 \\
(3.88)\end{array}$ & $\begin{array}{l}1.828 \\
(3.37)\end{array}$ & $\begin{array}{l}2.278 \\
(4.31)\end{array}$ & $\begin{array}{l}2.298 \\
(4.24)\end{array}$ & $\begin{array}{l}1.898 \\
(3.43)\end{array}$ \\
\hline CRD & & $\begin{array}{l}1.177 \\
(0.78)\end{array}$ & & & \\
\hline SDR & & & $\begin{array}{c}0.006 \\
(-2.43)\end{array}$ & $\begin{array}{c}0.005 \\
(-2.43)\end{array}$ & $\begin{array}{c}0.004 \\
(-2.77)\end{array}$ \\
\hline Credit Spread & & & $\begin{array}{l}1.184 \\
(1.56)\end{array}$ & $\begin{array}{l}1.182 \\
(1.54)\end{array}$ & $\begin{array}{l}1.309 \\
(2.61)\end{array}$ \\
\hline $\mathrm{CBO}$ & $\begin{array}{c}0.002 \\
(-5.05)\end{array}$ & $\begin{array}{c}0.002 \\
(-4.95)\end{array}$ & $\begin{array}{c}0.003 \\
(-4.72)\end{array}$ & $\begin{array}{c}0.003 \\
(-4.33)\end{array}$ & $\begin{array}{c}0.003 \\
(-5.53)\end{array}$ \\
\hline CLO & $\begin{array}{c}0.007 \\
(-4.60)\end{array}$ & $\begin{array}{c}0.006 \\
(-4.56)\end{array}$ & $\begin{array}{c}0.011 \\
(-3.89)\end{array}$ & $\begin{array}{c}0.012 \\
(-3.53)\end{array}$ & $\begin{array}{c}0.021 \\
(-4.13)\end{array}$ \\
\hline $\mathrm{CDO}^{2}$ & $\begin{array}{c}0.169 \\
(-1.13)\end{array}$ & $\begin{array}{c}0.155 \\
(-1.15)\end{array}$ & $\begin{array}{c}0.345 \\
(-0.71)\end{array}$ & $\begin{array}{c}0.382 \\
(-0.62)\end{array}$ & $\begin{array}{c}0.396 \\
(-0.77)\end{array}$ \\
\hline Synthetic & $\begin{array}{c}0.001 \\
(-4.13)\end{array}$ & $\begin{array}{c}0.001 \\
(-4.13)\end{array}$ & $\begin{array}{c}0.002 \\
(-3.16)\end{array}$ & $\begin{array}{c}0.002 \\
(-3.14)\end{array}$ & $\begin{array}{c}0.116 \\
(-1.28)\end{array}$ \\
\hline Fitch Rated & & & & $\begin{array}{l}1.376 \\
(0.68)\end{array}$ & $\begin{array}{l}1.501 \\
(0.96)\end{array}$ \\
\hline Insured & & & & $\begin{array}{l}2.856 \\
(1.07)\end{array}$ & $\begin{array}{l}2.700 \\
(1.22)\end{array}$ \\
\hline Log(Manager) & & & & $\begin{array}{l}1.001 \\
(0.01)\end{array}$ & $\begin{array}{l}1.147 \\
(1.46)\end{array}$ \\
\hline Log(Underwriter) & & & & $\begin{array}{c}0.859 \\
(-1.61)\end{array}$ & $\begin{array}{c}0.895 \\
(-1.22)\end{array}$ \\
\hline Shocks & $\mathrm{Y}$ & $\mathrm{Y}$ & $\mathrm{Y}$ & $\mathrm{Y}$ & $\mathrm{N}$ \\
\hline ABS Year Controls & Y & $\mathrm{Y}$ & $\mathrm{Y}$ & $\mathrm{Y}$ & $\mathrm{Y}$ \\
\hline Year Controls & $\mathrm{Y}$ & $\mathrm{Y}$ & Y & $\mathrm{Y}$ & $\mathrm{Y}$ \\
\hline No. Obs. & 470 & 470 & 469 & 469 & 469 \\
\hline R-Squared & 0.268 & 0.268 & 0.278 & 0.281 & 0.221 \\
\hline
\end{tabular}


Table 8

Continued

Panel B: Moody's Downgrades

\begin{tabular}{|c|c|c|c|c|c|}
\hline & (1) & (2) & (3) & (4) & (5) \\
\hline Moody's Adjustments & $\begin{array}{l}1.324 \\
(2.27)\end{array}$ & $\begin{array}{l}1.365 \\
(2.45)\end{array}$ & $\begin{array}{l}1.421 \\
(2.58)\end{array}$ & $\begin{array}{l}1.407 \\
(2.51)\end{array}$ & $\begin{array}{l}1.337 \\
(2.16)\end{array}$ \\
\hline CRD & & $\begin{array}{c}0.847 \\
(-1.30)\end{array}$ & & & \\
\hline SDR & & & $\begin{array}{c}0.061 \\
(-1.51)\end{array}$ & $\begin{array}{c}0.074 \\
(-1.32)\end{array}$ & $\begin{array}{c}0.010 \\
(-2.50)\end{array}$ \\
\hline Credit Spread & & & $\begin{array}{c}1.085 \\
(1.39)\end{array}$ & $\begin{array}{l}1.088 \\
(1.39)\end{array}$ & $\begin{array}{l}1.144 \\
(2.12)\end{array}$ \\
\hline $\mathrm{CBO}$ & $\begin{array}{c}0.018 \\
(-5.85)\end{array}$ & $\begin{array}{c}0.018 \\
(-5.87)\end{array}$ & $\begin{array}{c}0.026 \\
(-5.38)\end{array}$ & $\begin{array}{c}0.026 \\
(-4.31)\end{array}$ & $\begin{array}{c}0.028 \\
(-4.56)\end{array}$ \\
\hline CLO & $\begin{array}{c}0.016 \\
(-6.48)\end{array}$ & $\begin{array}{c}0.015 \\
(-6.43)\end{array}$ & $\begin{array}{c}0.020 \\
(-6.19)\end{array}$ & $\begin{array}{c}0.021 \\
(-5.10)\end{array}$ & $\begin{array}{c}0.036 \\
(-4.67)\end{array}$ \\
\hline $\mathrm{CDO}^{2}$ & $\begin{array}{c}0.542 \\
(-0.65)\end{array}$ & $\begin{array}{c}0.388 \\
(-0.91)\end{array}$ & $\begin{array}{c}0.580 \\
(-0.57)\end{array}$ & $\begin{array}{c}0.591 \\
(-0.54)\end{array}$ & $\begin{array}{c}0.551 \\
(-0.70)\end{array}$ \\
\hline Synthetic & $\begin{array}{c}0.011 \\
(-2.51)\end{array}$ & $\begin{array}{c}0.009 \\
(-2.77)\end{array}$ & $\begin{array}{c}0.004 \\
(-2.60)\end{array}$ & $\begin{array}{c}0.004 \\
(-2.63)\end{array}$ & $\begin{array}{c}0.041 \\
(-1.57)\end{array}$ \\
\hline Fitch Rated & & & & $\begin{array}{l}1.130 \\
(0.26)\end{array}$ & $\begin{array}{l}1.261 \\
(0.51)\end{array}$ \\
\hline Insured & & & & $\begin{array}{l}3.935 \\
(1.34)\end{array}$ & $\begin{array}{l}4.134 \\
(1.22)\end{array}$ \\
\hline Log(Manager) & & & & $\begin{array}{l}1.046 \\
(0.47)\end{array}$ & $\begin{array}{l}1.179 \\
(1.76)\end{array}$ \\
\hline Log(Underwriter) & & & & $\begin{array}{l}1.013 \\
(0.17)\end{array}$ & $\begin{array}{l}1.038 \\
(0.48)\end{array}$ \\
\hline Shocks & Y & Y & Y & Y & $\mathrm{N}$ \\
\hline ABS Year Controls & Y & Y & Y & Y & $\mathrm{Y}$ \\
\hline Year Controls & $\mathrm{Y}$ & $\mathrm{Y}$ & $\mathrm{Y}$ & $\mathrm{Y}$ & $\mathrm{Y}$ \\
\hline No. Obs. & 550 & 548 & 538 & 538 & 538 \\
\hline R-Squared & 0.211 & 0.211 & 0.208 & 0.210 & 0.173 \\
\hline
\end{tabular}


Table 8

Continued

Panel C: Downgrade Difference

\begin{tabular}{|c|c|c|c|c|c|}
\hline & $(1)$ & $(2)$ & (3) & $(4)$ & $(5)$ \\
\hline CRD & $\begin{array}{l}1.210 \\
(2.01)\end{array}$ & $\begin{array}{l}1.760 \\
(3.51)\end{array}$ & $\begin{array}{l}1.226 \\
(2.11)\end{array}$ & $\begin{array}{l}1.207 \\
(1.94)\end{array}$ & $\begin{array}{l}1.172 \\
(1.56)\end{array}$ \\
\hline S\&P's Adjustments & & $\begin{array}{c}0.742 \\
(-2.19)\end{array}$ & & & \\
\hline Moody's Adjustments & & $\begin{array}{l}1.151 \\
(1.00)\end{array}$ & & & \\
\hline SDR & & & $\begin{array}{c}0.519 \\
(-0.75)\end{array}$ & $\begin{array}{c}0.487 \\
(-0.81)\end{array}$ & $\begin{array}{c}0.491 \\
(-0.85)\end{array}$ \\
\hline Credit Spread & & & $\begin{array}{l}1.025 \\
(0.27)\end{array}$ & $\begin{array}{c}0.996 \\
(-0.05)\end{array}$ & $\begin{array}{c}0.995 \\
(-0.06)\end{array}$ \\
\hline $\mathrm{CBO}$ & $\begin{array}{l}3.770 \\
(4.01)\end{array}$ & $\begin{array}{l}2.438 \\
(2.20)\end{array}$ & $\begin{array}{l}3.621 \\
(3.73)\end{array}$ & $\begin{array}{l}3.402 \\
(3.19)\end{array}$ & $\begin{array}{l}2.425 \\
(2.55)\end{array}$ \\
\hline CLO & $\begin{array}{l}4.205 \\
(4.46)\end{array}$ & $\begin{array}{l}2.884 \\
(2.80)\end{array}$ & $\begin{array}{l}4.209 \\
(4.16)\end{array}$ & $\begin{array}{l}4.034 \\
(3.80)\end{array}$ & $\begin{array}{l}2.822 \\
(3.13)\end{array}$ \\
\hline $\mathrm{CDO}^{2}$ & $\begin{array}{l}1.099 \\
(0.16)\end{array}$ & $\begin{array}{c}0.422 \\
(-0.98)\end{array}$ & $\begin{array}{l}1.181 \\
(0.27)\end{array}$ & $\begin{array}{l}1.265 \\
(0.38)\end{array}$ & $\begin{array}{l}1.023 \\
(0.04)\end{array}$ \\
\hline Synthetic & $\begin{array}{c}0.370 \\
(-2.26)\end{array}$ & $\begin{array}{c}0.526 \\
(-0.82)\end{array}$ & $\begin{array}{c}0.361 \\
(-2.41)\end{array}$ & $\begin{array}{c}0.352 \\
(-2.38)\end{array}$ & $\begin{array}{c}0.372 \\
(-2.75)\end{array}$ \\
\hline Fitch Rated & & & & $\begin{array}{c}0.849 \\
(-0.74)\end{array}$ & $\begin{array}{c}0.880 \\
(-0.56)\end{array}$ \\
\hline Insured & & & & $\begin{array}{c}0.724 \\
(-0.46)\end{array}$ & $\begin{array}{c}0.699 \\
(-0.52)\end{array}$ \\
\hline Log(Manager) & & & & $\begin{array}{c}0.989 \\
(-0.13)\end{array}$ & $\begin{array}{l}1.019 \\
(0.23)\end{array}$ \\
\hline Log(Underwriter) & & & & $\begin{array}{c}0.830 \\
(-2.28)\end{array}$ & $\begin{array}{c}0.823 \\
(-2.43)\end{array}$ \\
\hline Shocks & $\mathrm{Y}$ & $\mathrm{Y}$ & $\mathrm{Y}$ & $\mathrm{Y}$ & $\mathrm{N}$ \\
\hline ABS Year Controls & $\mathrm{Y}$ & Y & $\mathrm{Y}$ & $\mathrm{Y}$ & $\mathrm{Y}$ \\
\hline Year Controls & $\mathrm{Y}$ & $\mathrm{Y}$ & $\mathrm{Y}$ & $\mathrm{Y}$ & $\mathrm{Y}$ \\
\hline No. Obs. & 667 & 469 & 654 & 654 & 654 \\
\hline R-Squared & 0.025 & 0.031 & 0.024 & 0.028 & 0.018 \\
\hline
\end{tabular}




\section{Internet Appendix IA 1}

Table IA.1

Amount of Bloomberg CDO Universe Rated by the Rating Agencies

Panel A: AAA Tranche Overlapping Rating Coverage by Year

\begin{tabular}{|c|c|c|c|c|c|c|}
\hline & & $\begin{array}{l}\text { Total \# of } \\
\text { Tranches }\end{array}$ & Total Capital (\$B) & \multicolumn{2}{|c|}{$\begin{array}{c}\% \text { Tranches } \\
\text { Rated by Both }\end{array}$} & $\begin{array}{c}\% \text { Capital Rated } \\
\text { by Both }\end{array}$ \\
\hline 1997 & & 20 & 13.0 & \multicolumn{2}{|c|}{50.0} & 63.4 \\
\hline 1998 & & 70 & 65.2 & \multicolumn{2}{|c|}{62.5} & 93.7 \\
\hline 1999 & & 131 & 43.0 & \multicolumn{2}{|c|}{75.7} & 89.0 \\
\hline 2000 & & 141 & 94.8 & \multicolumn{2}{|c|}{75.4} & 78.4 \\
\hline 2001 & & 178 & 190.5 & \multicolumn{2}{|c|}{80.5} & 96.3 \\
\hline 2002 & & 246 & 199.9 & \multicolumn{2}{|c|}{79.4} & 96.4 \\
\hline 2003 & & 290 & 140.5 & \multicolumn{2}{|c|}{76.9} & 92.3 \\
\hline 2004 & & 423 & 146.8 & \multicolumn{2}{|c|}{71.3} & 67.4 \\
\hline 2005 & & 590 & 132.6 & \multicolumn{2}{|c|}{72.2} & 80.3 \\
\hline 2006 & & 1154 & 259.5 & \multicolumn{2}{|c|}{83.2} & 88.7 \\
\hline 2007 & & 1051 & 242.3 & \multicolumn{2}{|c|}{80.4} & 77.6 \\
\hline \multicolumn{7}{|c|}{ Panel B: Universe Rated by Either S\&P or Moody's } \\
\hline & $\begin{array}{c}\text { Total \# of } \\
\text { Deals }\end{array}$ & $\begin{array}{c}\text { Both Rate } \\
\text { Equally }\end{array}$ & $\begin{array}{c}\text { Both, S\&P } \\
\text { Favorable }\end{array}$ & $\begin{array}{l}\text { Both, Moody's } \\
\text { Favorable }\end{array}$ & $\begin{array}{c}\text { S\&P } \\
\text { Exclusive }\end{array}$ & $\begin{array}{l}\text { Moody's } \\
\text { Exclusive }\end{array}$ \\
\hline Pre-2004 & 870 & 656 & 33 & 11 & 60 & 110 \\
\hline Year 2004 & 275 & 207 & 4 & 4 & 41 & 19 \\
\hline Year 2005 & 358 & 275 & 9 & 3 & 42 & 29 \\
\hline Year 2006 & 659 & 566 & 10 & 7 & 42 & 34 \\
\hline Year 2007 & 628 & 490 & 12 & 5 & 75 & 46 \\
\hline ABS & 766 & 648 & 16 & 6 & 69 & 27 \\
\hline $\mathrm{CDO}^{2}$ & 101 & 82 & 0 & 0 & 18 & 1 \\
\hline $\mathrm{CBO}$ & 154 & 119 & 11 & 1 & 19 & 4 \\
\hline CLO & 992 & 842 & 10 & 5 & 42 & 93 \\
\hline Total & 2790 & 2194 & 68 & 30 & 260 & 238 \\
\hline
\end{tabular}

This table reports the ratings coverage of S\&P, Moody's, and Fitch for all CDOs from January 1997 to December 2007 listed in the Bloomberg Database. Panel A reports the number of AAA tranches, total market capitalization, and percentage of tranches rated by both S\&P and Moody's on a yearly basis. Panel B reports the number of CDOs covered by Bloomberg that were rated by S\&P and/or Moody's. Both, S\&P (Moody's) Favorable denote deals that were rated by both agencies, but where S\&P (Moody's) gave more tranches a AAA rating. S\&P (Moody's) Exclusive denote deals where only S\&P (Moody's) assigned ratings to the deal. 


\section{Table IA.2}

\section{Replication of S\&P's Collateral Risk Model}

\begin{tabular}{lc}
\hline & Dependent Variable: S\&P Reported SDR \\
\hline & $(1)$ \\
\hline Estimated SDR & 1.13 \\
& $(118.34)$ \\
Intercept & -.006 \\
& $(-1.77)$ \\
\hline No. Obs. & 683 \\
R-squared & .9536 \\
\hline
\end{tabular}

This table reports the results of OLS regressions. The dependent variable is the SDR of the AAA tranches in the first surveillance report as published by S\&P. 'Estimated SDR', or Estimated Scenario Default Rate, is the SDR generated from our replication of S\&P's collateral risk model. White (1980) heteroskedasticity-adjusted t-statistics are in parentheses. 
Table IA.3

Multiple Credit Ratings and Worst Performance

\begin{tabular}{|c|c|c|c|c|}
\hline \multirow[b]{2}{*}{ One Rater } & \multicolumn{2}{|c|}{ All CDOs } & \multicolumn{2}{|c|}{ ABS CDOs } \\
\hline & $\begin{array}{c}0.998 \\
(-0.01)\end{array}$ & $\begin{array}{l}1.145 \\
(0.48)\end{array}$ & $\begin{array}{c}0.605 \\
(-1.39)\end{array}$ & $\begin{array}{c}0.978 \\
(-0.05)\end{array}$ \\
\hline Two - Disagree & $\begin{array}{c}0.864 \\
(-0.40)\end{array}$ & $\begin{array}{c}0.749 \\
(-0.77)\end{array}$ & $\begin{array}{l}1.785 \\
(1.20)\end{array}$ & $\begin{array}{l}1.876 \\
(1.37)\end{array}$ \\
\hline Credit Spread & & $\begin{array}{l}1.258 \\
(6.21)\end{array}$ & & $\begin{array}{l}1.220 \\
(3.59)\end{array}$ \\
\hline Spread w/ Price & & $\begin{array}{l}1.091 \\
(1.71)\end{array}$ & & $\begin{array}{l}1.016 \\
(0.16)\end{array}$ \\
\hline Fitch Rated & $\begin{array}{c}0.540 \\
(-3.66)\end{array}$ & $\begin{array}{c}0.523 \\
(-3.39)\end{array}$ & $\begin{array}{c}0.465 \\
(-3.72)\end{array}$ & $\begin{array}{c}0.460 \\
(-3.46)\end{array}$ \\
\hline $\mathrm{CDO}^{2}$ & $\begin{array}{l}1.388 \\
(1.27)\end{array}$ & $\begin{array}{l}1.057 \\
(0.19)\end{array}$ & & \\
\hline $\mathrm{CBO}$ & $\begin{array}{c}0.090 \\
(-2.37)\end{array}$ & $\begin{array}{c}0.119 \\
(-2.06)\end{array}$ & & \\
\hline CLO & $\begin{array}{c}0.054 \\
(-7.42)\end{array}$ & $\begin{array}{c}0.059 \\
(-6.02)\end{array}$ & & \\
\hline ABS Year Controls & $\mathrm{Y}$ & Y & $\mathrm{Y}$ & $\mathrm{Y}$ \\
\hline Year Controls & $\mathrm{Y}$ & $\mathrm{Y}$ & - & - \\
\hline No. Obs. & 2790 & 2466 & 766 & 686 \\
\hline R-Squared & 0.335 & 0.383 & 0.194 & 0.200 \\
\hline \multicolumn{5}{|c|}{$\begin{array}{l}\text { This table reports the results of ordered logit regressions. The dependent variables, 'Worst Performance', is a } \\
\text { binary variable that takes on a value of one if an originally AAA rated tranche in the deal either a) holds a } \\
\text { rating of 'C' or 'D' as of June } 30,2010 \text { or b) has its rating withdrawn as of June } 30,2010 \text { following sufficient } \\
\text { downgrades to classify the deal as speculative grade. One Rater is a dummy variable that takes on a value of } \\
\text { one when the deal is rated by either S\&P or Moody's, but not both agencies, and zero otherwise. Similarly, } \\
\text { Two - Disagree is a dummy variable that takes on a value of one when the CDO is rated by both S\&P and } \\
\text { Moody's and they disagree about ratings on some AAA tranches, and zero otherwise. Credit Spread (Spread } w / \\
\text { Price) is the weighted-average AAA credit (yield) spread scaled by } 10 \text { basis points. Fitch Rated is a dummy } \\
\text { variable that is set to one when Fitch rates at least one tranche in the CDO, and zero otherwise. CDO2 is a } \\
\text { dummy variable that takes on a value of one when the security is a CDO of CDOs and zero otherwise. CBO } \\
\text { is a dummy variable that takes on a value of one when the security is a collateralized bond obligation and zero } \\
\text { otherwise. CLO is a dummy variable that takes on a value of one when the security is a collateralized loan } \\
\text { obligation and zero otherwise. (ABS) Year Controls indicates specifications when year fixed effects (interacted } \\
\text { with an ABS collateral dummy) were used for years 2003-2007. Reported are odds ratios with White (1980) } \\
\text { heteroskedasticity-adjusted t-statistics in parentheses. }\end{array}$} \\
\hline
\end{tabular}


Table IA. 4

Bloomberg Universe, Alternative Regression Models on CDO Performance

Panel A: Ordered Probit Regression

\begin{tabular}{lcccc}
\hline & $\begin{array}{c}\text { S\&P } \\
\text { Downgrades }\end{array}$ & $\begin{array}{c}\text { Moody's } \\
\text { Downgrades }\end{array}$ & E.O.D. & $\begin{array}{c}\text { Worst } \\
\text { Performance }\end{array}$ \\
\hline One Rater & -0.373 & -0.038 & -0.538 & 0.139 \\
Two - Disagree & $(-3.17)$ & $(-0.30)$ & $(-3.66)$ & $(0.98)$ \\
Spread & -0.106 & -0.286 & -0.245 & -0.229 \\
& $(-0.70)$ & $(-2.01)$ & $(-1.16)$ & $(-1.10)$ \\
Spread w/ Price & 0.055 & 0.067 & 0.050 & 0.134 \\
& $(2.33)$ & $(2.44)$ & $(2.67)$ & $(6.81)$ \\
Fitch Rated & 0.027 & 0.049 & -0.046 & 0.056 \\
& $(1.15)$ & $(2.36)$ & $(-1.79)$ & $(2.17)$ \\
CDO & -0.049 & -0.178 & -0.167 & -0.356 \\
& $(-0.74)$ & $(-2.63)$ & $(-1.77)$ & $(-3.40)$ \\
CBO & -0.281 & -0.021 & -0.328 & 0.020 \\
& $(-1.93)$ & $(-0.16)$ & $(-2.10)$ & $(0.12)$ \\
CLO & -0.088 & -0.071 & -0.443 & -0.985 \\
& $(-0.59)$ & $(-0.54)$ & $(-1.35)$ & $(-2.42)$ \\
\hline ABS Year Controls & -0.550 & -0.721 & -1.345 & -1.202 \\
Year Controls & $(-6.99)$ & $(-9.28)$ & $(-8.56)$ & $(-6.68)$ \\
No. Obs. & $\mathrm{Y}$ & $\mathrm{Y}$ & $\mathrm{Y}$ & $\mathrm{Y}$ \\
R-Squared & $\mathrm{Y}$ & $\mathrm{Y}$ & $\mathrm{Y}$ & $\mathrm{Y}$ \\
\hline
\end{tabular}


Table IA.4

Continued

Panel B: OLS Regression

\begin{tabular}{lcccc}
\hline & S\&P & Moody's & Worst \\
Downgrades & Downgrades & E.O.D. & Performance \\
\hline One Rater & -1.233 & 0.955 & -0.072 & 0.008 \\
Two - Disagree & $(-2.10)$ & $(1.77)$ & $(-4.00)$ & $(0.46)$ \\
& -0.711 & -0.988 & -0.046 & -0.025 \\
Spread & $(-0.97)$ & $(-1.48)$ & $(-1.42)$ & $(-1.06)$ \\
& 0.285 & 0.344 & 0.012 & 0.024 \\
Spread w/ Price & $(2.52)$ & $(2.37)$ & $(3.14)$ & $(6.37)$ \\
& 0.140 & 0.265 & -0.003 & 0.012 \\
Fitch Rated & $(1.32)$ & $(2.47)$ & $(-0.90)$ & $(3.52)$ \\
& -0.165 & -0.119 & -0.028 & -0.045 \\
CDO & $(-0.54)$ & $(-0.37)$ & $(-1.74)$ & $(-3.26)$ \\
& -1.810 & -0.131 & -0.108 & 0.035 \\
CBO & $(-2.55)$ & $(-0.21)$ & $(-2.20)$ & $(0.76)$ \\
& -0.692 & -1.633 & -0.069 & -0.063 \\
CLO & $(-1.23)$ & $(-3.58)$ & $(-4.64)$ & $(-4.88)$ \\
& -4.639 & -4.963 & -0.107 & -0.066 \\
Intercept & $(-13.13)$ & $(-13.81)$ & $(-7.70)$ & $(-5.90)$ \\
& 2.964 & 2.918 & 0.077 & -0.011 \\
\hline ABS Year Controls & $(4.81)$ & $(4.32)$ & $(4.16)$ & $(-0.59)$ \\
Year Controls & $\mathrm{Y}$ & $\mathrm{Y}$ & $\mathrm{Y}$ & $\mathrm{Y}$ \\
No. Obs. & $\mathrm{Y}$ & $\mathrm{Y}$ & $\mathrm{Y}$ & $\mathrm{Y}$ \\
R-Squared & 2231 & 2175 & 2466 & 2466 \\
\hline
\end{tabular}

This table reports the results of ordered probit (Panel A) and OLS (Panel B) regressions. The dependent variables are listed in the column headers. 'S\&P Downgrades' is the number of notches that the lowest tranche originally rated AAA was downgraded by S\&P as of June 30, 2010. 'Moody's Downgrades' is the number of notches that the lowest tranche originally rated AAA was downgraded by Moody's as of June 30, 2010. E.O.D.', or Event of Default, is a binary variable that takes on a value of 1 if the deal has issued an event of default notice, and zero otherwise. 'Worst Performance' is a binary variable that takes on a value of 1 if an originally AAA rated tranche in the deal either a) holds a rating of ' $C$ ' or ' $D$ ' as of June 30, 2010 or b) has its rating withdrawn as of June 30, 2010 following sufficient downgrades to classify the deal as speculative grade. S\&P (Moody's) Exclusive is a dummy variable that takes on a value of 1 on deals where only S\&P (Moody's) assigned ratings to the deal. Both, $S \& P$ (Moody's) Favorable is a binary variable that assumes a value of 1 on deals that were rated by both agencies, but where S\&P (Moody's) gave more tranches a AAA rating. Fitch Rated is a dummy variable that is set to 1 when Fitch rates at least one tranche in the CDO, and zero otherwise. All other variables are described in Table 5. Reported are regression coefficients with White (1980) heteroskedasticity-adjusted t-statistics in parentheses. 
Table IA.5

AAA Adjustments Across Agencies and Number of Ratings

\begin{tabular}{|c|c|c|c|c|c|}
\hline \multicolumn{6}{|c|}{ Panel A: AAA Adjustments Across Rating Agencies } \\
\hline & $\mathrm{S} \& \mathrm{P}$ & Moody's & Difference & $p$-value & Welch $p$-value \\
\hline AAA Adjustment & $3.44 \%$ & $2.07 \%$ & $1.37 \%$ & 0.0006 & - \\
\hline Subordination Level & $23.64 \%$ & $26.55 \%$ & $-2.91 \%$ & 0.3345 & 0.3481 \\
\hline W.A. Collateral Rating & 10.67 & 11.21 & -0.54 & 0.6066 & 0.6273 \\
\hline Deal Size $(\$ M)$ & 409.00 & 420.00 & -11.20 & 0.8487 & 0.8537 \\
\hline \multicolumn{6}{|c|}{ Panel B: AAA Adjustments Across Number of Ratings } \\
\hline & 1 Rater & 2 Raters & Difference & $p$-value & Welch $p$-value \\
\hline S\&P's Adjustment (w/o C.F.) & $13.06 \%$ & $11.30 \%$ & $1.76 \%$ & 0.4212 & 0.5246 \\
\hline Moody's Adjustment & $3.85 \%$ & $4.18 \%$ & $-0.33 \%$ & 0.9028 & 0.9369 \\
\hline Subordination Level & $24.89 \%$ & $26.34 \%$ & $-1.45 \%$ & 0.3995 & 0.3537 \\
\hline W.A. Collateral Rating & 10.89 & 11.58 & -0.69 & 0.1352 & 0.1889 \\
\hline Deal Size $(\$ M)$ & 413.00 & 601.00 & -188.00 & 0.0003 & $<.0001$ \\
\hline \multicolumn{6}{|c|}{ Panel C: Multiple Credit Ratings and S\&P AAA Adjustments } \\
\hline & $(1)$ & $(2)$ & (3) & (4) & (5) \\
\hline One Rater & $\begin{array}{l}0.023 \\
(1.04)\end{array}$ & $\begin{array}{l}0.025 \\
(1.04)\end{array}$ & $\begin{array}{l}0.026 \\
(1.10)\end{array}$ & $\begin{array}{l}0.024 \\
(1.02)\end{array}$ & $\begin{array}{l}0.027 \\
(1.12)\end{array}$ \\
\hline Two - Disagree & $\begin{array}{l}-0.003 \\
(-0.13)\end{array}$ & $\begin{array}{l}-0.003 \\
(-0.11)\end{array}$ & $\begin{array}{l}-0.011 \\
(-0.48)\end{array}$ & $\begin{array}{l}-0.002 \\
(-0.06)\end{array}$ & $\begin{array}{l}-0.013 \\
(-0.53)\end{array}$ \\
\hline Fitch Rated & & $\begin{array}{l}-0.002 \\
(-0.16)\end{array}$ & $\begin{array}{l}0.014 \\
(1.01)\end{array}$ & $\begin{array}{l}-0.002 \\
(-0.11)\end{array}$ & $\begin{array}{l}0.014 \\
(0.97)\end{array}$ \\
\hline Has Price & & & & $\begin{array}{l}0.003 \\
(0.35)\end{array}$ & $\begin{array}{l}-0.005 \\
(-0.52)\end{array}$ \\
\hline $\mathrm{CDO}^{2}$ & $\begin{array}{l}0.047 \\
(1.53)\end{array}$ & $\begin{array}{l}0.047 \\
(1.52)\end{array}$ & $\begin{array}{l}0.067 \\
(2.14)\end{array}$ & $\begin{array}{l}0.047 \\
(1.54)\end{array}$ & $\begin{array}{l}0.067 \\
(2.14)\end{array}$ \\
\hline $\mathrm{CBO}$ & $\begin{array}{l}0.019 \\
(1.21)\end{array}$ & $\begin{array}{l}0.019 \\
(1.09)\end{array}$ & $\begin{array}{l}-0.005 \\
(-0.28)\end{array}$ & $\begin{array}{l}0.019 \\
(1.08)\end{array}$ & $\begin{array}{l}-0.005 \\
(-0.26)\end{array}$ \\
\hline CLO & $\begin{array}{l}0.077 \\
(8.07)\end{array}$ & $\begin{array}{l}0.077 \\
(7.57)\end{array}$ & $\begin{array}{l}0.032 \\
(2.04)\end{array}$ & $\begin{array}{l}0.077 \\
(7.55)\end{array}$ & $\begin{array}{l}0.033 \\
(2.04)\end{array}$ \\
\hline Intercept & $\begin{array}{l}0.082 \\
(8.14)\end{array}$ & $\begin{array}{l}0.083 \\
(6.77)\end{array}$ & $\begin{array}{l}0.105 \\
(7.19)\end{array}$ & $\begin{array}{l}0.081 \\
(5.63)\end{array}$ & $\begin{array}{l}0.109 \\
(6.48)\end{array}$ \\
\hline ABS Year Controls & $\mathrm{N}$ & $\mathrm{N}$ & $\mathrm{Y}$ & $\mathrm{N}$ & $\mathrm{Y}$ \\
\hline Year Controls & $\mathrm{Y}$ & $\mathrm{Y}$ & $\mathrm{Y}$ & $\mathrm{Y}$ & $\mathrm{Y}$ \\
\hline No. Obs. & 1182 & 1182 & 1182 & 1179 & 1179 \\
\hline R-Squared & 0.091 & 0.091 & 0.115 & 0.090 & 0.115 \\
\hline
\end{tabular}


Panel D: Multiple Credit Ratings and Moody's AAA Adjustments

\begin{tabular}{lccccc}
\hline & $(1)$ & $(2)$ & $(3)$ & $(4)$ & $(5)$ \\
\hline One Rater & -0.010 & -0.010 & -0.006 & -0.010 & -0.007 \\
Two - Disagree & $(-0.25)$ & $(-0.26)$ & $(-0.16)$ & $(-0.26)$ & $(-0.16)$ \\
& -0.091 & -0.092 & -0.093 & -0.091 & -0.092 \\
Fitch Rated & $(-2.54)$ & $(-2.57)$ & $(-2.55)$ & $(-2.55)$ & $(-2.52)$ \\
& & 0.002 & 0.002 & 0.002 & 0.002 \\
Has Price & & $(0.12)$ & $(0.09)$ & $(0.14)$ & $(0.11)$ \\
& & & & 0.002 & 0.003 \\
CDO2 & & & $(0.20)$ & $(0.32)$ \\
& -0.065 & -0.064 & -0.061 & -0.064 & -0.061 \\
CBO & $(-2.43)$ & $(-2.35)$ & $(-1.98)$ & $(-2.32)$ & $(-1.97)$ \\
& -0.025 & -0.025 & -0.023 & -0.025 & -0.023 \\
CLO & $(-1.42)$ & $(-1.31)$ & $(-1.17)$ & $(-1.31)$ & $(-1.14)$ \\
& -0.041 & -0.040 & -0.023 & -0.040 & -0.022 \\
Intercept & $(-2.99)$ & $(-2.77)$ & $(-1.59)$ & $(-2.75)$ & $(-1.51)$ \\
& 0.056 & 0.055 & 0.055 & 0.054 & 0.052 \\
\hline ABS Year Controls & $(6.11)$ & $(4.87)$ & $(4.19)$ & $(4.04)$ & $(3.39)$ \\
Year Controls & $\mathrm{N}$ & $\mathrm{N}$ & $\mathrm{Y}$ & $\mathrm{N}$ & $\mathrm{Y}$ \\
No. Obs. & $\mathrm{Y}$ & $\mathrm{Y}$ & $\mathrm{Y}$ & $\mathrm{Y}$ & $\mathrm{Y}$ \\
R-Squared & 794 & 794 & 794 & 791 & 791 \\
\hline
\end{tabular}

This table reports the results of difference in means tests (Panels A \& B) and OLS regressions (Panels C \& D). Reported are $p$-values assuming equal variances across samples ( -value) and unequal variances (Welch $p$-value) with one exception. In Panel A, S\&P's model has been augmented with an estimate of deal-specific cash flow protection and a paired $t$-test is reported. The details of the estimation can be found in Internet Appendix IA 2.G. For the OLS regressions, the dependent variable is S\&P's AAA Adjustment (Panel C) and Moody's AAA Adjustment (Panel D). All independent variables are defined in Table IA.4. White (1980) heteroskedasticity-adjusted t-statistics are in the parentheses. 
Table IA.6

\section{Regressing S\&P AAA Adjustment on Differences in Assumptions and Deal Characteristics}

\begin{tabular}{|c|c|c|c|c|c|c|}
\hline & $(1)$ & $(2)$ & (3) & $(4)$ & (5) & $(6)$ \\
\hline Positive CRD & $\begin{array}{l}0.845 \\
(7.77)\end{array}$ & $\begin{array}{l}0.908 \\
(8.08)\end{array}$ & $\begin{array}{l}0.770 \\
(5.41)\end{array}$ & $\begin{array}{l}0.786 \\
(6.02)\end{array}$ & $\begin{array}{l}0.356 \\
(5.23)\end{array}$ & $\begin{array}{l}0.468 \\
(4.63)\end{array}$ \\
\hline Negative CRD & $\begin{array}{l}0.620 \\
(4.47)\end{array}$ & $\begin{array}{l}0.623 \\
(4.48)\end{array}$ & $\begin{array}{l}0.470 \\
(3.05)\end{array}$ & $\begin{array}{l}0.439 \\
(2.88)\end{array}$ & $\begin{array}{l}0.436 \\
(4.34)\end{array}$ & $\begin{array}{l}0.463 \\
(3.97)\end{array}$ \\
\hline SDR & & & & & $\begin{array}{c}0.575 \\
(17.41)\end{array}$ & $\begin{array}{c}0.570 \\
(12.31)\end{array}$ \\
\hline $\mathrm{CBO}$ & & & $\begin{array}{l}0.079 \\
(4.87)\end{array}$ & $\begin{array}{l}0.080 \\
(4.95)\end{array}$ & & $\begin{array}{l}0.004 \\
(0.30)\end{array}$ \\
\hline CLO & & & $\begin{array}{l}0.083 \\
(7.78)\end{array}$ & $\begin{array}{l}0.091 \\
(8.00)\end{array}$ & & $\begin{array}{l}0.000 \\
(0.01)\end{array}$ \\
\hline $\mathrm{CDO}^{2}$ & & & $\begin{array}{l}0.143 \\
(4.19)\end{array}$ & $\begin{array}{l}0.154 \\
(4.70)\end{array}$ & & $\begin{array}{l}0.014 \\
(0.66)\end{array}$ \\
\hline Other & & & $\begin{array}{l}-0.085 \\
(-2.31)\end{array}$ & $\begin{array}{l}-0.066 \\
(-2.78)\end{array}$ & & $\begin{array}{l}-0.144 \\
(-3.07)\end{array}$ \\
\hline Fitch Rated & & $\begin{array}{l}-0.033 \\
(-2.53)\end{array}$ & & $\begin{array}{l}0.009 \\
(0.71)\end{array}$ & & $\begin{array}{l}-0.004 \\
(-0.39)\end{array}$ \\
\hline Insured & & $\begin{array}{l}0.087 \\
(2.95)\end{array}$ & & $\begin{array}{l}0.078 \\
(2.76)\end{array}$ & & $\begin{array}{l}0.058 \\
(3.10)\end{array}$ \\
\hline Log(Manager) & & $\begin{array}{l}-0.014 \\
(-3.44)\end{array}$ & & $\begin{array}{l}-0.015 \\
(-4.04)\end{array}$ & & $\begin{array}{l}-0.003 \\
(-1.06)\end{array}$ \\
\hline Log(Underwriter) & & $\begin{array}{l}-0.004 \\
(-1.19)\end{array}$ & & $\begin{array}{l}-0.009 \\
(-2.77)\end{array}$ & & $\begin{array}{l}-0.005 \\
(-2.05)\end{array}$ \\
\hline Intercept & $\begin{array}{c}0.106 \\
(19.51)\end{array}$ & $\begin{array}{l}0.139 \\
(9.26)\end{array}$ & $\begin{array}{l}0.046 \\
(3.54)\end{array}$ & $\begin{array}{l}0.075 \\
(4.39)\end{array}$ & $\begin{array}{l}-0.095 \\
(-7.91)\end{array}$ & $\begin{array}{l}-0.075 \\
(-4.73)\end{array}$ \\
\hline Year Controls & $\mathrm{N}$ & $\mathrm{N}$ & $\mathrm{Y}$ & $\mathrm{Y}$ & $\mathrm{N}$ & $\mathrm{Y}$ \\
\hline No. Obs. & 643 & 643 & 643 & 643 & 643 & 643 \\
\hline R-squared & 0.279 & 0.327 & 0.426 & 0.467 & 0.635 & 0.660 \\
\hline
\end{tabular}

This table reports the results of OLS regressions. The dependent variable is the S\&P AAA Adjustment (Panel A) and Moody's AAA Adjustment (Panel B). 'Positive (Negative) CRD' is set equal to CRD when the value is positive (negative), and zero otherwise. CRD, or Collateral Risk Disagreement, is the SDR using S\&P's assumptions minus the SDR using Moody's assumptions, under our version of S\&P's model. 'SDR' is the AAA SDR reported in S\&P's surveillance report. 'CBO', 'CLO, and 'CDO' are dummy variables that take on a value of one when the security is collateralized with bonds, loans, or CDOs respectively and zero otherwise. 'Other' is a dummy variable that takes on a value of one when the security is not any of the preceding types, or an ABS CDO, and zero otherwise. Fitch Rated' is a dummy variable that takes on a value of one when Fitch also rated the AAA tranches and zero otherwise. Insured' is a dummy variable that takes on a value of one when at least one of the AAA tranches was wrapped and zero otherwise. 'Log(Manager)' is the log of the number of previous deals the collateral manager has been involved with. 'Log(Underwriter)' is the $\log$ of the number of previous deals the lead underwriter has previously underwritten. Year Controls indicates specifications when year fixed effects were used for years 2003-2007. 81 additional reports lack the initial AAA scenario SDR needed to calculate the AAA adjustment and are excluded from the sample. White (1980) heteroskedasticity-adjusted t-statistics are in the parentheses. 
Table IA. 7

Average Distance from Realized AAA Sizes to Model-Implied AAA Sizes

\begin{tabular}{|c|c|c|c|}
\hline & Full Sample & $\begin{array}{c}\mathrm{AAA}_{\text {Moody's }}>\mathrm{AAA}_{\text {Actual }}> \\
\mathrm{AAA}_{\text {S\&P }}\end{array}$ & $\begin{array}{c}\mathrm{AAA}_{\text {S\&P }}>\mathrm{AAA}_{\text {Actual }}> \\
\mathrm{AAA}_{\text {Moody's }} \\
\end{array}$ \\
\hline \multirow[t]{2}{*}{ AAA Distance to S\&P's Model } & $8.42 \%$ & $7.08 \%$ & $4.87 \%$ \\
\hline & $(.0023)$ & $(.0080)$ & $(.0080)$ \\
\hline \multirow[t]{2}{*}{ AAA Distance to Moody's Model } & $6.53 \%$ & $4.07 \%$ & $3.20 \%$ \\
\hline & $(.0030)$ & $(.0041)$ & $(.0045)$ \\
\hline Difference & $1.88 \%$ & $3.01 \%$ & $1.67 \%$ \\
\hline$p$-value & $<0.0001$ & 0.0006 & 0.0860 \\
\hline No. Obs. & 492 & 72 & 49 \\
\hline
\end{tabular}




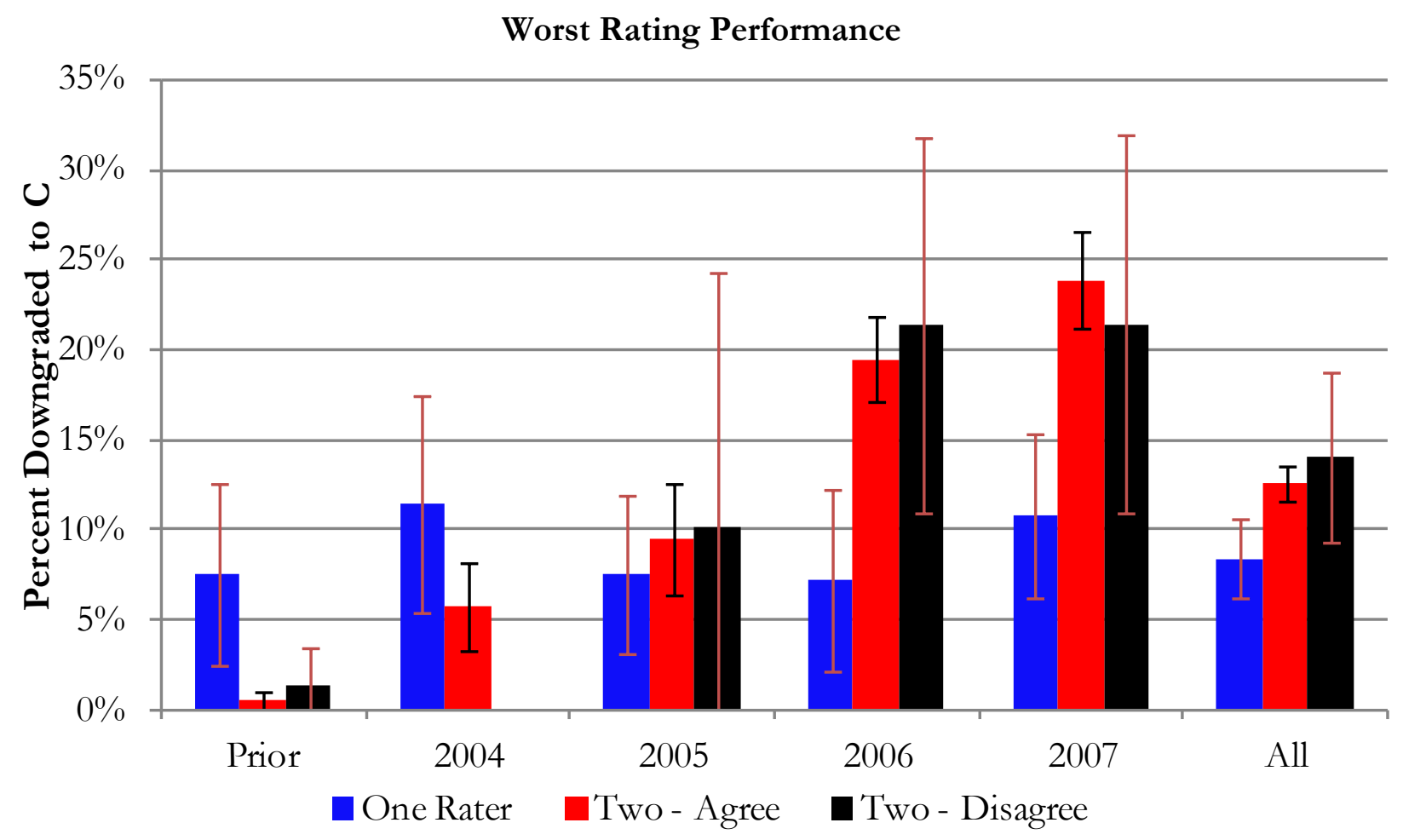

Figure IA.1

CDO Performance and Agency Participation and Agreement

This figure illustrates the percentage of CDOs experiencing downgrades to a rating of $\mathrm{C}$ or $\mathrm{D}$ by year of issuance. The number of notches downgraded is computed as of June 30, 2010. Two - Agree refers to CDOs who receive a rating by both Moody's and S\&P, and they agree about ratings for all originally AAA tranches. Two - Disagree refers to CDOs who are rated by both S\&P and Moody's and they disagree about ratings on some AAA tranches. The collateral-type distribution for each column is standardized using weights from the overall sample before calculating the mean. Reported for each column is its $90 \%$ confidence interval. 


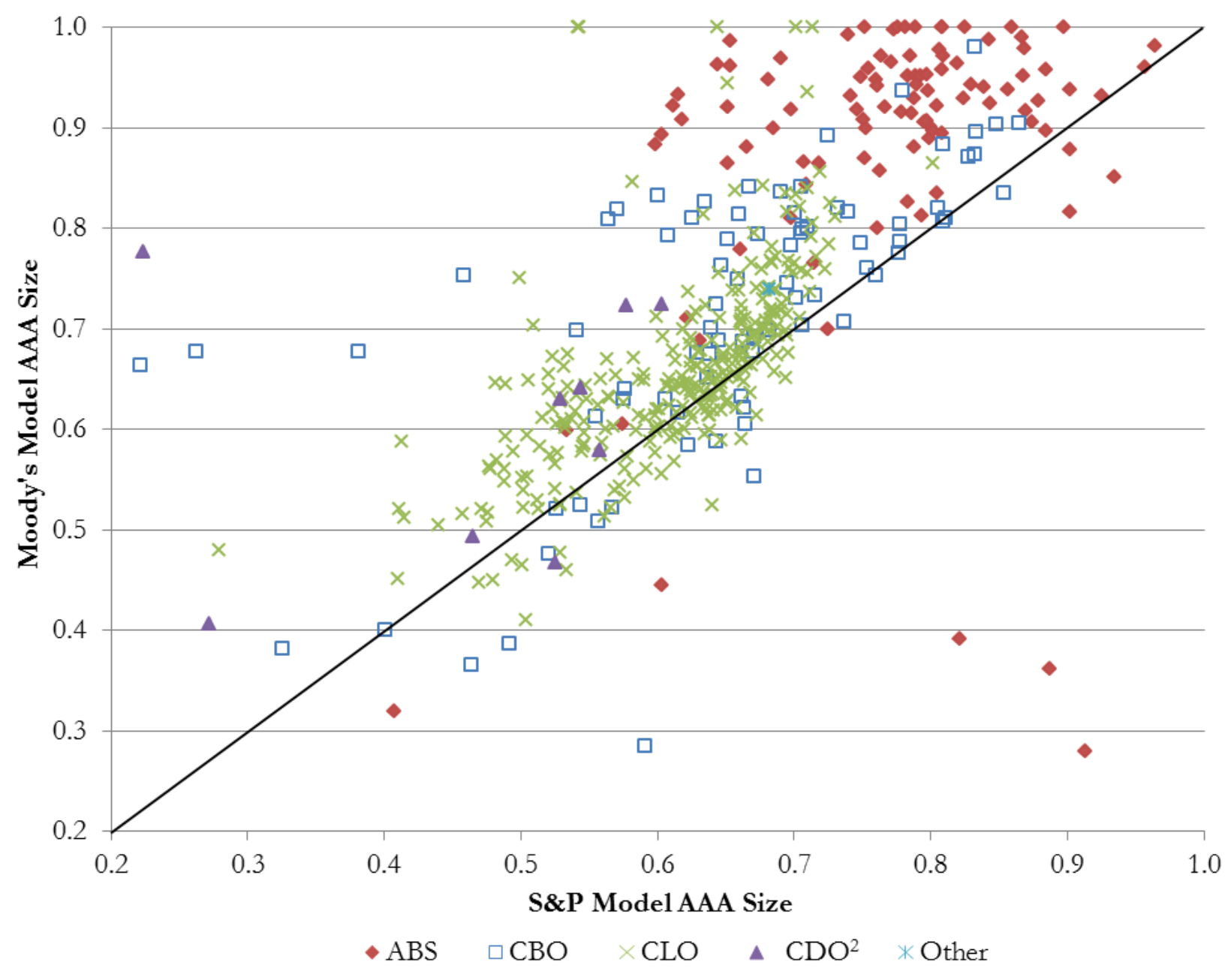

Figure IA.2

S\&P Model AAA with S\&P's Assumptions (x-axis) and Moody's Model AAA with Moody's Assumptions (y-axis)

This figure graphs the allowable percentage of AAA from S\&P's model and Moody's model. S\&P's allowable AAA is calculated using S\&P's assumptions and Moody's allowable AAA is calculated using Moody's assumptions. 